\title{
$8 \quad$ Neutron and X-ray diffraction studies on complex liquids
}

\author{
G. W. Neilson, ${ }^{* a}$ A. K. Adya ${ }^{b}$ and S. Ansell ${ }^{c}$
}

${ }^{a}$ H. H. Wills Physics Laboratory, University of Bristol, Tyndall Avenue, Bristol, UK BS8 $1 T L$

${ }^{b}$ Division of Molecular \& Life Sciences, School of Science \& Engineering, University of Abertay-Dundee, Bell Street, Dundee, UK DD1 1 HG

${ }^{c}$ ISIS Division, Rutherford Appleton Laboratory, Chilton, Didcot, Oxon, UK OX110QX

\section{Introduction}

This review contains results of neutron and X-ray scattering experiments on complex liquids, and includes structural information on molecular liquids, molten salts, aqueous and non-aqueous solutions, and glassy and amorphous materials. Most of the work referred to has been published during the past five years and the results derived from neutron diffraction studies follow on from those reported in a previous review in this series. ${ }^{1}$ For completeness some X-ray results published prior to this period are also included.

It is recalled that X-ray and neutron scattering methods provide the best experimental means currently available to probe the atomic structure of complex liquids. ${ }^{2}$ It can be proved that a formal mathematical (Fourier transformation) link can be formed between the neutron or X-ray scattering pattern obtained experimentally and the distribution functions $g_{a \beta}(r)$ of pairs of atoms $\alpha$ and $\beta$ of the system. ${ }^{2}$ Knowledge of these functions, either individually, or as combinations $\left(G_{a}(r)\right)$ specific to a particular atom (or ion), $a$, or even as total functions $(G(r))$, of all species in the liquid can be used to define interatomic distances, coordination numbers and the extent of local order around a particular atom (Fig. 1). The structural information obtained can be used to characterise the interatomic correlations in all types of liquids, and to test the quality of molecular dynamic (MD) simulation studies based on model potentials for particular components. It can also be usefully compared with structural parameters inferred from less direct techniques such as the various spectroscopic and thermodynamic methods.

Although X-rays and neutrons have been used to investigate liquid structure for over fifty years, it is really only since the mid 1970s that methods became sufficiently robust to obtain detailed interatomic structure in complex liquids. Foremost amongst these methods is that of neutron diffraction and isotopic substitution (NDIS): combinations of differences between the scattering patterns of isotopically labelled samples can be used to obtain information directly on the pairwise structure of a 


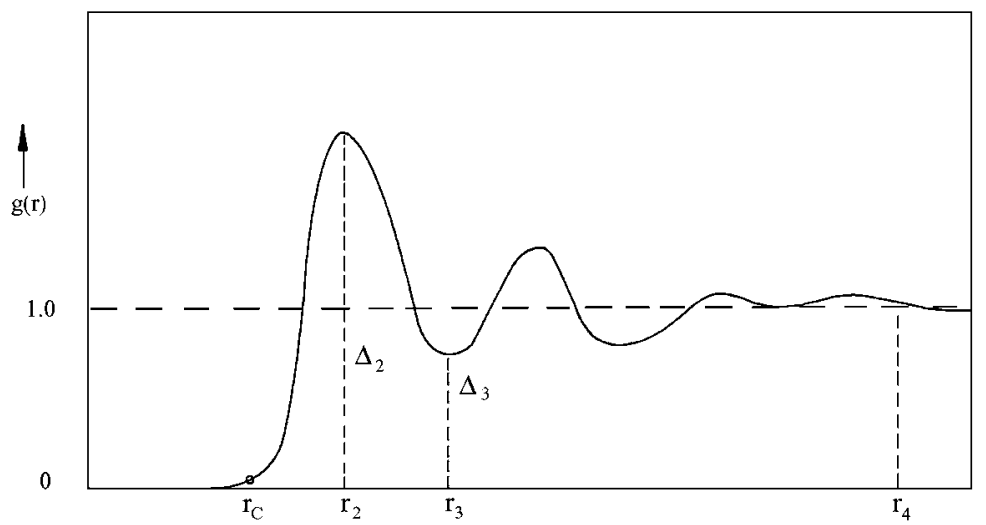

Fig. 1 A typical pair distribution function $g(r)$ for a liquid: $r_{\mathrm{c}}$ is the closest distance of approach of the two particles, $r_{2}$ the most probable nearest neighbour separation, $r_{3}$ the extent of the first coordination shell, $r_{4}$ the end of short range order and $\Delta_{2} / \Delta_{3}$ a measure of the degree of sharpness (or stability) of the first coordination shell. Figure adopted from ref. 1.

polyatomic liquid. A similar but less exact method based on differences between X-ray diffraction data on studies of isomorphically substituted species, was also developed. ${ }^{3,4}$ In the same period, second generation X-ray synchrotron sources enabled the application of EXAFS (extended X-ray absorption fine structure) spectroscopy and DAS (differential anomalous scattering), or as termed in this article, AXD (anomalous X-ray diffraction), as viable methods to probe the local structure around relatively heavy atoms (ions), in condensed phases. ${ }^{5}$ EXAFS and AXD exploit the high X-ray flux and the wide range of wavelengths available on synchrotrons and are now commonly used to investigate structure which is specific to atoms whose atomic numbers are greater than $Z=28$.

More recently, and with the construction of third generation X-ray synchrotron sources in the 1990s, both techniques have been improved and extended to determine structure in a large number of complex liquids held under a variety of states and conditions. The AXD method is in principle equivalent to NDIS and becomes as exact at what is termed the second difference level. ${ }^{6}$

This review presents a critical and up-to-date account of the structural information obtained from diffraction methods on a number of complex liquid systems. Where appropriate, it also includes results from other methods such as EXAFS spectroscopy and computer simulations. We end each section by identifying some of the outstanding problems to be solved in the short and longer term, and conclude by speculating on how diffraction studies on liquids will continue to progress.

\section{Experimental methods}

X-rays and neutrons have their distinct advantages in the determination of structure of liquids, glasses and amorphous materials; depending on the system and information required a particular choice is made (Table 1). The main advantage of neutron 
Table 1 Advantages and disadvantages of X-ray and neutron scattering methods

\begin{tabular}{lll}
\hline & X-rays & Neutrons \\
\hline Advantages & High fluxes & Isotopes \\
& Single sample & Scattering isotropic \\
& Scattering proportional to atomic & $\begin{array}{l}\text { Formal link to pairwise } \\
\text { structure }\end{array}$ \\
& & Null container \\
& & Can identify hydrogen \\
& & easily \\
Disadvantages & Strong container scattering & Relatively low fluxes \\
& Convolution of structure due to & Expense and availability of \\
& $q$-dependent form factor & isotopes \\
& & Several identical samples \\
\hline
\end{tabular}

methods rests on the fact that neutrons interact predominantly with atomic nuclei through the strong force and the interaction is isotropic. As a result structural information in the form of $g_{a \beta}(r) \mathrm{s}$ is accessible directly from the experimental diffraction data. Moreover, the strength of interaction, which is characterised by the parameter $b_{a}$, varies from isotope to isotope. Therefore, two liquids with the same composition of atomic material but containing isotopically different nuclei (e.g., $\mathrm{H}$ for $\mathrm{D},{ }^{35} \mathrm{Cl}$ for ${ }^{37} \mathrm{Cl}$, etc.) will give different neutron scattering patterns. This enables detailed information to be obtained which is specific to the isotopically substituted species. ${ }^{2}$

The main advantage of X-ray methods is the availability of large fluxes, as much as $10^{5}$ times greater than those available in equivalent neutron experiments. These can be used to gather data quickly and to investigate solutions at low concentrations.

The formalism for both probes begins with the same initial equation. If neutrons or $\mathrm{X}$-rays are incident on a liquid containing several nuclear/atomic species the intensity of the scattered neutrons or X-rays, $I(q)$ is given by

$$
\begin{array}{r}
I(q)=\sum_{\alpha} \sum_{\beta} b_{\alpha} b_{\beta}\left\langle\sum_{i(\alpha)} \sum_{i(\beta)} \exp i \boldsymbol{q} \cdot\left(\boldsymbol{r}_{\mathrm{j}}(\beta)-\boldsymbol{r}_{\mathrm{i}}(\alpha)\right)\right\rangle= \\
N\left[\sum_{\alpha} c_{\alpha} b_{\alpha}^{2}+\sum_{\alpha} \sum_{\beta} c_{\alpha} c_{\beta} b_{\alpha} b_{\beta}\left[S_{\alpha \beta}(q)-1\right]\right]
\end{array}
$$

with $c_{a}=N_{a} / N$. In eqn. (1) $r_{i}(\alpha)$ denotes the position of the $i$ th nucleus of $a$-type characterised by a neutron scattering length or X-ray form factor $b_{a}$ and $\mathbf{q}$ is the scattering vector whose modulus, $q$, for elastic scattering (i.e. $\left|k_{0}\right|=\left|k_{1}\right|=2 \pi / \lambda$ ), is given by

$$
q=4 \pi \sin \theta / \lambda
$$

where $\theta$ is half the scattering angle and $\lambda$ is the wavelength of the incident neutrons or $\mathrm{X}$-rays. The angular brackets show that an ensemble average has been taken, and $S_{a \beta}(q)$ are the partial structure factors. Each $S_{a \beta}(q)$ can be inverted to yield $g_{a \beta}(r)$ through the Fourier transformation 


$$
g_{\alpha \beta}(r)=1+\frac{V}{2 \pi^{2} N r} \int \mathrm{d} q\left(S_{\alpha \beta}(q)-1\right) q \sin q r
$$

The $b_{a}$ s are independent of $q$ for neutrons, i.e. the scattering is isotropic, and depend on $q$ for X-rays, i.e. the scattering is anisotropic. It is this property which facilitates the direct determination of solution structure by neutron diffraction.

Thus $S_{\mathrm{MO}}(q)$ and $S_{\mathrm{MH}}(q)$ can in principle yield the real space distribution functions $g_{\mathrm{MO}}(r)$ and $g_{\mathrm{MH}}(r)$ which are necessary if a proper description of ionic hydration is to be given. Unfortunately the contribution of these partial structure factors to the scattered intensity is very small, even for relatively concentrated solutions and special procedures must be adopted for their determination.

At this stage it is appropriate to consider each probe individually.

\subsection{Neutrons}

Although total neutron diffraction studies of complex liquids have been carried out, they are generally less informative than total X-ray diffraction. ${ }^{7}$ This is due to the close similarity in the strength of scattering characterised by the scattering length $b$ of the atomic nuclei of the atoms in the liquid. Therefore, models are required to assist in the interpretation of single diffraction patterns.

By contrast, the difference methods of NDIS referred to above are ideally suited to the determination of structure in terms of individual $g_{a \beta}(r) \mathrm{s}$ or as their linear combinations of the form $G_{a}(r)$ which is specific to the substituted species $\alpha$. The information obtained in an NDIS experiment can provide a critical test of model potentials and liquid state theories. ${ }^{8}$

The NDIS method is most conveniently illustrated by reference to an aqueous electrolyte solution of a salt $\left(\mathrm{MX}_{n}\right)$ in water $\left(\mathrm{H}_{2} \mathrm{O}\right){ }^{2}$ (Of course it is universally applicable to any polyatomic liquid.) The first difference method applied to cations or anions by isotopic exchange $\mathrm{M}^{\prime}$ for $\mathrm{M}$ or $\mathrm{X}^{\prime}$ for $\mathrm{X}$ can be used to obtain information concerning aqua-ion structure in terms of the function $G_{\mathbf{M}}(r)$ or $G_{\mathbf{X}}(r)$. In mathematical terms

$$
\begin{gathered}
G_{\mathrm{M}}(r)=A g_{\mathrm{MO}}(r)+B g_{\mathrm{MH}}(r)+C g_{\mathrm{MX}}(r)+D g_{\mathrm{MM}}(r)+E \\
E=-(A+B+C+D)
\end{gathered}
$$

where $A=2 c_{\mathrm{M}} c_{\mathrm{O}} b_{\mathrm{O}} \Delta b_{\mathrm{M}}, B=2 c_{\mathrm{M}} c_{\mathrm{H}} b_{\mathrm{H}} \Delta b_{\mathrm{M}}, C=2 c_{\mathrm{M}} c_{\mathbf{X}} b_{\mathbf{X}} \Delta b_{\mathrm{M}}, D=c_{\mathrm{M}}{ }^{2}\left(b_{\mathrm{M}}{ }^{2}-\left(b_{\mathrm{M}}{ }^{\prime}\right)^{2}\right)$, $\Delta b_{\mathbf{M}}=b_{\mathbf{M}}-b_{\mathbf{M}^{\prime}}$ and $c_{a}$ is the atomic concentration of species $a$, whose neutron coherent scattering length is $b_{a}$. By extension it can be shown that second difference experiments involving isotopic exchanges of $\mathrm{M}^{\prime}$ for $\mathrm{M}, \mathrm{X}^{\prime}$ for $\mathrm{X}$, and deuterium (D) for hydrogen $(\mathrm{H})$, can be used to obtain the individual pair functions for the solute $\left(g_{\mathrm{MM}}(r), g_{\mathrm{MX}}(r), g_{\mathrm{XX}}(r)\right)$ and the solvent $\left(g_{\mathrm{HH}}(r), g_{\mathrm{OH}} *(r)\right)$. Note that the asterisk on $g_{\mathrm{OH}}(r)$ means that it is only an approximation to the true $g_{\mathrm{OH}}(r)$. However, in the limit of high dilution it will tend to the exact function as in pure water (see Section 3.4.1). It is also worth noting that because the scattering lengths of the oxygen isotopes, ${ }^{16} \mathrm{O}$, 
${ }^{17} \mathrm{O}$ and ${ }^{18} \mathrm{O}$ are almost the same, determination of $g_{\mathrm{oo}}(r)$ in pure water is liable to large errors, and is not accessible in solution. For a determination of $G_{\mathbf{M}}(r)$ or $G_{\mathbf{X}}(r)$, it is preferential to work with solutions of heavy water $\left(\mathrm{D}_{2} \mathrm{O}\right)$ because of the prohibitively large neutron incoherent scattering of the proton $(\mathrm{H})$ spins and the large inelastic scattering from the proton nuclei in $\mathrm{H}_{2} \mathrm{O}$. Indeed, unless one really needs to resolve the hydration structure at the pair distribution function level, the total distribution function description will be sufficient.

The coordination number of $\alpha$ atoms around $\beta$ is defined for the range $r_{1} \leq r / \AA \leq r_{2}$ as

$$
\bar{n}_{\beta}^{\alpha}=4 \pi c_{\alpha} \rho \int_{r_{1}}^{r_{2}} g_{\alpha \beta}(r) r^{2} \mathrm{~d} r
$$

where $\rho$ is the total number density in $\AA^{-3}$. A hydration number for an ion I in solution can be defined as

$$
\bar{n}_{\mathrm{I}}^{\mathrm{H}_{2} \mathrm{O}}=4 \pi \rho c_{\mathrm{O}} \int_{r_{1}}^{r_{2}} g_{I \mathrm{O}}(r) r^{2} \mathrm{~d} r
$$

or

$$
\bar{n}_{\mathrm{I}}^{\mathrm{H}_{2} \mathrm{O}}=4 \pi \rho c_{\mathrm{H}} \int_{r_{1}}^{r_{2}} g_{I \mathrm{H}}(r) r^{2} \mathrm{~d} r
$$

depending on which of these functions can be more readily identified. For more complex systems NDIS methods can again be used to isolate structures around a particular species or to determine individual radial distribution functions (RDFs). As we show by examples in the Results sub-sections, this procedure has been used successfully to determine the structure of, molecular liquids and their mixtures, molten salts, liquid metals, aqueous solutions of large molecules, aqueous solutions of electrolytes and polyelectrolytes, and amorphous materials.

The success of NDIS experiments depends crucially on several factors. These include $(i)$ high quality samples whose composition is accurately known in terms of atomic concentration and isotope content, (ii) a high flux neutron source which can provide sufficient statistical accuracy in the data and, (iii) stable instrumentation so that data are highly reproducible during the course of an experiment which takes typically $\sim 10 \mathrm{~h} / \mathrm{sample}$. Results of NDIS experiments can be usefully compared with information on structure obtained from other methods.

\subsection{X-rays}

X-ray diffraction techniques have been used since the 1930s to study structure in liquids. ${ }^{9}$ In general a total X-ray diffraction pattern from a complex liquid is a linear combination of partial structure factors weighted by the corresponding form factors (eqn. (1)). Because of the $q$ dependence of the form factors, direct determination of 
pair distribution functions is not possible, and models based on information obtained on crystal hydrates are often employed in the data analysis. For certain favourable cases it is possible to obtain useful results for certain aspects of the solution structure.

In order to obtain more definitive structural information on complex liquids from $\mathrm{X}$-ray scattering three experimental techniques have been devised. The first of these is $\mathrm{X}$-ray diffraction and isomorphic substitution, which is carried out in combination with NDIS on one of the species to ensure isomorphism exists between the two species (e.g. $\mathrm{Ni}^{2+}$ and $\mathrm{Mg}^{2+}$ etc.). ${ }^{4,10}$ The technique is based on pairs of ions possessing the same effective size and charge in solution. It is clear that the method of isomorphic substitution can also be used for neutrons, provided there is a large enough difference in scattering length between the atomic nuclei of the substituted species. Clearly the ideal choice of isomorphs must be such as to ensure a large difference in X-ray atomic form factors, $f_{\mathrm{o}}(q)$, which scale with the atomic number. Once isomorphism has been established, diffraction data are gathered on the two solutions at the same concentration. A first difference, $\tilde{\Delta}_{M}(q)$, is then taken which includes pairwise structural information specific to the isomorphic species. Because X-ray atomic form factors depend on the scattering angle between the incident and scattered X-ray beam, Fourier transformation of $\tilde{\Delta}_{M}(q)$ does not give structural information directly in terms of the $g_{\mathrm{M} a}(r) \mathrm{s}$. However, where a strong correlation exists (e.g. as in the first hydration shell of $\mathrm{Ni}^{2+}$ in aqueous solution), one can show that quantitative information associated with that correlation may be extracted. The advantages of this method are that relatively inexpensive samples are required and insight can be gained on structural changes, which may be induced by changes in temperature, pressure etc.

The other two X-ray methods exploit the fact that the scattering of X-rays by atoms is strongly modified when the X-ray energy (wavelength, $\lambda$ ) is close to an atomic absorption edge. In that case, the total atomic form factor $f$, which characterises the interaction between X-rays and the electrons of the atom, is defined by:

$$
f(q, E)=f_{\mathbf{o}}(q)+f^{\prime}(q, E)+\mathrm{i} f^{\prime \prime}(q, E)
$$

$f_{\mathrm{o}}(q)$ is the normal atomic form factor, and $f^{\prime}(q, E)$ and $f^{\prime \prime}(q, E)$ are the dispersion corrections that account for resonant scattering processes. The energy dependent terms are called 'anomalous', and can be obtained classically by first measuring the attenuation coefficient which is directly related to the imaginary component $f^{\prime \prime}(q, E)$ and then using a Kramers-Kronig relation to calculate $f^{\prime}(q, E) \cdot{ }^{11}$ The two possibilities of AXD (or DAS) which is a true diffraction method, and EXAFS spectroscopy are now considered:

2.2.1 AXD or DAS. If the energy of the incoming X-rays is allowed to change only below the edge, it is mainly $f^{\prime}(q, E)$ that changes. By fixing $E$ to a value of about $5 \mathrm{eV}$ below the absorption edge and varying $q$ (or $\theta$ ) as in a normal diffraction experiment, one obtains a first scattering pattern for a given $f^{\prime}(q, E)$ for the atom or ion of interest. The value of $E$ is then altered by a further few hundred $\mathrm{eV}$ below the absorption edge, and the value of $f^{\prime \prime}\left(q, E^{\prime}\right)$ is systematically changed to a larger value. A second scattering experiment on the same sample gives a slightly different pattern. The difference between the two scattering patterns is then calculated, and its Fourier transformation related to the hydration structure around the specific atom or ion. The technique is 
based on similar principles to NDIS, but is not limited by availability of isotopes. However, it is constrained by the $q$ dependence of the form factors, and is only applicable to atoms or ions with atomic numbers $>28$, which in turn sets a limit on the $q$ range of the diffraction data.

The actual structure function $\left(\tilde{G}_{a}(r)\right)$ is calculated from the Fourier transformation of the sum over partial structure factors $S_{a \beta}(q)$ convoluted with their $q$-dependent $\mathrm{X}$-ray atomic form factors. The effect of this convolution is to broaden peaks associated with the real structure as defined by $g_{a \beta}(r)$, and thereby obscure the structural information in the true $G_{a}(r)$. The peak positions, however, remain unchanged by the convolution process. Despite these drawbacks, it has been shown that for aqueous electrolyte solutions it is possible to obtain accurate information on interatomic correlations and coordination numbers. ${ }^{5,6,12}$ Perversely, this procedure becomes more exact at a second difference level such as might be used to calculate $g_{a a}(r)$, in an electrolyte solution or any other complex liquid.

As in the case of NDIS, the AXD method is generally applicable, and can be used to give structural information around a specific atom type in any polyatomic liquid.

2.2.2 EXAFS. The second method is that of EXAFS spectroscopy which exploits energy changes that occur when X-rays are absorbed in the region of the absorption edge of a particular particle in a system. This is represented by $f^{\prime \prime}(q, E)$ in eqn. (7). In contrast to diffraction methods EXAFS spectroscopy is strongly model dependent, and although Fourier transformation procedures are used, the range of ' $q$ ' (or more usually $k$ ) space information is much more limited than in straightforward diffraction. Indeed, the absorption measurement itself has been shown to change the sample. This is particularly problematic for dilute solutions when the number of interacting photons becomes a significant fraction of the absorbing atoms. The effects have also been seen in some more concentrated samples, e.g. $\mathrm{CuCl}_{2}$ solutions. ${ }^{13}$ Nevertheless, for the study of liquids, EXAFS is potentially a superb tool since it can provide ion specific short range structural information which is not limited to the pair correlation functions. Although several general problems exist which make data interpretation difficult, significant improvements have been made in the past few years. A detailed review article has recently been written on the current state of EXAFS measurements on liquids. ${ }^{14}$

The measurement of an EXAFS spectrum for one sample at one temperature is relatively quick on most modern synchrotron beam lines. This has allowed one of the major difficulties of EXAFS data interpretation to be overcome; although absolute coordination numbers and correct distances can be obtained, relative comparisons between measurements between two different state points yield significant information. Many of the published papers do not concentrate on the analysis of individual EXAFS spectra but on differences induced by temperature, pressure or during some chemical process e.g. catalysis.

In the simplified EXAFS experiment, the sample's absorption coefficient $\mu(E)$ is measured across a constituent atom's absorption edge. The EXAFS oscillation occurs due to the interference resulting from the backscattering of a photoelectron with the excited atom and its local neighbouring atoms. The EXAFS part of the oscillation is considered to start where the single scattering of the photoelectron dominates the multiple scattering processes. ${ }^{15}$ 
The EXAFS signal is defined as

$$
\chi(k)=\left(\mu(E)-\mu_{0}(E)\right) / \Delta \mu_{\text {Edge }}
$$

where the photo-wavevector

$$
k=\sqrt{2 m_{\mathrm{e}}\left(E-E_{0}\right)} / \hbar
$$

$\mu_{0}(E)$ refers to the atomic background and the term $\Delta \mu_{\text {Edge }}$ refers to the change in atomic background that occurs at the edge. The signal $\chi(k)$ is unique to each material and depends on the electronic and structural properties of the material. Extraction of the structural properties is often difficult, complicated and non-unique, even considering the difficulties in obtaining an accurate $\chi(k)$. The problem is made more difficult by the smoothness of the atomic absorption background being strongly perturbed by double electron effects called 'shake-up' and 'shake-off' processes. Apart from a few elements that have simple gaseous forms this background contamination is hard to calculate. Theoretical and experimental approaches are only now beginning to make progress, e.g. the analysis of $\mathrm{RbNO}_{3}$ solution was carried out using the atomic background from $\mathrm{Rb}$ metal vapour. ${ }^{16}$

Theoretically, the approximation developed by Sayers et al. ${ }^{17}$ for the sum averaged over all photoabsorbing atoms gives for the K-edge

$$
\begin{array}{r}
\chi(k)=\sum_{j} S_{0}^{2} \frac{1}{k R_{j}^{2}} \mathrm{e}^{-2 R_{j} / \lambda_{j}(k)}\left|f_{j}(k)\right| \sin \left(2 k R_{j}+2 \delta_{1}(k)+\right. \\
\left.\varphi_{j}(k)\right) \mathrm{e}^{-2 \sigma_{j}^{2} k^{2}}+\text { multiple scatter terms }
\end{array}
$$

where $R_{j}$ is the distance to the $j$ th atom, $\delta_{1}$ is the phase shift for the $1=1$ phase shift for the photo absorbing atom, $\left|f_{j}(k)\right|$ and $\varphi_{j}(k)$ are, respectively, the back scattering amplitude and phase function of the atom $j, \lambda_{j}(k)$ is the mean-free path of the photoelectron and the last term $\mathrm{e}^{-2 \sigma_{j}^{2} k^{2}}$ is the so-called EXAFS Debye-Waller term. This is used to take into account the vibration of the atom at position $j$ since it models a Gaussian vibration about the centre of mass. Since this is not realistic for most atoms the term has been generalised into the cumulant expansion, with the introduction of more fitting parameters. ${ }^{18}$ This illustrates why the EXAFS signal from liquids is much weaker than that from a solid, since the disorder washes out the signal.

For a multicomponent liquid, eqn. (10) is rewritten in terms of $\chi_{a}(k)$ which characterises the EXAFS signal from atom $\alpha$. Specifically, ${ }^{19,20}$

$$
\chi_{\alpha}(k)=\sum_{\beta} \int_{0}^{\infty} \mathrm{d} r\left(4 \pi r^{2} \rho_{\beta} \gamma_{\alpha \beta}(k, r) g_{\alpha \beta}(r)+O\left(g^{3}(r)\right)+\text { higher order terms }\right)
$$

The sum is taken over all independent atomic species. The integral replaces the sum in eqn. (10), and the integrand accounts for the diffuse liquid structure in terms of a product of the partial pair RDFs, $g_{a, \beta}(r)$, and the term $\gamma_{\alpha \beta}$ which is calculated theoretically and represents the effective EXAFS scattering from atoms $\alpha$ and $\beta . \rho_{\beta}$ is the 
number density of $\beta$ atoms and $g^{3}(r)$ represents the triplet distribution functions of the system.

Unfortunately, even after dropping the higher order terms, the calculation of the $g(r)$ is ill-determined for a number of reasons. ${ }^{21}$ Difficulties to consider include the facts that $E_{0}$ is unknown, since the edge shifts as a function of the chemical bonding, and the EXAFS function involves a coupled structural and dynamic equation. It has been shown that for ions which form complexes in solution, the multiple scattering terms have a significant contribution to the signal. This causes great difficulty since the strength of the multiple scattering contribution is strongly dependent on the precise bonding angle and the distribution of these angles in the ensemble average. This is in part overcome by obtaining $k$-space data over a larger range and by improving the signal to noise ratio of the measured spectra but remains a problem that is not necessarily solvable with standard EXAFS experimental methods alone. Additional problems come about due to the $S_{0}$ factor, which accounts for many-body loss effects and is often freely fitted in a range between 0.95 and 0.6 and provides an overall reduction of the signal. This procedure can lead to problems in the absolute determination of coordination numbers.

Current analytic methods for experimental data from disordered materials follow one of several basic procedures. The approach most akin to the standard method for ordered materials is to generate a model of the local environment, then calculate the expected EXAFS signal. For liquids, this model is refined by adding a disorder term, and making small changes to the individual atom positions within the cluster model while at the same time comparing the calculated EXAFS with the experiment data. There have been several successful efforts in taking models from molecular dynamic simulations of liquids to obtain model $g(r)$ s which are refined to fit the EXAFS data. $^{22-24}$

Preference should be given to data analysed in this way because the EXAFS measurement (unlike a diffraction measurement) does not have sensitivity to the absolute density. (The electropath is always too short.) This means that effectively this information is not used to constrain the solutions obtained by the other method. It has been shown that the measured coordination number changes significantly if the tail of the $g(r)$ is considered in the analysis of liquid EXAFS. ${ }^{25}$

\section{Results}

Each of the methods discussed above has been used with varying degrees of success to obtain structural information on complex liquids. The diffractometers most useful in the determination of structure in liquids are D4 at ILL (Grenoble), SANDALS at ISIS (Rutherford Appleton Laboratory) for NDIS, and ID1 of the ESRF (Grenoble) for AXD. Each of these has its own strengths and when used in combination can effectively provide detailed information on the three aspects of the solution structure: the water solvent, the ionic hydration and the solute structure. In some cases the results discussed below have been combined with molecular dynamic (MD) simulation in order to deepen our knowledge of structure in specific systems. The information presented is limited to those liquids of most interest to the chemical community. The review does not contain results on liquid metals, binary alloys, liquid semiconductors

Annu. Rep. Prog. Chem., Sect. C, 2002, 98, 273-322 
and glasses of these materials; reference to these systems the reader should consult ref. ${ }^{26}$ Besides the results published in the literature, a rich source of additional information is available in the form of Annual Reports of the various Neutron and X-ray Facilities, e.g., ISIS at Rutherford Appleton Laboratory, Chilton, UK; ILL, Grenoble, France; KENS at the KEK Facility in Tsukuba, Japan; ESRF Grenoble, ALS, Argonne National Laboratory, etc. These publications contain progress reports on the status of experiments and describe state-of-the-art methods being used to tackle many topical problems concerning the atomic and molecular properties of condensed matter.

\subsection{Molecular liquids}

The complexity of molecular liquids stems from the fact that $(i)$ the basic entities 'the molecules' are not rigid, (ii) there exist orientational correlations in addition to the correlations between molecular centres, (iii) the same type of nucleus may be present in more than one position in the molecule, and (iv) only a limited number of isotopic substitutions are possible. For the case of a single ND measurement on a molecular liquid, computer-modelling techniques are also required to extract structural information. To avoid proliferation of spurious models, it is also helpful to have accurate diffraction data collected over a number of thermodynamic state $(p, T)$ points. The use of H/D substitution, wherever possible, provides additional information in assessing the reliability of model potentials used in computer modelling.

Since reviewing this field about five years ago, we have found about 45 references to new work on molecular liquid structure (Table 2). Rather than discuss results of these studies here we merely choose a few examples to illustrate the type of information, which diffraction data can provide.

As an example, methanol is the simplest alcohol studied extensively for several decades by both X-rays and ND. X-rays being relatively insensitive to light elements such as hydrogen, X-ray data of methanol have been treated in earlier studies to consist of only two scattering centres (methyl and hydroxy groups). Earlier ND studies ${ }^{1}$ concentrated on investigating the intramolecular structure purely from a form factor fitting to the diffraction data. Since the intermolecular RDF comprises many pair contributions, this function provided very little information on the intermolecular structure such as hydrogen bonding. Recently, Weitkamp et al. ${ }^{60}$ used the H/D substitution technique on both methyl and hydroxy hydrogen (Ho) to obtain the intermolecular partial distribution function, $\mathrm{Y}-\mathrm{Ho}(\mathrm{Y}=\mathrm{C}$ and $\mathrm{O})$. Surprisingly, their data show no sign of a sharp feature, which could be identified with the $\mathrm{O} \cdots$ Ho bond. Yamaguchi et al. ${ }^{61,62}$ used the H/D substitution on Ho to extract the $\mathrm{X}-\mathrm{X}$, $\mathrm{X}-\mathrm{Ho}$, and Ho-Ho partials at the intra- + intermolecular level, where $\mathrm{X}$ is an unsubstituted atom. They used the ND data to constrain empirical potential structure refinement (EPSR) where intra- and intermolecular potentials used in computer simulations were modified to obtain best agreement between the experimental and calculated structure functions. The EPSR results provided a detailed model for the intermolecular partials, allowing analysis of the size distribution of hydrogen-bonded clusters. However, application of the EPSR with a flexible molecular model can lead to strange molecular parameters during subsequent refinements of molecular 
Table 2 Molecular liquids/fluids and liquid/fluid mixtures investigated by diffraction techniques (ND/NDIS, XRD). The classification follows the same style as in our previous review $^{1}$

\begin{tabular}{lll}
\hline System & Technique & Ref.
\end{tabular}

Molecular liquids/fluids

Diatomics (heteronuclear)

DF (hydrogen fluoride)

$\mathrm{HCl} / \mathrm{DCl}$ (hydrogen chloride)

ND

27

NDIS + MC 28

NDIS + EPSR 29

$\mathrm{HBr} / \mathrm{DBr}$ (hydrogen bromide)

ND + XRISM

NDIS + EPSR

HI/DI (hydrogen iodide)

NDIS + EPSR

Triatomics

$\mathrm{CO}_{2}$ (carbon dioxide)

$\mathrm{ND}+\mathrm{MD}$

ND

XRD (WAXD)

ND + XRISM

$\mathrm{CS}_{2}$ (carbon disulfide)

$\mathrm{ND}+\mathrm{RMC}$

$\mathrm{CSe}_{2}$ (carbon diselenide)

ND

37

$\mathrm{H}_{2} \mathrm{~S}$ (hydrogen sulfide)

$\mathrm{ND}+\mathrm{RMC}$

36

NDIS + EPSR

Alkanes and alkenes

$\mathrm{CH}_{4}$ (methane)

ND + XRISM 30

$\mathrm{C}_{2} \mathrm{D}_{6}$ (ethane)

$\mathrm{ND}+$ XRISM + RMC

$\mathrm{ND}+\mathrm{RMC}+\mathrm{MC}$

40

$\mathrm{ND}+\mathrm{RISM}+\mathrm{HNC}$

41

$\mathrm{C}_{3} \mathrm{H}_{8}$ (cyclo propane)

$\mathrm{ND}+\mathrm{MD}$

Polyethylene

NDIS + PRISM

Aromatics

$\mathrm{C}_{6} \mathrm{H}_{6} / \mathrm{C}_{6} \mathrm{D}_{6}$ (benzene)

$\mathrm{ND}+\mathrm{MD}$

m-Toluidine

NDIS + MD

$\mathrm{ND}+\mathrm{MC}$

Fluorinated compounds

$\mathrm{CF}_{4}$ (carbon tetrafluoride)

$\mathrm{CH}_{2} \mathrm{~F}_{2}$ (difluoromethane, R32)

$\mathrm{ND}+\mathrm{RMC} \quad 50$

$\mathrm{C}_{6} \mathrm{H}_{3} \mathrm{~F}_{3}$ (1,3,5-trifluoro benzene)

ND 51

$\mathrm{C}_{6} \mathrm{~F}_{6}$ (hexafluorobenzene)

$\mathrm{ND}+\mathrm{MD}$

51

$\mathrm{ND}+\mathrm{MD}$

$\mathrm{CHF}_{3}$ (trifluoromethane)

$\mathrm{ND}+\mathrm{XRD} \quad 53$

$\mathrm{CH}_{3} \mathrm{~F}$ (methyl fluoride)

$\mathrm{ND}+\mathrm{EPSR}+\mathrm{RMC} \quad 54$

ND + XRD 53

Octafluoropropane (perfluoropropane, R218) ND 55

$\begin{array}{lll}\text { Decafluoro-n-butane (perfluorobutane) } & \text { ND } & 55\end{array}$

$\mathrm{SF}_{6}$ (sulfur hexafluoride)

ND + XRISM 30

Other halogenated compounds

$\mathrm{CF}_{3} \mathrm{Cl}$

ND 33

$\mathrm{ND}+\mathrm{RMC} \quad 56$

$\mathrm{CBr}_{4}$ (carbon tetrabromide)

1-Chloronaphthalene

XRD $\quad 57$

1,1,1-Trichloroethane

XRD + MD

$\begin{array}{ll}\mathrm{XRD}+\mathrm{MD} & 58\end{array}$ 
Table 2 (Contd.)

\begin{tabular}{|c|c|c|}
\hline System & Technique & Ref. \\
\hline 2,2-Dichloropropane & $\mathrm{XRD}+\mathrm{MD}$ & 58 \\
\hline $\mathrm{CCl}_{4}$ (carbon tetrachloride) & $\mathrm{NDIS}+\mathrm{MD}$ & 59 \\
\hline \multicolumn{3}{|l|}{ Alcohols and ketones } \\
\hline \multirow{3}{*}{$\mathrm{CH}_{3} \mathrm{OH} / \mathrm{CD}_{3} \mathrm{OD}$ (methanol) } & $\mathrm{ND}+\mathrm{XRD}$ & 60 \\
\hline & NDIS + EPSR & $61,62,63$ \\
\hline & NDIS + MD & $64,65,66$ \\
\hline $\mathrm{C}_{2} \mathrm{H}_{5} \mathrm{OH} / \mathrm{C}_{2} \mathrm{D}_{5} \mathrm{OD}$ (ethanol) & NDIS + MD & 67 \\
\hline tert-Butanol & NDIS + EPSR & 68 \\
\hline \multicolumn{3}{|l|}{ Acids } \\
\hline $\mathrm{HCOOH} / \mathrm{DCOOD}$ (formic acid) & $\mathrm{ND}+\mathrm{XRD}$ & 69 \\
\hline $\mathrm{H}_{3} \mathrm{PO}_{4}$ (phosphoric acid) & NDIS & 70 \\
\hline \multicolumn{3}{|l|}{ Miscellaneous } \\
\hline $\mathrm{NH}_{3}$ (ammonia) & $\mathrm{ND}+\mathrm{XRISM}$ & 30 \\
\hline \multicolumn{3}{|l|}{ Liquid/fluid mixtures } \\
\hline $\mathrm{CH}_{4}+\mathrm{CF}_{4}$ & $\mathrm{ND}+\mathrm{XRISM}$ & 71 \\
\hline Benzene $+1,3,5$-trifluoro benzene $(\mathrm{BT})$ & $\mathrm{ND}+\mathrm{MD}$ & 72 \\
\hline $\begin{array}{l}\text { Hexafluorobenzene + 1,3,5-trifluorobenzene } \\
\quad(\mathrm{HT})\end{array}$ & $\mathrm{ND}+\mathrm{MD}$ & 72 \\
\hline Benzene + hexafluorobenzene $(\mathrm{BH})$ & $\mathrm{ND}+\mathrm{MD}$ & 72 \\
\hline Benzene + methanol & NDIS + MD & 47,48 \\
\hline
\end{tabular}

configurations. The $\mathrm{X}-\mathrm{X}, \mathrm{X}-\mathrm{Ho}$, and $\mathrm{Ho}-\mathrm{Ho}$ partial structure functions obtained by Adya et al. ${ }^{64}$ using H/D substitution are in excellent agreement with those of Yamaguchi et al. Adya and co-workers used H/D substitution to show that, although slightly different molecular models may not produce any perceivable difference in the total intermolecular RDFs, clear differences can be seen in the partial RDFs. The average position of the $\mathrm{O} \cdots$ Ho hydrogen bond determined (see Fig. 2) purely from experimental intermolecular, $G_{\mathbf{X H o}}(r)$ partial distribution function, at $1.75 \pm 0.03 \AA$ lies in the range of values $(1.75-1.95 \AA)$ reported from computer simulation results. The experimental results have also been used to assess ${ }^{65,66}$ the relative merits of two 3-sites and one 6-site force field models used in the MD simulations of liquid methanol. Although different potential models used in MD simulations reproduce the total experimental RDFs rather well, discrepancies appear at a quantitative level when comparisons are made at the partial distribution function level.

Similarly, the structural studies on liquid benzene are not new. Actually, Debye and Scherrer carried out the pioneering work on the application of the XRD technique to the study of liquids on liquid benzene in 1916. Since then several studies have reported conflicting results by modelling the ND or XRD data at the total distribution function level. Such conflicts may well be resolved by using the NDIS to extract the three: C-C, $\mathrm{C}-\mathrm{H}$ and $\mathrm{H}-\mathrm{H}$ pair radial distribution functions (RDFs), which can provide a critical test of the validity of the model potentials. Adya and coworkers ${ }^{47,48}$ have recently used the NDIS results at the partial RDF level to test the validity of different model 

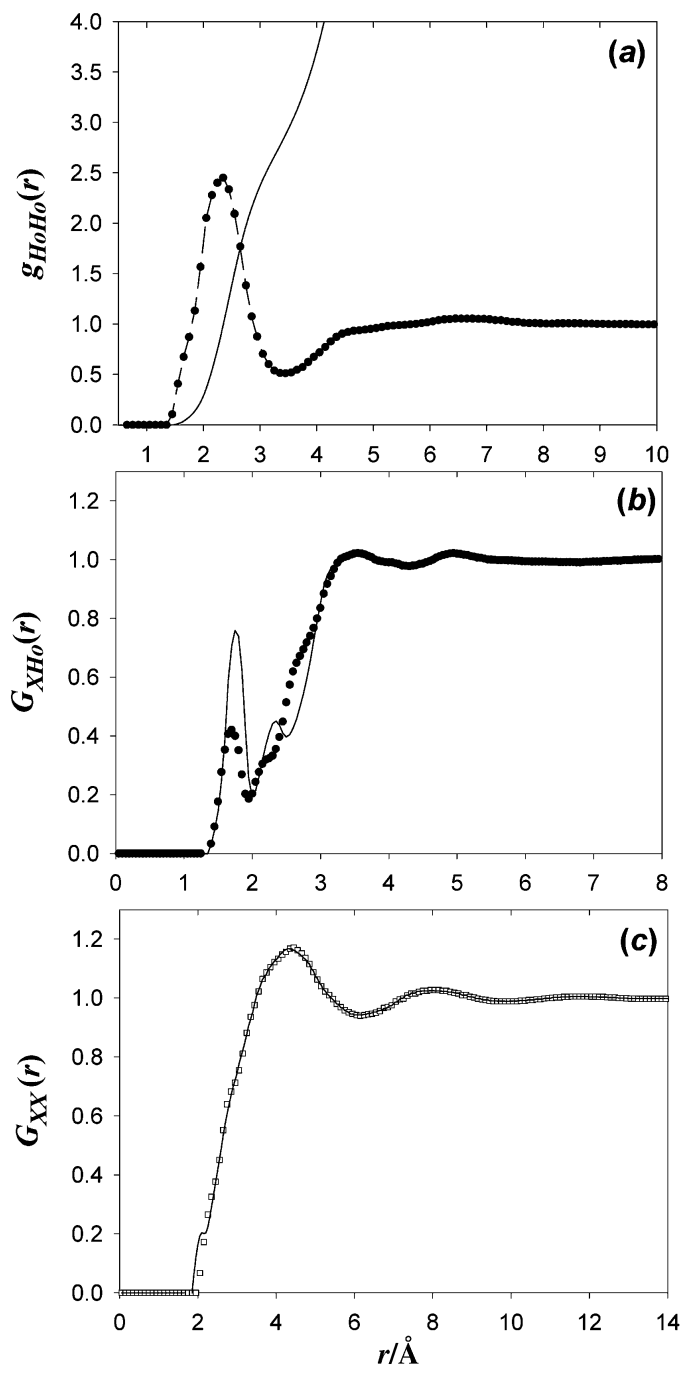

Fig. 2 The Ho-Ho pair: (a), the intermolecular X-Ho: $(b)$ and $\mathrm{X}-\mathrm{X}:(c)$, partial distribution functions obtained by $\mathrm{H} / \mathrm{D}$ substitution technique of $\mathrm{ND}$ using three samples: $\mathrm{CD}_{3} \mathrm{OD}, \mathrm{CD}_{3} \mathrm{OH}$, and $\mathrm{CD}_{3} \mathrm{O}(\mathrm{H} / \mathrm{D})$. In $(b)$ and $(c)$ symbols: after subtracting intramolecular form factor fitting using Debye type equation, and lines: after subtracting intramolecular structure with parameters fixed to the gas phase values. The line in $(a)$ : Ho-Ho running coordination number. The average position of the hydrogen bond in $(b)$ occurs at $1.75 \pm 0.03 \AA$, and the extent to which the intermolecular structure is affected by using two different intramolecular models can be seen. Figure adopted from ref. 64.

potentials in pure benzene and benzene-methanol mixture. The results of solutesolute, solute-solvent and solvent-solvent correlations obtained from H/D isotopic substitution technique of ND show that hydrogen bonding of methanol molecules in 
pure methanol is not disrupted by the addition of benzene, which plays the role of an inert solute in the mixture. The results also do not support the view that a $\pi$-hydrogen bond is formed between benzene and methanol. It is difficult, however, to comprehend why two entirely different potential models used in the simulations predict different dimer conformations (T-shaped $v s$. parallel displaced), yet produce similar RDFs in liquid benzene.

Most diffraction experiments present only the site-site RDFs, which contain far less information than the orientational pair correlation functions (OPCFs), and the challenge is to determine such OPCFs uniquely from the ND/NDIS or XRD data. Soper ${ }^{73}$ has recently presented an EPSR method to determine them. Since the challenge now to workers in the field is to determine accurate intermolecular potentials, it is desirable to impose as many experimental constraints as possible to critically examine the validity of such model potentials. It is, therefore, essential that the NDIS technique is used to determine accurately the partial distribution functions over a number of thermodynamic state points $(p, T)$ for different molecular liquids and over a number of compositions for the liquid mixtures. In addition, dynamic results obtained through scattering techniques will further help in discarding the spurious models.

\subsection{Molten salts}

Molten salt electrolytes offer several benefits over conventional aqueous and organic electrolytes, and have physical properties closely related to their ionic liquid structure, which can be determined by neutron and X-ray diffraction techniques. The acquisition of partial structure factors (PSFs), $S_{\mathrm{MM}}(Q), S_{\mathrm{Mx}}(Q), S_{\mathrm{xx}}(Q)$, and corresponding pair distribution functions (PDFs), of all the pairs of elements of a molten salt, $\mathrm{MX} n$, remains a challenge for many molten salts. In favourable cases full information can be obtained from NDIS experiments provided suitable isotopes are available and affordable. These functions can also be calculated from computer simulations and liquid structure theories based on pair interactions.

3.2.1 1:1 Molten metal halides and their mixtures. Structural properties of all the molten alkali metal chlorides, $\mathrm{LiCl}, \mathrm{NaCl}, \mathrm{KCl}, \mathrm{RbCl}$ and $\mathrm{CsCl}$, typical of loosely coordinated structure, are well documented, see for example our earlier review. ${ }^{1}$ All of these show a deep "Coulombic dip" in the cation-anion, $S_{+-}(Q)$, lying in phase with the main "Coulombic" peaks in $S_{-}(Q)$ and $S_{+}(Q)$, a feature representative of simple Coulombic ordering, and the $g_{++}(r)$ and $g_{-}(r)$ PDFs being phased to give complete charge cancellation for large $r$-values, a feature characteristic of complete ionisation in these melts. Theoretical models based on Fumi-Tosi potentials can adequately describe the above structural features of these 1:1 fused salts. By the same NDIS methods, molten $\mathrm{CuCl}, \mathrm{CuBr}$ and $\mathrm{AgCl}$ are shown to possess characteristics typical of weakly ionic systems. For instance, the PDFs show a deep penetration of $\mathrm{M}^{+}$ions into the first coordination shell of the $\mathrm{M}^{+}$ion, a considerable asymmetry between $\mathrm{M}-\mathrm{M}$ and $\mathrm{Cl}-\mathrm{Cl}$ PDFs, and almost featureless $g_{++}(r)$ and $S_{++}(Q)$. These features are unlike those observed in molten alkali metal halides. Although, theoretical models based on simple ionic pair-potentials can still reproduce the gross 
structural features of these melts, polarisation effects cannot be neglected in the model potentials. The structural results from total ND measurements on molten $\mathrm{CuX}$ and $\operatorname{AgX}(\mathrm{X}=\mathrm{Cl}, \mathrm{Br}, \mathrm{I})$, and on mixed molten salts $(\mathrm{CuCl})_{x}-(\mathrm{CuBr})_{1-x}$ and $(\mathrm{AgBr})_{x}-$ $(\mathrm{AgI})_{1-x}$ were also covered in our previous review. ${ }^{1}$

In some cases, anomalous X-ray diffraction (AXD) has been used to extract the partial PDFs, $g_{a \beta}(r)$, by varying the relative weighting factors. Saito et al. ${ }^{74}$ extracted the three PSFs and corresponding PDFs in molten $\mathrm{CuBr}$ from AXD. The structural characteristics are found to be similar to those using the NDIS technique. The lack of highly accurate experimental data prevented these authors from obtaining a unique and exact solution of the ill-conditioned simultaneous equations from the AXD measurements alone, and they used reverse Monte Carlo (RMC) simulations to help resolve these difficulties.

The EXAFS technique has been used to calculate the partial PDFs, in molten $\mathrm{KBr}$, $\mathrm{RbBr}$ and $\mathrm{CuBr},{ }^{75-78}$ and $\mathrm{RbCl}^{79,80}$ These PDFs are then compared with those obtained from the NDIS and/or MD simulations. It is interesting to note ${ }^{75-78}$ that although the PSFs, $S_{\text {cu-Br }}(Q)$ obtained from EXAFS and NDIS are in good agreement, $g_{\mathrm{CuBr}}(r)$ obtained from the EXAFS is much narrower and sharper. $\mathrm{AgBr}$ has also been investigated recently by Di Cicco et $a l^{81}$ both in the solid and liquid phases with simultaneous analysis of both the $\mathrm{Ag}$ and $\mathrm{Br}$ K-edges. The authors report that the double-edge refinement leads to a considerable improvement in the results over the previous data using standard data-analysis procedures.

The structural results from XRD measurements on a large number of 1:1 halide melts such as $\mathrm{LiF}$, $\mathrm{LiCl}$, $\mathrm{LiBr}$, LiI, $\mathrm{NaF}, \mathrm{NaCl}$, NaI, KF, KCl, $\mathrm{KBr}$, CsBr, CsI, and $\mathrm{AgCl}$ have been compiled and discussed by Ohno et al. ${ }^{82}$

3.2.2 2:1 Molten metal halides and their mixtures. A number of 2:1 halide melts including $\mathrm{MgCl}_{2}, \mathrm{CaCl}_{2}, \mathrm{BaCl}_{2}, \mathrm{SrCl}_{2}, \mathrm{ZnCl}_{2}$, and $\mathrm{NiX}_{2}(\mathrm{X}=\mathrm{Cl}, \mathrm{Br}$ and $\mathrm{I})$ have been studied by the NDIS experiments, and others such as $\mathrm{MnCl}_{2}, \mathrm{ZnBr}_{2}$, and $\mathrm{ZnI}_{2}$, investigated by the total ND measurements were also reviewed earlier by us. ${ }^{1}$ The structural features in the PSFs of molten alkaline-earth metal chlorides are in contrast to those of molten alkali-metal chlorides. For instance, the principal peak in $S_{\mathrm{MM}}(Q)$ here lies neither in phase with the peak in $S_{\mathrm{ClCl}}(Q)$ nor with the valley in the cross-term structure factor, $S_{\mathrm{MCl}}(Q)$. This behaviour suggests that the Coulombic ordering of the two ionic species clearly observed in the case of the alkali-metal halides is disturbed by the relatively strong Coulombic repulsions between the divalent cations. Although a simple ionic pair-potential is still able to reproduce the broad features of structural ordering in these $\mathrm{MCl}_{2}$ melts, significant discrepancies at a quantitative level between the computed and experimental data are now apparent.

The structural behaviour of molten $\mathrm{ZnCl}_{2}$ is quite different from the other 2:1 melts discussed above. The principal peaks in $S_{\mathrm{ClCl}}(Q)$ and $S_{\mathrm{ZnZn}}(Q)$ are again, as in molten alkali-metal halides, in phase with each other and also with the valley in the crossterm structure factor, $S_{\mathrm{ZnCl}}(Q)$. An interesting aspect of ND data on 2:1 and also 3:1 (see later) molten halides is the appearance of a first sharp diffraction peak (FSDP) at $\sim 1 \AA^{-1}$ which is absent in the diffraction patterns of $1: 1$ halide melts. Its presence has been linked to the existence of intermediate range order (IRO). For example, all the three zinc halide melts show a well resolved pre-peak in the total structure factors, $F(Q)$. A significant shift in its position to a lower $Q$-value and an increase in its height 
occur with increase in the anion size or with decreasing ionicity from chloride to bromide to iodide. A similar trend in the pre-peaks is also found in molten $\mathrm{NiCl}_{2}$, $\mathrm{NiBr}_{2}$ and $\mathrm{NiI}_{2}$.

Molten salts of stoichiometry $\mathrm{MX}_{2}$, show an intriguing evolution of short- and intermediate-range order structure as a function of cation size. For instance, as the cation size decreases from $\mathrm{Ba}(1.35 \AA) \rightarrow \mathrm{Sr}(1.12 \AA) \rightarrow \mathrm{Ca}(0.99 \AA) \rightarrow \mathrm{Zn}(0.74 \AA)$, the coordination number $(\mathrm{CN}), n_{+}$- decreases from $7.7,6.9,5.4$ to $\sim 4$; the first peak in $g_{++}(r)$ shifts markedly inwards relative to that in $g_{--}(r)$ to an extent that in $\mathrm{CaCl}_{2}$ and $\mathrm{ZnCl}_{2}$ these peaks coincide, which is contrary to the requirements of maximising the separation between the doubly charged cations. Also, with a decrease in the cation size the nearest-neighbour shell in $g_{+}(r)$ becomes progressively better defined with lesser penetration of like ions into the first coordination shell of unlike pairs. The most successful attempts to reproduce such an evolution of structure in 2:1 melts with decreasing cation size have been by Wilson et al. $^{83}$

Molten $\mathrm{ZnCl}_{2}, \mathrm{RbCl}$ and $\mathrm{Rb}_{2} \mathrm{ZnCl}_{4}{ }^{79,80}$ have been investigated by EXAFS, and the results show the existence of isolated $\mathrm{ZnCl}_{4}$ tetrahedral units and an absence of the tetrahedral network in $\mathrm{Rb}_{2} \mathrm{ZnCl}_{4}$, which dominates the structure in $\mathrm{ZnCl}_{2}$. Molten $\mathrm{Rb}_{2} \mathrm{ZnCl}_{4}$ can be considered a mixture of the two binary melts in which $\mathrm{RbCl}$ acts as a network breaker. These results are consistent with those obtained from $\mathrm{ND}$ on $\mathrm{ZnCl}_{2}$ $\mathrm{LiCl}$ and $\mathrm{ZnCl}_{2}-\mathrm{KCl}$ melts, which along with $\mathrm{NiCl}_{2}-\mathrm{LiCl}$ and $\mathrm{NiCl}_{2}-\mathrm{KCl}$ were discussed in our earlier review. ${ }^{1}$

The structural results from XRD on a large number of molten 2:1 halides and their mixtures with alkali-metal halides such as $\mathrm{CaCl}_{2},(\mathrm{LiCl})_{x}\left(\mathrm{CaCl}_{2}\right)_{(1-x)}(x=0.67,0.50)$, $(\mathrm{NaCl})_{x}\left(\mathrm{CaCl}_{2}\right)_{(1-x)}(x=0.67,0.50,0.33),(\mathrm{KCl})_{0.67}\left(\mathrm{BaCl}_{2}\right)_{0.33}, \mathrm{MnCl}_{2}, \quad(\mathrm{LiCl})_{0.67^{-}}$ $\left(\mathrm{MnCl}_{2}\right)_{0.33},(\mathrm{KCl})_{0.67}\left(\mathrm{MnCl}_{2}\right)_{0.33}, \mathrm{ZnCl}_{2},(\mathrm{KCl})_{x}\left(\mathrm{ZnCl}_{2}\right)_{(1-x)}(x=0.67,0.50,0.33)$, $\mathrm{CoCl}_{2}, \mathrm{PbCl}_{2},(\mathrm{LiCl})_{x}\left(\mathrm{PbCl}_{2}\right)_{(1-x)}(x=0.50,0.33), \mathrm{ZnBr}_{2}, \mathrm{BeF}_{2},(\mathrm{LiF})_{x}\left(\mathrm{BeF}_{2}\right)_{(1-x)}$ $(x=0.80,0.67,0.50),(\mathrm{NaF})_{x}\left(\mathrm{BeF}_{2}\right)_{(1-x)}(x=0.67,0.50,0.33)$, and $(\mathrm{KF})_{0.5}\left(\mathrm{BeF}_{2}\right)_{0.5}$ have been compiled. ${ }^{82}$

3.2.3 3:1 Molten metal halides and their mixtures. A large number of 3:1 halide melts of type $\mathrm{MX}_{3}$, spanning a wide range of ionic radii, have recently been investigated by combining the experimental data with results from MD simulations. The $\mathrm{MX}_{3}$ salts undergo a variety of structural transitions on melting. It is now well known that $(i)$ the macroscopic parameters of the melting transition such as melting temperature, $T_{\mathrm{m}}$, entropy change, $\Delta S_{\mathrm{m}}$ and fractional volume change $\Delta V / V_{\mathrm{l}}$, (ii) the structure of the high-temperature crystal phase before melting and, (iii) the values of transport properties such as ionic conductivity, $\sigma$, and shear viscosity, $\eta$, of the melt near freezing, are a good indication of structural ordering in these molten salts.

For the MD simulations two approaches have been used. Firstly, the rigid ion model (RIM) in which the simulations are performed by using only the Born-Mayer-like pair potentials. The details are described elsewhere. ${ }^{84,85}$ Secondly, those simulations where this potential was supplemented by taking into account the polarisation effects via the polarisable ion model (PIM) developed by Wilson and Madden. ${ }^{86,87}$ For the PIM results reported in this section, only the chloride ion was treated as polarisable.

As discussed before (Table 1), there is an intrinsic limitation in the use of the NDIS technique because it is possible to prepare suitable samples with high isotopic contrasts in only a few select cases. In fact, molten $\mathrm{DyCl}_{3}$ is the only $3: 1$ system in which 
the NDIS technique has been used ${ }^{88-91}$ to determine all three PSFs, $S_{\text {Dy-Dy }}(Q)$, $S_{\mathrm{Dy}-\mathrm{Cl}}(Q)$ and $S_{\mathrm{Cl}-\mathrm{Cl}}(Q)$, and the corresponding PDFs. For the other $\mathrm{MX}_{3}$ systems, such as chlorides $\left(\mathrm{LaCl}_{3},{ }^{9,93} \mathrm{CeCl}_{3},{ }^{92} \mathrm{TbCl}_{3},{ }^{94} \mathrm{YCl}_{3},{ }^{93-96} \mathrm{ScCl}_{3},{ }^{93,97} \mathrm{HoCl}_{3}\right.$ and $\mathrm{ErCl}_{3},{ }^{94,98}$ $\mathrm{AlCl}_{3},{ }^{99} \mathrm{SbCl}_{3},{ }^{100,101} \mathrm{FeCl}_{3},{ }^{102,103} \mathrm{BiCl}_{3},{ }^{104,105} \mathrm{InCl}_{3},{ }^{105} \mathrm{NdCl}_{3}{ }^{106}$ and $\mathrm{UCl}_{3}{ }^{107,108}$ ), bromides $\left(\mathrm{BiBr}_{3},{ }^{104} \mathrm{AlBr}_{3}\right.$ and $\mathrm{GaBr}_{3},{ }^{109} \mathrm{LaBr}_{3}$ and $\mathrm{CeBr}_{3},{ }^{92} \mathrm{DyBr}_{3}, \mathrm{YBr}_{3}, \mathrm{HoBr}_{3}$ and $\mathrm{ErBr}_{3}{ }^{98,110}$ ), and iodides $\left(\mathrm{BiI}_{3},{ }^{104} \mathrm{GaI}_{3},{ }^{109} \mathrm{LaI}_{3}\right.$ and $\left.\mathrm{CeI}_{3},{ }^{92} \mathrm{ScI}_{3}{ }^{97}\right)$, total structure factors, $F(Q)$ and RDFs, $G(r)$ have been obtained by ND.

XRD results of $\mathrm{MX}_{3}$ melts $\left(\mathrm{AlCl}_{3},{ }^{111} \mathrm{SbCl}_{3},{ }^{100,101} \mathrm{NdCl}_{3},{ }^{82,12-114} \mathrm{LaCl}_{3},{ }^{82,115,116}\right.$ $\mathrm{LaBr}_{3},{ }^{117} \mathrm{CeCl}_{3}, \mathrm{PrCl}_{3}, \mathrm{GdCl}_{3}, \mathrm{DyCl}_{3}$ and $\mathrm{SmCl}_{3},{ }^{82,113,115} \mathrm{ErCl}_{3},{ }^{118} \mathrm{UCl}_{3}{ }^{116}$ ) have usually been analysed by a model fitting of the experimental $F(Q)$ by using the Debye equation to obtain structural information in terms of the nearest-neighbour distances and CNs. Such studies have been made primarily on laboratory-based equipment. It may be noted that the CNs of metal-Cl pairs obtained in all the above lanthanide and actinide halides from XRD are reported to be six, and the existence of octahedral complex anion, $\mathrm{MX}_{6}{ }^{3-}$ in these $\mathrm{MX}_{3}$ melts is found to be consistent with the results of Raman spectroscopy. However, as we shall see later, the $\mathrm{CNs}$ of metal-Cl pairs in $\mathrm{LaCl}_{3}, \mathrm{LaBr}_{3}$ and $\mathrm{UCl}_{3}$ obtained from the above XRD studies are in disagreement with those obtained from recent ND + MD studies.

Wasse and Salmon ${ }^{93}$ found from ND measurements on molten $\mathrm{LaCl}_{3}$ that the $\mathrm{CN}$ of $\mathrm{Cl}^{-}$ions around the cation reduces from 9 in its high-temperature crystalline form to $\approx 6.4$ in its liquid phase. The first peak at $2.88 \AA$ in the total RDF shows a significant overlap from other pair correlations. However, since these values compared reasonably with those reported earlier $\left(r_{\mathrm{La}-\mathrm{Cl}}=2.83 \AA, \bar{n}_{\mathrm{La}}^{\mathrm{Cl}}=5.7\right)$ from $\mathrm{XRD},{ }^{82}$ the authors concluded that there is a breakdown in the local structure of $\mathrm{LaCl}_{3}$ on melting since the $\mathrm{CN}$ drops significantly. The same authors ${ }^{92}$ subsequently determined the total $F(Q)$ of molten $\mathrm{LaX}_{3}$ and $\mathrm{CeX}_{3}(\mathrm{X}=\mathrm{Cl}, \mathrm{Br}, \mathrm{I})$ systems. They employed the difference techniques of $\mathrm{ND}$ by assuming $\mathrm{LaX}_{3}$ and $\mathrm{CeX}_{3}$ melts, for a given halide ion, to be isomorphic. The results now showed the nearest-neighbour, $\mathrm{La}-\mathrm{Cl}$ distance and the $\mathrm{CN}, \bar{n}_{\mathrm{La}}^{\mathrm{Cl}}$ to be $2.93 \AA$ and 8.2 as compared to the previous values of $2.88 \AA$ and 6.4 , respectively. It should be noted ${ }^{119,120}$ that it is sometimes difficult to derive quantitative structural information from the total $F(Q)$ for $3: 1$ halide melts. This is particularly true when there are overlapping contributions to a given peak in the total $G(r)$. It appears that the structural parameters obtained from the isomorphic substitution technique are more accurate since the two difference functions are heavily weighted in $\mathrm{M}-\mathrm{Cl}$ and $\mathrm{Cl}-\mathrm{Cl}$ correlations, respectively, and do not contain significant contributions from other pairs. Hutchinson et al. ${ }^{84}$ performed MD simulations on $\mathrm{LaCl}_{3}$ and $\mathrm{CeCl}_{3}$ using the PIM, and found reasonably good agreement not only between the simulated and experimental $F(Q)$ but also between the isomorphic difference functions.

The ND results on the $\mathrm{MX}_{3}(\mathrm{M}=\mathrm{La}, \mathrm{Ce}$ and $\mathrm{X}=\mathrm{Cl}, \mathrm{Br}, \mathrm{I})$ melts show that the FSDP in the $F(Q)$ arising from the cation correlations moves to lower $Q$-values with increasing anion size $\left(1.12 \AA^{-1}\right.$ for $\mathrm{La} / \mathrm{CeCl}_{3} ; 0.93 / 0.88 \AA^{-1}$ for $\mathrm{La} / \mathrm{CeBr}_{3}$ and $0.81 /$ $0.77 \AA^{-1}$ for $\mathrm{La} / \mathrm{CeI}_{3}$ ), which is indicative of enhanced separation in real space of the cation-centred polyhedra. A similar shift in the position of the prepeak to lower $Q$-values with increase in the anion size from $\mathrm{Cl}^{-}(1.81 \AA)$ to $\mathrm{Br}^{-}(1.96 \AA)$ to $\mathrm{I}^{-}$ $(2.20 \AA)$ has been observed previously in the three zinc and nickel halides. The CNs, $\bar{n}_{\mathrm{M}}^{\mathrm{X}}$ decrease from 9 for $\mathrm{MCl}_{3}$ and $\mathrm{MBr}_{3}$, which melt from $\mathrm{UCl}_{3}$-type structure to 8.2 and 
7.4, respectively, and from 8 for $\mathrm{MI}_{3}$, melting from $\mathrm{PuBr}_{3}$-type structure to 6.7. Thus, the $\mathrm{CNs}$ for the three systems do not change substantially on melting. The XRD results of Okamoto et al. ${ }^{117}$ predicting octahedral coordination $\left(\bar{n}_{\mathrm{L}}^{\mathrm{Br}},=6\right)$ in molten $\mathrm{LaBr}_{3}$ are in contradiction to the above ND $\left(\bar{n}_{\mathrm{La}}^{\mathrm{Br}}=7.4\right)$ and $\mathrm{MD}^{121}\left(\bar{n}_{\mathrm{La}}^{\mathrm{Br}}=7.1\right)$ results.

ND measurements on molten $\mathrm{UCl}_{3}$ in conjunction with the RIM and PIM simulations showed that the $\mathrm{U}^{3+}$ ion is coordinated to $\sim 7$ chloride ions, suggesting a polyhedral arrangement with a nearest-neighbour $\mathrm{U}-\mathrm{Cl}$ distance of $2.82 \AA .^{107,108}$ These results are again at variance with those obtained from earlier XRD and MD work by Okamoto et al., ${ }^{116}$ where the structure of $\mathrm{UCl}_{3}$ is proposed to be octahedral. In the molten state, $\mathrm{UCl}_{3}$ is structurally isomorphic to $\mathrm{LaCl}_{3}$, both showing similar features in their total $F(Q)$. This is consistent with the fact that both compounds melt from $\mathrm{UCl}_{3}$-type crystal structure with similar melting points. The ionic radii of $\mathrm{La}^{3+}(1.032 \AA)$ and $\mathrm{U}^{3+}(1.025 \AA)$ are also similar. The $F(Q)$ of molten $\mathrm{UCl}_{3}$ shows a FSDP at $1.1 \AA^{-1}$ arising from intermediate-range correlations, and reflecting strong local structures linked by some form of connectivity between local coordination polyhedra.

$\mathrm{NdCl}_{3}$ also crystallises in the $\mathrm{UCl}_{3}$-type structure. Saboungi et al. ${ }^{106}$ used XRD data of Mochinaga et al. ${ }^{82,112}$ in conjunction with their ND results to obtain a model structure using the RMC modelling. The results did not provide structural details of much significance. However, from the similarity of the RMC generated triplet correlation functions for the liquid with those in the crystalline state, it is suggested that the local structure in the melt although considerably more disordered still retains some characteristics of the solid phase. Also, the presence of a FSDP in the total $F(Q)$ at $\sim 1 \AA^{-1}$ indicates the existence of IRO in this melt.

The EXAFS spectra of $\mathrm{NdCl}_{3}$ and $\mathrm{DyCl}_{3}$ at the $\mathrm{Nd}$ and $\mathrm{Dy} \mathrm{L}_{\mathrm{III}}$-absorption edges over a range of temperatures have been obtained in both the solid and liquid phases. ${ }^{122,123}$ The results show that $(i)$ both compounds undergo structural changes on melting and the effect is larger in $\mathrm{NdCl}_{3},(i i)$ the type of phase transition on melting of the two compounds is different, and (iii) $\mathrm{NdCl}_{3}$ shows a solid-solid structural phase transition, which is absent in $\mathrm{DyCl}_{3}$.

$\mathrm{DyCl}_{3}$ transforms into the $\mathrm{AlCl}_{3}$ structure before melting where it is structurally isomorphous to $\mathrm{YCl}_{3}$ and melts with similarly low values of $\Delta S_{\mathrm{m}}$ and $\Delta V / V_{\mathrm{l}}$. From the proximity of Dy to $\mathrm{Y}$ in Pettifor's chemical scale, Tosi et al. ${ }^{95}$ suggested that $\mathrm{DyCl}_{3}$ should show a similar melting mechanism and liquid structure to $\mathrm{YCl}_{3}$.

NDIS data were used to calculate the partial PDFs in molten $\mathrm{DyCl}_{3}{ }^{88-91}$ The experimental total $F(Q)$ s for the three isotopic samples of $\mathrm{DyCl}_{3}$ show ${ }^{89}$ that the predominant contribution to the FSDP at $Q \approx 1 \AA^{-1}$ is the metal-metal term, and these Dy-Dy correlations exist on the scale of IRO through chlorine sharing linkages. While the RIM and PIM simulated PDFs, $g_{\text {Dy-Cl }}(r)$ and $g_{\mathrm{Cl}-\mathrm{Cl}}(r)$ reproduce ${ }^{90}$ equally well the experimental PDFs, and have similar shapes from the two models, the results for the Dy-Dy PDF from the two models are quite different (see Fig. 3). The NDIS results show that the first peak in $g_{\text {Dy-Dy }}(r)$ is split into two component distances and the PIM results reproduce the experimental function nicely, highlighting the importance of including polarisation effects in the model potential used for simulations. The results show that $(i)$ the distribution of anions is hardly affected by the polarisation effects and, (ii) although repulsion between triply charged $\mathrm{Dy}^{3+}$ should maximise the separation between the cations, this effect is offset by the polarisation of anions by 

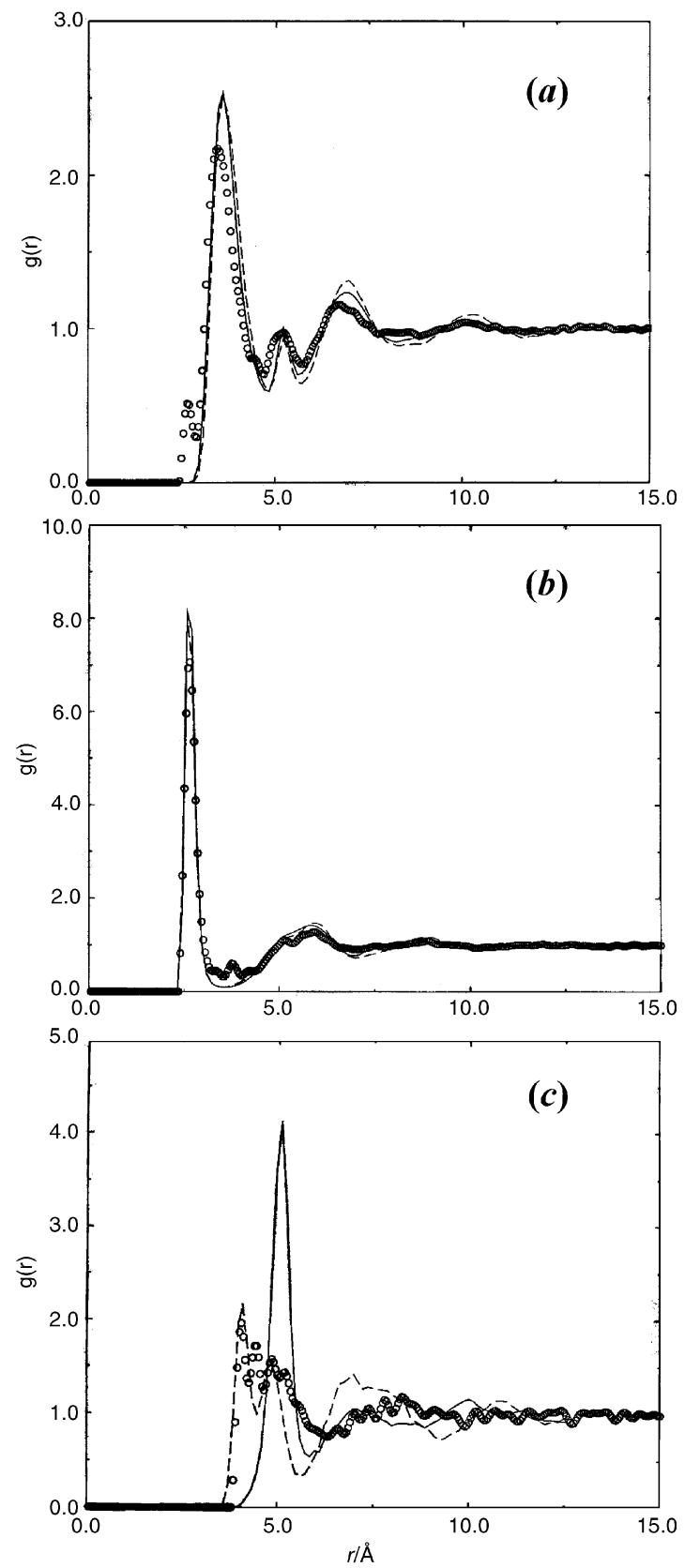

Fig. 3 The partial PDFs for pure molten $\mathrm{DyCl}_{3}$ : experimental NDIS data (open circles), RIM results (solid line) and PIM results (dashed line) for $(a) \mathrm{Cl}-\mathrm{Cl},(b)$ Dy-Cl and (c) Dy-Dy correlations. Figure adopted from ref. 90. 
highly charged cations, leading to shortened cation-cation distances by Dy-Cl-Dy 'bond bending'.

The average CNs calculated from the PDFs obtained by PIM reveal that the cation in molten $\mathrm{UCl}_{3}$ is 7-fold coordinate. In contrast, the first peak in $g_{\mathrm{Dy}-\mathrm{Cl}}(r)$ yields a $\mathrm{CN}$ of 6 , and the $\mathrm{Cl}-\mathrm{Dy}-\mathrm{Cl}$ bond angle distribution and the $\mathrm{Cl}-\mathrm{Cl}$ separation distance are consistent with octahedral coordination in molten $\mathrm{DyCl}_{3}$. For $\mathrm{UCl}_{3}$ however, the $\mathrm{Cl}-\mathrm{Cl}$ distance is found to be far less. The next peak in $g_{\mathrm{Cl}-\mathrm{Cl}}(r)$ reflecting the correlations across the first coordination shell has a larger area in $\mathrm{UCl}_{3}$ than in $\mathrm{DyCl}_{3}$, which is again consistent with a higher $\mathrm{CN}$ in $\mathrm{UCl}_{3}$. Similar behaviour has been observed in molten $\mathrm{LaCl}_{3}{ }^{84}$ These results show that while the octahedral coordination in $\mathrm{DyCl}_{3}$ is preserved on melting, the $\mathrm{CN}$ in $\mathrm{UCl}_{3}$ decreases from 9 in the crystal to 7 in the melt. Also, the depth of the first minimum in $g_{\mathrm{M}-\mathrm{Cl}}(r)$ increases with the decrease in cation size from $\mathrm{UCl}_{3}$ to $\mathrm{DyCl}_{3}$. This indicates that with the decrease in cation size the first coordination shell becomes more tightly bound and, it is less likely to exchange anions with the bulk. Integration of the first peak to this first minimum gives $\mathrm{CN}$ of 7.05 for $\mathrm{UCl}_{3}$ and 5.99 for $\mathrm{DyCl}_{3}$. These results suggest that with decrease in cation radius from $\mathrm{UCl}_{3}$ (or $\mathrm{LaCl}_{3}$ ) to $\mathrm{DyCl}_{3}$, $(i)$ the octahedral coordination becomes progressively more stable and, $(i i)$ the ionic conductivity should decrease gradually, as has been observed.

Moreover, the polarisation effects are found not to be as significant in molten $\mathrm{UCl}_{3}$ as in $\mathrm{DyCl}_{3}$. This can be easily understood in terms of greater ionicity of the bond in $\mathrm{UCl}_{3}$. Hutchinson et al. ${ }^{84}$ also noted that the polarisation effects in $\mathrm{LaCl}_{3}$ (similar to those in $\mathrm{UCl}_{3}$ ) are weaker than those in $\mathrm{YCl}_{3}$ (isomorphic to $\mathrm{DyCl}_{3}$ ) because of the larger cation radius. This indicates that the structures in $\mathrm{LaCl}_{3}$ and $\mathrm{UCl}_{3}$ melts are more dominated by the Coulomb repulsion effects. From this point of view both $\mathrm{LaCl}_{3}$ and $\mathrm{UCl}_{3}$ appear to be closer to the classical ionic model.

$\mathrm{YCl}_{3}$ is structurally isomorphous to $\mathrm{AlCl}_{3}$ in the crystalline state but the two compounds show entirely different melting mechanisms, with very different values for their melting and transport properties. The ionic sizes of $\mathrm{Y}^{3+}$ and $\mathrm{Dy}^{3+}$ are also similar. ND results for molten $\mathrm{YCl}_{3}$ studied earlier by saboungi et al. ${ }^{95,96}$ show $(i)$ a FSDP at $Q \approx 0.95 \AA^{-1}$ associated with IRO in the melt and, (ii) a $\mathrm{CN}$ for $\mathrm{Cl}$ about $\mathrm{Y}$ of 5.9 , thus confirming an octahedral coordination for Y. Tosi et al. ${ }^{124}$ performed liquid structure calculations for an ionic model of molten $\mathrm{YCl}_{3}$, and the results indicate melting of $\mathrm{YCl}_{3}$ into a loose ionic network structure formed by edge-sharing octahedra. Wasse and Salmon ${ }^{94}$ fitted the first two peaks in the $G(r)$ from a recent ND study to a sum of Gaussians, and report the distances and CNs as $r_{\mathrm{Y}-\mathrm{Cl}}=2.72 \AA, \bar{n}_{\mathrm{Y}}^{\mathrm{Cl}}=$ $5.7, r_{\mathrm{Cl}-\mathrm{Cl}}=3.55 \AA$ and $\bar{n}_{\mathrm{Cl}}^{\mathrm{Cl}}=7.8$, which are in agreement with the values, $r_{\mathrm{Y}-\mathrm{Cl}}=2.71$ $\AA, \bar{n}_{\mathrm{Y}}^{\mathrm{Cl}}=5.9$ and $\bar{n}_{\mathrm{Cl}}^{\mathrm{Cl}}=8$ to 9 , obtained earlier by a Gaussian fitting procedure by Saboungi et al. The PIM results on molten $\mathrm{YCl}_{3}$ by Hutchinson et al. ${ }^{84}$ show a substantial disagreement between the simulated and either of the two experimental ${ }^{94,96}$ $F(Q)$ almost over the entire range $\left(\sim 2-8 \AA^{-1}\right)$. To what extent these discrepancies are due to strong cancellation effects between contributing PSFs could not be ascertained ${ }^{84}$ since the same PIM simulations reproduce the behaviour of molten $\mathrm{DyCl}_{3}$ at the PSF level very well, and the two systems are believed to be isomorphic. It is likely ${ }^{84}$ that the above discrepancies have exposed the limitations of the "generic" nature of the PIM. 
Wasse and Salmon ${ }^{94}$ measured the $F(Q)$ s of molten $\mathrm{TbCl}_{3}, \mathrm{HoCl}_{3}$ and $\mathrm{ErCl}_{3}$ by ND. They all show a FSDP indicative of IRO, and its position shifts to smaller $Q$-values from $1.01 \AA^{-1}\left(\mathrm{TbCl}_{3}\right) \longrightarrow 0.95 \AA^{-1}\left(\mathrm{HoCl}_{3}\right) \longrightarrow 0.92 \AA^{-1}\left(\mathrm{ErCl}_{3}\right)$ with decreasing cation size: $0.92 \rightarrow 0.90 \rightarrow 0.89 \AA$, respectively. The first and second peaks in the $G(r)$ show a significant overlap, and the peaks are broadened due to the limited $Q$-range $\left(\cong 10 \AA^{-1}\right)$ for the three sets of data. The two peaks in real space were fitted to a sum of Gaussians, and the distances and CNs are reported as: $r_{\mathrm{M}-\mathrm{Cl}}\left(\bar{n}_{\mathrm{M}}{ }^{\mathrm{Cl}}\right)=2.72 \AA$ (6.3), $2.76 \AA$ (6.4), $2.74 \AA$ (5.6), and $r_{\mathrm{Cl}-\mathrm{Cl}}\left(\bar{n}_{\mathrm{Cl}}^{\mathrm{Cl}}\right)=3.58 \AA(8.1), 3.59 \AA(8.1)$ and $3.58 \AA$ (8.9), respectively for $\mathrm{TbCl}_{3}, \mathrm{HoCl}_{3}$ and $\mathrm{ErCl}_{3}$. The $\mathrm{CNs}$ of $\approx 6$ in the molten phase are in accord with the octahedral coordination of the cations in the high-temperature crystal structures of the three compounds. The ratios, $r_{-} / r_{+-}$for the three melts and also for the $\mathrm{YCl}_{3}$, discussed before, fall in the range 1.30-1.34, suggesting a distortion of $\mathrm{MCl}_{6}{ }^{3-}$ from regular (expected value 1.41 ) octahedral geometry. The octahedral coordination in these compounds, similar to that in $\mathrm{YCl}_{3}$ and $\mathrm{DyCl}_{3}$, is thus preserved on melting, which is consistent with a small $\Delta V / V_{1}$ observed for all of them; the five cations $\left(\mathrm{Tb}^{3+}, \mathrm{Ho}^{3+}, \mathrm{Er}^{3+}, \mathrm{Y}^{3+}, \mathrm{Dy}^{3+}\right)$ have similar values of ionic radii $(0.90-0.92 \AA)$.

Iwadate et al. ${ }^{118}$ investigated the structure of molten $\mathrm{ErCl}_{3}$ by $\mathrm{XRD}$, and report the $\mathrm{Er}^{3+}-\mathrm{Cl}^{-}, \mathrm{Cl}^{-}-\mathrm{Cl}^{-}, \mathrm{Er}^{3+}-\mathrm{Er}^{3+}$ distances and corresponding $\mathrm{CNs}$ as $2.63 \AA$ (5.8), $3.75 \AA(8-9)$ and $4.05 \AA(1-2)$. The ratio $r_{-} / r_{+-}=1.43$ is found to be closer to 1.41 expected for octahedral geometry. By considering different structural models they proposed that clustering of distorted octahedra with edge-sharing arrangement $\left(\mathrm{Er}_{2} \mathrm{Cl}_{10}{ }^{4-}\right)$ is expected, with a small amount of $\mathrm{Er}_{2} \mathrm{Cl}_{11}{ }^{5-}$ (corner-sharing octahedra) ions being also formed in the melt.

Wasse et al..$^{98,110}$ investigated the structures of molten $\mathrm{DyBr}_{3}, \mathrm{YBr}_{3}, \mathrm{HoBr}_{3}$ and $\mathrm{ErBr}_{3}$ by ND. FSDPs occurring at $0.87(2), 0.82(2), 0.80(2)$ and $0.79(2) \AA^{-1}$, respectively, in the $F(Q)$ indicate the existence of IRO in these melts. All of them crystallise into the same hexagonal close-packed $\mathrm{FeCl}_{3}$-type structure at room temperature. The ND data for the four systems show $(i)$ the survival on melting of a substantial number of $\mathrm{MBr}_{6}{ }^{3-}$ octahedral units, (ii) the distortion of these octahedra from a regular geometry, (iii) a large number of these octahedra being connected by edge-sharing to give IRO of cation correlations. The difference functions were also analysed by assuming structural isomorphism between $\mathrm{DyBr}_{3}$ and $\mathrm{YBr}_{3}$. The results show that the $\mathrm{M}-\mathrm{Br} \mathrm{CN}$ does not change significantly from 6 when $(\mathrm{Dy} / \mathrm{Y}) \mathrm{Br}_{3}$ melts and the ratio, $r_{--} / r_{+-}=1.33$ in the liquid. However, as seen previously, for $(\mathrm{La} / \mathrm{Ce}) \mathrm{Br}_{3}$ there is a reduction in the $\mathrm{CN}$ from 9 to 7.4 on melting, and the ratio $r_{-} / r_{+}$in this case is 1.25 . The decrease in the cation radius from $1.02 \AA$ for $\mathrm{La}^{3+} / \mathrm{Ce}^{3+}$ to $0.91 \AA$ for $\mathrm{Dy}^{3+} / \mathrm{Y}^{3+}$ leads to an increasing covalent character, and the polarisation effects in the $\mathrm{La} / \mathrm{Ce}$-systems are expected not to be as significant as in the Dy/Y-systems. Similar observations were made earlier in $\mathrm{DyCl}_{3} / \mathrm{YCl}_{3}$ vis a vis $\mathrm{LaCl}_{3} / \mathrm{CeCl}_{3}$ systems.

$\mathrm{InCl}_{3}$ has the $\mathrm{AlCl}_{3}$ structure in the crystal and its volume change on melting is large. However, both its melting temperature and ionic conductivity are similar to $\mathrm{YCl}_{3}$ rather than $\mathrm{AlCl}_{3}$. From the total ND measurements on molten $\mathrm{InCl}_{3}$ which yielded a value for the $\mathrm{CN}, \bar{n}_{\text {In }}{ }^{\mathrm{Cl}}$, between 5 and 6 , Price et al. ${ }^{105}$ suggested a partial survival of the network structure in the melt which is in contrast to the low metal-ion coordination in $\mathrm{BiCl}_{3}$ (see below).

Fukushima et al. ${ }^{104}$ concluded from ND measurements on bismuth trihalides, $\mathrm{BiX}_{3}$ $(\mathrm{X}=\mathrm{Cl}, \mathrm{Br}, \mathrm{I})$ at a number of temperatures that the molten $\mathrm{BiX}_{3}$ systems behave like 
molecular liquids similar to $\mathrm{PX}_{3}$. The results of $\mathrm{ND}$ on molten $\mathrm{BiCl}_{3}$ by Price et al. ${ }^{105}$ indicate a metal-ion coordination of $\sim 3$, suggesting a molecular configuration in the melt. If monomers are the basic constituents present, they should be strongly interacting to allow relatively fast exchange of the halogen ions in accord with the observed ionic conductivity of the melt, which is appreciable. Price et al. ${ }^{105}$ suggested that the nature of the structure and bonding of $\mathrm{InCl}_{3}$ and $\mathrm{BiCl}_{3}$ is intermediate between the network structure of $\mathrm{YCl}_{3}$ and $\mathrm{DyCl}_{3}$ on the one hand and well defined molecular configurations of $\mathrm{AlCl}_{3}$ and $\mathrm{FeCl}_{3}$ (see later) on the other.

Wasse and Salmon ${ }^{97}$ investigated the structures of molten $\mathrm{ScCl}_{3}$ and $\mathrm{ScI}_{3}$ by ND. The $F(Q)$ of both the melts show a FSDP at $0.75 \AA^{-1}$ indicative of the IRO. The first peaks in the $G(r)$ gave values for the Sc-X distances and $\mathrm{CNs}$, of $2.48 \AA$ (4.8) for $\mathrm{ScCl}_{3}$ and $2.76 \AA$ (4.7) for $\mathrm{ScI}_{3}$. The process of melting, therefore, reduces the $\mathrm{Sc}-\mathrm{X} \mathrm{CN}$ from 6 in the solid to $\sim 5$ in both the melts. Also, the first peaks in the $G(r)$ do not return to their $G(0)$ limits on their high- $r$ sides, suggesting a significant mobility of the ions from and to the first coordination shells which is consistent with the observed high electrical conductivity. It is proposed that $\mathrm{ScCl}_{3}$, similarly to $\mathrm{InCl}_{3}$ and $\mathrm{BiCl}_{3}$ (discussed before), may have characteristics that are intermediate between $\mathrm{YCl}_{3} / \mathrm{DyCl}_{3}$ on the one hand and $\mathrm{AlCl}_{3} / \mathrm{FeCl}_{3}$ on the other.

Badyal et al. ${ }^{99}$ analysed the total $\mathrm{ND}$ results on molten $\mathrm{AlCl}_{3}$ by $\mathrm{RMC}$ modelling. The experimental $G(r)$ show a clear first deep minimum (unlike that in $\mathrm{ScCl}_{3}$ or $\mathrm{ScI}_{3}$ ) after the well-resolved $\mathrm{Al}-\mathrm{Cl}$ principal peak at $2.11 \AA$, indicating little movement of anions into and out of the first shell. The $\mathrm{CN}, \bar{n}_{\mathrm{Al}}^{\mathrm{Cl}}=4$, and $r_{-} / r_{+-}=1.66$ indicate a regular four-fold tetrahedral geometry in molten $\mathrm{AlCl}_{3}$. The PIM results by Hutchinson et al. $^{85}$ show that an overwhelming majority of the four-fold coordinate $\mathrm{Al}^{3+}$ ions are involved in dimers.

The structural results of molten $\mathrm{AlBr}_{3}, \mathrm{GaBr}_{3}$ and $\mathrm{GaI}_{3}$ by ND show the existence of dimeric $\mathrm{M}_{2} \mathrm{X}_{6}$ units associated with tetrahedral coordination. ${ }^{1}$ The melting of $\mathrm{AlCl}_{3}$ from an ionic layer-structure into a molecular liquid of $\mathrm{Al}_{2} \mathrm{Cl}_{6}$ units is accompanied by low melting point, and very large values of $\Delta S_{\mathrm{m}}$ and $\Delta V / V_{\mathrm{l}}$. The large increase in volume and entropy on melting is explained in terms of the dramatic change in the $\mathrm{CN}$ of $\mathrm{Al}^{3+}$ ion from 6 in the crystal to 4 in the melt. In crystalline $\mathrm{AlBr}_{3}$ however, the $\mathrm{Al}^{3+}$ ions are in a tetrahedral coordination in the crystal lattice of molecular $\mathrm{Al}_{2} \mathrm{Br}_{6}$ dimers, and this coordination is retained in the melt. This is consistent with the observation that $\Delta S_{\mathrm{m}}$ and $\Delta V / V_{1}$ for $\mathrm{AlBr}_{3}$ are less than half of those observed for $\mathrm{AlCl}_{3}$.

ND measurements on molten $\mathrm{FeCl}_{3}$ by Price et al. ${ }^{102,103}$ combined with model calculations and computer simulations indicate that melting is accompanied by a change in the local structure from the octahedral environment of the $\mathrm{Fe}^{3+}$ ions in the crystal to a tetrahedral environment where $\mathrm{Fe}_{2} \mathrm{Cl}_{6}$ molecular units exhibit substantial intermolecular correlations. This behaviour is similar to that observed in $\mathrm{AlCl}_{3}$ but in contrast to that in $\mathrm{YCl}_{3}$ or $\mathrm{DyCl}_{3}$ where octahedral coordination of $\mathrm{M}^{3+}$ ions is preserved on melting. The PIM simulated results ${ }^{85}$ also show the cation to be 4 -fold coordinate in molten $\mathrm{FeCl}_{3}$, which is present as $\mathrm{Fe}_{2} \mathrm{Cl}_{6}$ dimers.

Triolo et al. ${ }^{100,101}$ found from combined ND and XRD analyses of $\mathrm{SbCl}_{3}$ that the liquid is structured in monomeric molecular units. The average arrangement of the discrete units is far from random and, with close intermolecular $\mathrm{Sb}-\mathrm{-Cl}$ contacts, results in a well defined distribution centred $\sim 3.4 \AA$, a distance much shorter than that 
expected from van der Waals interactions alone. The results suggest a distorted octahedral arrangement of $\mathrm{Cl}$ atoms around each $\mathrm{Sb}$ atom, which has $3 \mathrm{Cl}$ neighbours from other molecules at $3.4 \AA$ in addition to the 3 bonded $\mathrm{Cl}$ atoms at $2.35 \AA$. The structure of the liquid $\mathrm{SbCl}_{3}$ is described in terms of chains of $\mathrm{SbCl}_{3}$ molecules stacked in the "umbrella" configurations with the interaction between pairs of molecules within a given chain being much stronger than the van der Waals forces. However, the interactions between the chains are much weaker.

Adya et al. ${ }^{89}$ performed ND measurements on $\left(\mathrm{DyCl}_{3}\right)_{0.25}(\mathrm{NaCl})_{0.75}$ mixed melt at the composition around which the enthalpy of mixing goes through a minimum, indicating compound formation of stoichiometry $\mathrm{DyNa}_{3} \mathrm{Cl}_{6}$. The ND studies were combined with RIM and PIM simulations. ${ }^{90}$ The results show that the addition of $\mathrm{NaCl}$ breaks the octahedral network in pure $\mathrm{DyCl}_{3}$, and that at $\sim 75 \% \mathrm{NaCl}$ the concentration of $\mathrm{Cl}^{-}$ions is sufficient to isolate discrete $\mathrm{DyCl}_{6}{ }^{3-}$ octahedral molecular ion units. Polarisation effects were found to be responsible for promoting such breakup of the network. The first coordination shell, sharply defined by the $g_{\text {Dy-Cl }}(r)$, integrates to give six nearest-neighbours. However, in contrast to the case for the pure $\mathrm{DyCl}_{3}$ melt (see Fig. 3), the first minimum in $g_{\mathrm{Dy}-\mathrm{Cl}}(r)$ in the mixed melt now goes to zero, indicating a very stable coordination complex from which $\mathrm{Cl}^{-}$ions exchange very slowly with the bulk.

Adya et al. ${ }^{107,108}$ performed $\mathrm{ND}$ measurements on $\mathrm{UCl}_{3}+\mathrm{MCl}(\mathrm{M}=\mathrm{Li}, \mathrm{Na}, \mathrm{K}, \mathrm{Cs})$ mixed melts at different compositions. A FSDP appears in the structure factors of all these systems. The pre-peak decreases and shifts to smaller $Q$-value with increase in the concentration of ${ }^{0} \mathrm{LiCl}$, suggesting a gradual loosening and final break-up of the polyhedral network in pure $\mathrm{UCl}_{3}$. The effect of adding increasing amounts of ${ }^{0} \mathrm{LiCl}$ is to make available additional halide ions to the polyvalent metal ion. The pre-peak increases and moves to smaller $Q$-values with increase in size of the alkali metal ion in the order $\mathrm{Li}<\mathrm{Na}<\mathrm{K}<\mathrm{Cs}$, suggesting that in addition to the Coulombic ordering, packing effects also play a role in determining their structure. Further analysis of the $\mathrm{ND}$ data, and MD simulations using RIM/PIM on these $\left(\mathrm{UCl}_{3}\right)_{x}(\mathrm{MCl})_{(1-x)}$ melts are in progress.

The results from NDIS on $\left(\mathrm{AlCl}_{3}\right)_{0.5}(\mathrm{LiCl})_{0.5}$ melt, from total $\mathrm{ND}$ on $\mathrm{AlCl}_{3}+\mathrm{LiCl}$ and $\mathrm{AlCl}_{3}+\mathrm{NaCl}$ covering the entire composition range, and on mixed melts, $\left(\mathrm{AlX}_{3}\right)_{0.67}(\mathrm{KX})_{0.33}$ and $\left(\mathrm{AlX}_{3}\right)_{0.75}(\mathrm{KX})_{0.25}$, both for $\mathrm{X}=\mathrm{Cl}$ and $\mathrm{Br}$, were discussed in our earlier review. ${ }^{1}$

Iwadate et al. ${ }^{125}$ investigated the structures of $\left(\mathrm{ErCl}_{3}\right)_{0.25}(\mathrm{NaCl})_{0.75}$ and $\left(\mathrm{ErCl}_{3}\right)_{0.25^{-}}$ $(\mathrm{KCl})_{0.75}$ melts by XRD, and analysed the data by a least squares model fitting of the experimental total $F(Q)$. The nearest-neighbour distances and $\mathrm{CNs}$ for the $\mathrm{Er}^{3+}-\mathrm{Cl}^{-}$, $\mathrm{Cl}^{-}-\mathrm{Cl}^{-}, \mathrm{Er}^{3+}-\mathrm{Er}^{3+}$ correlations are $2.61 \AA$ (5.67), $3.90 \AA$ (9.49), $5.15 \AA$ (4.25), and $2.65 \AA$ (5.73), $3.89 \AA$ (8.93), $5.17 \AA$ (4.10), respectively for the $\mathrm{ErNa}_{3} \mathrm{Cl}_{6}$ and $\mathrm{ErK}_{3} \mathrm{Cl}_{6}$ melts. Since the $\mathrm{Er}^{3+}-\mathrm{Er}^{3+}$ distance of 5.15 and $5.17 \AA$ in the two mixed melts is much longer than $4.05 \AA$ in pure $\mathrm{ErCl}_{3}$ melt, it is proposed that the edge- and corner-shared clustering $\left(\mathrm{Er}_{2} \mathrm{Cl}_{10}{ }^{4-}\right.$ and $\mathrm{Er}_{2} \mathrm{Cl}_{11}{ }^{5-}$ ) of distorted octahedra observed in pure $\mathrm{ErCl}_{3}$ (see earlier discussion) is broken into discrete octahedra of the type $\mathrm{ErCl}_{6}{ }^{3-}$ by the addition of alkali metal chlorides. The structural results from XRD on other mixed halide melts such as $\left(\mathrm{AlCl}_{3}\right)_{0.5}(\mathrm{LiCl})_{0.5},\left(\mathrm{AlCl}_{3}\right)_{x}(\mathrm{NaCl})_{(1-x)}(x=0.5,0.55,0.6,0.7)$, and $\left(\mathrm{AlCl}_{3}\right)_{x}(\mathrm{BPC})_{(1-x)}(x=0.5,0.67)$, where $\mathrm{BPC}=\mathrm{n}$-butyl pyridinium chloride, have been compiled and discussed by Ohno et al. ${ }^{82}$ 
3.2.4 Molten metal nitrates and their mixtures. Molten nitrates, in comparison with molten halides, have relatively low melting points, and are used in thermal energy storage as low temperature baths in industry. They show superior glass forming tendencies, and exhibit rich phase behaviour on mixing with other nitrates. The structural results on several single and mixed molten nitrate systems, such as $\mathrm{LiNO}_{3}, \mathrm{NH}_{4} \mathrm{NO}_{3}$, and $\mathrm{NH}_{4} \mathrm{NO}_{3}-\mathrm{Ca}\left(\mathrm{NO}_{3}\right)_{2}$ by the NDIS technique, and $\mathrm{MNO}_{3}(\mathrm{M}=\mathrm{Li}, \mathrm{Na}, \mathrm{K}, \mathrm{Rb}, \mathrm{Cs}$, $\mathrm{Ag}$, and $\mathrm{Tl}$ ) and $\mathrm{LiNO}_{3}-\mathrm{RbNO}_{3}$ by the $\mathrm{ND}$ technique, have already been discussed in our previous review. ${ }^{1}$ Some of the XRD results on molten metal nitrates of $\mathrm{Li}, \mathrm{Na}, \mathrm{K}$, $\mathrm{Rb}, \mathrm{Cs}$ and $\mathrm{Ag}$ have been compiled by Ohno et al. $^{82}$ Adya et al. ${ }^{126}$ reported the structure of molten $\mathrm{NaNO}_{3}, \mathrm{NaNO}_{2}$, and $\mathrm{NaNO}_{3}-\mathrm{NaNO}_{2}$ eutectic by XRD and MD. The structures are reported of molten systems of the type $(\mathrm{Ag}, \mathrm{K}, \mathrm{Na})-\left(\mathrm{I}, \mathrm{NO}_{3}\right)$, including mixed cation systems such as $\mathrm{AgNO}_{3}-\mathrm{KNO}_{3}$ and mixed anion systems such as $\mathrm{AgI}-\mathrm{AgNO}_{3}$, at different compositions. ${ }^{127}$

3.2.5 Miscellaneous single and mixed melts. The structural results from XRD on a variety of other single and mixed melts such as, metal sulfates: $\mathrm{Li}_{2} \mathrm{SO}_{4}, \mathrm{Na}_{2} \mathrm{SO}_{4}$, $\mathrm{K}_{2} \mathrm{SO}_{4}, \mathrm{Cs}_{2} \mathrm{SO}_{4}, \mathrm{Ag}_{2} \mathrm{SO}_{4},\left(\mathrm{Li}_{2} \mathrm{SO}_{4}\right)_{x}\left(\mathrm{Na}_{2} \mathrm{SO}_{4}\right)_{(1-x)}(x=0.75,0.5,0.25)$, hydrogen sulfates: $\mathrm{NaHSO}_{4}, \mathrm{KHSO}_{4}$, and $\mathrm{NH}_{4} \mathrm{HSO}_{4}$, carbonates: $\mathrm{Li}_{2} \mathrm{CO}_{3}, \mathrm{Na}_{2} \mathrm{CO}_{3}, \mathrm{~K}_{2} \mathrm{CO}_{3},\left(\mathrm{Li}_{2} \mathrm{CO}_{3}\right)_{0.5^{-}}$ $\left(\mathrm{Na}_{2} \mathrm{CO}_{3}\right)_{0.5},\left(\mathrm{Li}_{2} \mathrm{CO}_{3}\right)_{0.5}\left(\mathrm{~K}_{2} \mathrm{CO}_{3}\right)_{0.5},\left(\mathrm{Na}_{2} \mathrm{CO}_{3}\right)_{0.5}\left(\mathrm{~K}_{2} \mathrm{CO}_{3}\right)_{0.5},\left(\mathrm{Li}_{2} \mathrm{CO}_{3}\right)_{0.43}\left(\mathrm{Na}_{2} \mathrm{CO}_{3}\right)_{0.32^{-}}$ $\left(\mathrm{K}_{2} \mathrm{CO}_{3}\right)_{0.25}$, tungstates: $\mathrm{Na}_{2} \mathrm{WO}_{4}, \mathrm{Na}_{2} \mathrm{~W}_{2} \mathrm{O}_{7}$, thiocyanates: $\mathrm{NaSCN}, \mathrm{KSCN}, \mathrm{CaSCN}$, silicates: $\mathrm{MgSiO}_{3}, \mathrm{CaSiO}_{3}$, and oxides: $\mathrm{V}_{2} \mathrm{O}_{5}, \mathrm{~B}_{2} \mathrm{O}_{3},(\mathrm{PbO})_{0.8}\left(\mathrm{~B}_{2} \mathrm{O}_{3}\right)_{0.2}$ (in melt and glass $),(\mathrm{PbO})_{x}\left(\mathrm{SiO}_{2}\right)_{(1-x)}(x=0.67,0.5,0.33$, glass $),(\mathrm{PbO})_{x}\left(\mathrm{SiO}_{2}\right)_{(1-x)}(x=0.6512$, $0.5036,0.3378$, in both melt and glass), $(\mathrm{PbO})_{0.5}\left(\mathrm{GeO}_{2}\right)_{0.5}$ (in both melt and glass), $\mathrm{SiO}_{2},\left(\mathrm{M}_{2} \mathrm{O}\right)_{x}\left(\mathrm{SiO}_{2}\right)_{(1-x)}(\mathrm{M}=\mathrm{Li}, \mathrm{Na}, \mathrm{K}$, and $x=0.0-0.6), \mathrm{GeO}_{2}$ and $\mathrm{Al}_{2} \mathrm{O}_{3}$ have been compiled. ${ }^{82}$

3.2.6 Molten metal oxides by levitation techniques. There has recently been much interest in exploring the use of levitation techniques to examine the structure by ND and XRD of molten salts such as oxides, which have very high melting temperatures $(>2000 \mathrm{~K})$, and are very reactive. Such containerless scattering avoids the possibility of chemical contamination by the container material used in furnace experiments. The technique, however, presents a major challenge for a diffraction experiment because the amount of material $(\sim 20-50 \mathrm{mg})$ that can be supported by a levitator is only $1 / 20$ th $-1 / 100$ th of the material conventionally used in a diffraction experiment on a liquid.

Ansell et al. ${ }^{128,129}$ demonstrated the use of aerodynamic levitation in association with $\mathrm{CO}_{2}$ laser heating to look at the structure of molten $\mathrm{Al}_{2} \mathrm{O}_{3}$ (alumina) and $\mathrm{Y}_{2} \mathrm{O}_{3}$ (yttria) by XRD using synchrotron radiation. They found that predominantly fourfold coordinated $\mathrm{Al}$ atoms exist as $\mathrm{AlO}_{4}{ }^{5-}$ tetrahedral units with an average $\mathrm{Al}-\mathrm{O} \mathrm{CN}$ of 4.4. In contrast to drastic changes in $\mathrm{Al}_{2} \mathrm{O}_{3}$, no major structural rearrangements and changes in the cation coordination occur on melting $\mathrm{Y}_{2} \mathrm{O}_{3}$. This difference in behaviour of the change in the coordination upon melting of $\mathrm{Al}_{2} \mathrm{O}_{3}$ and $\mathrm{Y}_{2} \mathrm{O}_{3}$ clearly mirrors the difference observed previously between $\mathrm{AlCl}_{3}$ (or $\mathrm{FeCl}_{3}$ ) and $\mathrm{YCl}_{3}$ (or $\mathrm{DyCl}_{3}$ ) (see earlier discussion on $\mathrm{MX}_{3}$ melts). Landron et al. ${ }^{130}$ performed ND on molten $\mathrm{Al}_{2} \mathrm{O}_{3}$ at ISIS using the levitation technique, and interpreted the data using a simulation in which model ensembles of $\mathrm{Al}$ and $\mathrm{O}$ ions were set up to best reproduce the experimental $F(Q)$. The calculated site-site RDFs and the average $\mathrm{CN}$ (4.5) of $\mathrm{O}$ 
about $\mathrm{Al}$ in this simulation are found to be consistent with the earlier X-ray data. The results reveal the presence of significant numbers of 5- and 6-fold coordinated $\mathrm{Al}$ in the melt, and the authors stress that molten alumina certainly cannot be described simply as a predominantly 'tetrahedral liquid'. The true picture of $\mathrm{Al}_{2} \mathrm{O}_{3}$ should be one where the octahedral coordination in the crystalline form becomes highly defective in the liquid phase.

\subsubsection{Ionic liquids or "room temperature molten salts". Room temperature molten} salts, also termed "ionic liquids", are currently attracting great interest as "green solvents" for catalysis and low temperature synthetic chemical purposes, and as electrolytes in energy technology field for electrochemical energy storage (primary batteries) and generation (e.g., fuel cells and photovoltaic devices). They consist solely of ions, and retain many of the benefits of high temperature electrolytes discussed above, but without the thermal handling problems. Many ionic liquids are composed of 1,3-dialkylimidazolium, e.g., 1-ethyl-3-methylimidazolium $\left(\mathrm{EMI}^{+}\right)$, or 1,2,3trialkylimidazolium cations and chloroaluminate $\left(\mathrm{AlCl}_{4}^{-}\right)$or perfluorinated anions, e.g., $\left[\mathrm{BF}_{4}\right]^{-},\left[\mathrm{PF}_{6}\right]^{-},\left[\mathrm{CF}_{3} \mathrm{SO}_{3}\right]^{-},\left[\left(\mathrm{CF}_{3} \mathrm{SO}_{3}\right)_{2} \mathrm{~N}\right]^{-},\left[\left(\mathrm{CF}_{3} \mathrm{SO}_{2}\right)_{3} \mathrm{C}\right]^{-}$, and $\left[\mathrm{CF}_{3} \mathrm{CO}_{2}\right]^{-}$. By changing the alkyl chain on the cation or the anion, a wide variation in their properties can be obtained. Although numerous studies concerning their preparation, physical and electrochemical properties, and their use as a reaction medium have been reported, little is known about their liquid structure.

Takahashi et al. ${ }^{131}$ employed ND in conjunction with ab initio calculations to investigate the structure at room temperature of $\mathrm{AlCl}_{3}-1$-ethyl-3-methyl-imidazolium chloride melts at four concentrations (40, 50, 60 and $67 \mathrm{~mol}_{0} \% \mathrm{AlCl}_{3}$ ). Ab initio calculations using 6-31G $\mathrm{G}^{*}$ basis set were performed on the isolated ions $\left(\mathrm{AlCl}_{4}{ }^{-}, \mathrm{Al}_{2} \mathrm{Cl}_{7}{ }^{-}\right.$, $\left.\mathrm{EMI}^{+}\right)$and some of their complexes $\left(\mathrm{AlCl}_{4}{ }^{-}-\mathrm{EMI}^{+}, \mathrm{Al}_{2} \mathrm{Cl}_{7}{ }^{-}-\mathrm{EMI}^{+}\right)$, which are known to form in these melts. The ab initio results showed no significant change in the geometry in going from isolated ions $\mathrm{AlCl}_{4}^{-}$and $\mathrm{EMI}^{+}$to $\mathrm{AlCl}_{4}^{-}{ }^{---} \mathrm{EMI}^{+}$but did show a change in the $\mathrm{Cl}-\mathrm{Cl}$ distance on going from $\mathrm{Al}_{2} \mathrm{Cl}_{7}{ }^{-}$and $\mathrm{EMI}^{+}$to $\mathrm{Al}_{2} \mathrm{Cl}_{7}^{-}---\mathrm{EMI}^{+}$, in reasonable agreement with the ND results.

Hardacre et al. ${ }^{132}$ recently attempted a ND structural study on a model ionic liquid dimethylimidazolium chloride (m.p. $128{ }^{\circ} \mathrm{C}$ ) by using selective H/D substitution on the imidazolium ion. The RDFs of chloride around imidazolium and imidazolium about imidazolium were obtained from computer simulation of the liquid where the forces between atoms and hence their positions were refined to give the best fit with the ND data. The results show a significant order within the liquid, and the close relationship observed between the crystal and liquid structures implies that the molecular packing in the first two or three coordination shells is similar in both the phases.

The above discussion on a variety of molten salts shows that our knowledge of their structural aspects has greatly improved due to significant advances made in the experimental ND and XRD techniques. These techniques, in conjunction with computer simulations and liquid-state structural theory, will continue to play a significant role in deepening our understanding of the molten salt systems. The disagreement between the CNs of molten $\mathrm{LaCl}_{3}, \mathrm{LaBr}_{3}$ and $\mathrm{UCl}_{3}$ obtained by XRD with those obtained by recent ND + MD has yet to be resolved. It is anticipated that the neutron and X-ray techniques will continue to be further developed and applied to a wide 
variety of more complex molten systems, such as ionic liquids, molten oxides, fluorides, cryolites and molten salt mixtures of importance in nuclear industry, electrochemical devices and energy storage systems.

\subsection{Water}

Neutron diffraction methods continue to be the best means to determine the structure of water in a variety of states and conditions. This is emphasised by Steiner ${ }^{133}$ whose wide-ranging study of the changes in the $\mathrm{H}-\mathrm{O}-\mathrm{H}$ angle in crystalline hydrates due to hydrogen bonding concludes that 'the neutron diffraction technique is indispensable when hydrogen bond phenomena are to be investigated in depth'. His paper is particularly targeted at protein crystallographers seeking to identify the conformation of waters of hydration around protein molecules.

NDIS experiments on water/heavy water mixtures have enabled the determination of all three radial distribution functions, $g_{\mathrm{HH}}(r), g_{\mathrm{OH}}(r)$ and $g_{\mathrm{OO}}(r),{ }^{134}$ in liquid, fluid and amorphous phases of $\mathrm{H}_{2} \mathrm{O}$. The use of a self-consistent empirical potential structural refinement (EPSR) procedure has enabled Soper, Ricci and colleagues to define the accuracy of the three RDFs from neutron diffraction ${ }^{135}$ Accordingly the structural information obtained experimentally is now better able to challenge results from molecular dynamics computer simulation of the model potential for water. ${ }^{136,137}$

Amongst the many new insights from diffraction, has been the observation that an increase in temperature significantly alters the hydrogen bond network. ${ }^{138,139}$ In particular, the tetrahedral orientation of the hydrogen bond neighbours is already lost at $423 \mathrm{~K}\left(150^{\circ} \mathrm{C}\right)$, although the hydrogen bonds themselves remain preferentially linear above the critical point $\left(T_{\mathrm{c}}=647^{\circ} \mathrm{C}\right)$.

The work being carried out currently meets the two challenges set in our previous review ${ }^{1}$ viz. to gather more accurate information in order to help comprehend the large amount of thermodynamic and spectroscopic information, and to use structural information to examine the accuracy of model pair potentials and suggest how they must be modified to match the experimental results.

A state-of-the-art X-ray diffraction experiment on water at ambient conditions on a synchrotron source has been reported recently. ${ }^{140}$ The results show that the first peak in $g_{\text {oo }}(r)$ is sharper than the earlier results of Narten, ${ }^{141}$ and shifted to slightly lower value. In the analysis the authors have exploited the high monochromaticity of the source, the use of a CCD detector, and included new corrections for Compton scattering, and polarisation. However, in the analysis of X-ray data for aqueous solutions, it is always questionable how to represent the form factor for the high asymmetric water molecule. Nevertheless, the X-ray method is probably the best available to obtain $g_{\text {oo }}(r)$, as the NDIS method is unable to give an accurate measure of this function.

At the other extreme of temperature, work on supercooled and amorphous heavy water often under pressure, gives insight into the origins of its anomalous behaviour at low temperatures. ${ }^{142}$ Based on results of studies of Teixeira and colleagues on undercooled water, Stanley and co-workers ${ }^{143}$ have proposed an interesting phase diagram for $\mathrm{H}_{2} \mathrm{O}$ in the regime from $-40{ }^{\circ} \mathrm{C}<T<0{ }^{\circ} \mathrm{C}$, which importantly contains a lower critical point at around $200 \mathrm{~K}$ and a pressure of 1000 bar. This speculation is based on the existence of a two state model for amorphous $\mathrm{H}_{2} \mathrm{O}$, a so-called low density 
amorphous and high density amorphous phases with a sharp transition between the two. Soper and Ricci challenge the interpretation of the NDIS results from which these assertions are made. ${ }^{144}$ Instead, they suggest from their own experiments at $268 \mathrm{~K}$, a continuous transformation with increasing pressure from a low density form of water with an open hydrogen bonded tetrahedral structure, to a high density form with non tetrahedral $\mathrm{O}-\mathrm{O}-\mathrm{O}$ angles and a collapsed second coordination. And it is this second coordination shell where the main structural changes occur when the system is subjected to an increase in hydrostatic pressure. Moreover, the idea that water itself can be represented in terms of a mixture of the two phases is clearly an oversimplification of the actual situation.

Although, diffraction work on water in all its different phases is likely to continue in the foreseeable future, it is doubtful whether much new insight will be gained in attempts to obtain a truly comprehensive understanding of the properties of water based purely on its structural properties. It is more likely that structural studies of water in confined geometries will receive even more attention than is currently the case. Such studies may well have important implications for biological systems in which water molecules are often confined to certain regions of a hydrated biomolecular compound. A paper by Dore ${ }^{145}$ presents a useful summary of the contribution that NDIS studies are making in this field, and stresses the care needed in the preparation of isotopically labelled samples when working below the freezing point of $\mathrm{D}_{2} \mathrm{O}\left(4{ }^{\circ} \mathrm{C}\right)$.

Finally, we mention results of critical scattering experiments (opalescence) carried out on heavy water near its critical point. ${ }^{146,147}$ Results of two independent studies confirm that water is in the Ising universality class and has a characteristic correlation length of $1.32 \AA$. The work was undertaken using the small angle neutron scattering (SANS) technique and importantly will enable more ambitious studies to be undertaken over a wide range of $p$ and $T$ on complex liquids which contain large molecules, thus enabling the determination of large-scale structural correlations.

\subsection{Aqueous solutions}

3.4.1 Electrolytes in water. The structure of an aqueous electrolyte solution in the form of a salt $\left(\mathrm{MX}_{n}\right)$ in water $\left(\mathrm{H}_{2} \mathrm{O}\right)$, can be divided into three parts: the water solvent with its 3 RDFs $\left(g_{\mathrm{HH}}(r), g_{\mathrm{HO}}(r), g_{\mathrm{OO}}(r)\right)$; the solute with its 3 RDFs $\left(g_{\mathrm{MM}}(r), g_{\mathrm{XX}}(r)\right.$, $\left.g_{\mathrm{MX}}(r)\right)$, and the ion hydration with its $4 \mathrm{RDFs}\left(g_{\mathrm{MH}}(r), g_{\mathrm{MO}}(r), g_{\mathrm{XO}}(r), g_{\mathrm{XH}}(r)\right)$. The first and second order difference methods of NDIS and AXD can in principle be used to determine some of these functions individually or in combination with others. ${ }^{\mathbf{1 4 8}}$ From the viewpoint of this review it is sensible to discuss results within each of these three categories.

Water structure in electrolyte solutions. The determination of water-solvent structure in aqueous solution is similar to that for pure water, i.e. NDIS difference methods based on H/D substitution are the preferred means to determine all aspects of the pairwise water structure. However, the accuracy of $g_{\text {oo }}(r)$ is appreciably less than the other two functions $g_{\mathrm{HH}}(r)$ and $g_{\mathrm{HO}}(r)$. As shown initially by Tromp et al. ${ }^{149} \mathrm{H} / \mathrm{D}$ isotopic substitution of the water molecules in concentrated aqueous solutions of lithium chloride can be used to calculate $g_{\mathrm{HH}}(r)$ and a good approximation to $g_{\mathrm{HO}}(r)$. This type of work was extended by Leberman and Soper, ${ }^{150}$ to aqueous solutions of a 
Table 3 AXD structural results for several ions

\begin{tabular}{lllll}
\hline Ion & $r_{\text {ionic }} / \AA^{a}$ & $r_{\mathrm{IO}} / \AA^{b}$ & $\mathrm{CN}\left(\mathrm{H}_{2} \mathrm{O}\right)^{c}$ & 2nd Shell $^{d}$ \\
\hline $\mathrm{Rb}^{+}$ & 1.48 & 3.05 & 6.9 & - \\
$\mathrm{Sr}^{2+}$ & 1.13 & 2.67 & 9.09 & 4.96 \\
$\mathrm{Y}^{3+}$ & 0.93 & 2.95 & 8.0 & 4.77 \\
$\mathrm{Br}^{-}$ & 1.96 & 3.40 & 7.0 & -
\end{tabular}

${ }^{a}$ Pauling radii. ${ }^{b}$ Nearest-neighbour distance. ${ }^{c}$ Hydration number. ${ }^{d}$ Mean ion-oxygen distance $\left(r_{\mathrm{IO}} / \AA ̊ \AA\right)$.

number of different salts in water and most recently has been used to investigate an aqueous solution of 10 molar sodium hydroxide in its liquid and glassy states. ${ }^{151}$ The main conclusion drawn from these studies is that the ions effectively cause a change in water structure that is equivalent to an increase of pressure. It is also noteworthy that the $g(r)$ s only change significantly when molal quantities of salt are present.

In contrast to the NDIS methods, total X-ray diffraction can be used to give limited information on the $\mathrm{O}-\mathrm{O}$ correlations in solutions. However, the determination of such information relies on the use of models to fit the experimental data. ${ }^{152}$

Aqua ion structure. Since our previous review in this series, ${ }^{1}$ several new initiatives have been undertaken in this area. Most notable has been the introduction and development of AXD as a fully quantitative structural probe, which complements the difference methods of NDIS (Table 3). ${ }^{6}$ Besides this, NDIS experiments have been carried out on a few more select ionic species in solution.

We recall that the first order difference from an NDIS experiment gives the total ion specific radial distribution function of the form given in eqn. (4), which for concentrations below 1 molal can be approximated to

$$
G_{\mathrm{I}}(r) \cong A g_{\mathrm{IO}}(r)+B g_{\mathrm{ID}}(r)+E
$$

Analysis of this function gives the hydration numbers $\bar{n}_{\mathrm{I}}$ for the various hydration shells. If the first hydration shell is well resolved with clearly identified I $\cdots O$ and I $\cdots$ H correlations one can obtain information on the aqua ion conformation. ${ }^{153}$ First shell coordination numbers can be calculated in three different ways. For cations, where the I $\cdots$ O peak is well-resolved, integration of $G_{\mathrm{I}}(r)$ over the range defined by the correlation in $g_{\text {IO }}(r)$ according to eqn. (6) gives the appropriate hydration number. For anions, where the nearest neighbour I $\cdots H(D)$ peak is well-resolved, integration of $G_{\mathrm{I}}(r)$ over the range of the correlation $g_{\mathrm{ID}}(r)$ according to eqn. (6) gives the anion hydration number. Where individual peaks are not well resolved, as in the case of $\mathrm{K}^{+}$, integration of $G_{\mathrm{I}}(r)$ over the entire range and the condition $n_{\mathrm{I}}^{\mathrm{D}} \equiv 2 n_{\mathrm{I}}^{\mathrm{O}}$ will give the total number of water molecules in the hydration shell.

A similar equation to that for ' ${ }_{\mathrm{I}}(r)$ can be obtained from results obtained in AXD experiments. However, in this case $G_{\mathrm{I}}(r)$ is replaced by $\bar{G}_{\mathrm{I}}(r)$ which is the Fourier transformation of a sum of the corresponding partial structure factors $S_{\alpha \beta}(q)$ convoluted with their form factors $f_{0, a}(Q)$ and $f_{0, \beta}(Q){ }^{6}$ Interestingly the dominant terms in this sum are usually those associated with the $g_{\mathrm{IO}}(r)$ and $g_{\mathrm{IJ}}(r)$. 
The NDIS and AXD results can be conveniently discussed within the particular Groups of the Periodic Table. For completeness we also cite some EXAFS results within each subsection.

Alkali metal ions $\left(\mathrm{Li}^{+}, \mathrm{Na}^{+}\right.$(isomorphic with $\left.\mathrm{Ag}^{+}\right), \mathrm{K}^{+}, \mathrm{Rb}^{+}$). The alkali metal series of cations are probably the most extensively studied of all cation series. The hydration of $\mathrm{Li}^{+}$is now well established; at concentrations below 4 molal the hydration number $\bar{n}_{\mathrm{Li}}^{\mathrm{D} 2 \mathrm{O}}$ is $\sim 6 .{ }^{154}$ When compared with ab initio calculations of $\left[\mathrm{Li} . \cdots\left(\mathrm{H}_{2} \mathrm{O}\right)_{n}\right]$ configurations, the NDIS results show good agreement for the $r_{\mathrm{LiO}}$ near-neighbour distance however, the $r_{\mathrm{LiH}}$ distance is calculated to be significantly larger, at $2.6 \AA$, than found experimentally. The discrepancy is probably due to the dominance of the ion-dipole interaction and the neglect of effects due to dipoledipole interactions of the water molecules.

The sodium ion $\left(\mathrm{Na}^{+}\right)$hydration has also been investigated by the approximate method of XDIS and exploitation of the isomorphism between $\mathrm{Na}^{+}$and $\mathrm{Ag}^{+} .{ }^{10}$ Recently AXD has been used to obtain information on $\mathrm{Rb}^{+}$hydration in an aqueous solution of 4 molal rubidium chloride. ${ }^{6}$ These studies taken together show that as the ion size increases and the charge density is reduced down the series, the hydration shell becomes less well resolved. Interestingly however, it appears that the coordination number does not change significantly from a value of between about 5 and 8 . The studies also show that the extent of the perturbations to the water structure is limited primarily to the range of the first hydration shell. Only $\mathrm{Li}^{+}$has a significant second shell and even here only at very high concentration where counterion effects may also contribute.

EXAFS measurements have also been made on a 0.5 molar $\mathrm{RbBr}$ solution up to its critical point; ${ }^{155}$ the resullts show both a contraction in the bond length $(2.93(3) \AA$ to 2.81(3) $\AA$ and a change of coordination number from 5.6(7) to 3.9(7) with pressure corresponding to a linear scaling with density. The conclusion drawn is that there are no $\mathrm{Rb}-\mathrm{Br}$ contacts. This is attributed to the increase of $\mathrm{Br}^{-}$localisation, although they saw no evidence for $\mathrm{RbBr}$ pairs. A rubidium nitrate solution has also been measured with EXAFS and the results show a decreasing $\mathrm{Rb}-\mathrm{O}$ distance of $3.20 \AA$ to $2.83 \AA$ with increasing salt concentration.

Halide ions $\left(\mathrm{Cl}^{-}, \mathrm{Br}^{-}\right)$. Because of its favourable isotopes ${ }^{35} \mathrm{Cl}$ and ${ }^{37} \mathrm{Cl}$, the chloride ion $\left(\mathrm{Cl}^{-}\right)$has been extensively studied by NDIS. Indeed it can be considered as an ideal probe of structural perturbations which are induced when aqueous electrolyte solutions contain large polyions. ${ }^{156,157}$ Results for $g_{\mathrm{CIO}}(r)$ and $g_{\mathrm{CIH}}(r)$ show in aqueous electrolyte solutions that $\mathrm{Cl}^{-}$has a well-defined first hydration shell and no longer range structure. Moreover, its structure is remarkably independent of counterion, concentrations to $\sim 1$ molal and moderate changes of temperature and pressure. At more elevated concentrations, and in the presence of $\mathrm{Zn}^{2+}$ or $\mathrm{Cu}^{2+}$ counterions, there is an appreciable reduction of coordination number to $\sim 4$. Significantly, however, the general conformation of the $\mathrm{Cl}^{-}-.-\mathrm{H}_{2} \mathrm{O}$ water molecules does not change with concentration. The hydration of $\mathrm{Cl}^{-}$is also sensitive to large changes in temperature and pressure. ${ }^{158}$ Again the effect seems more pronounced for the case of relatively weaker counterions. Evidence for this observation comes from studies of $\mathrm{Cl}^{-}$hydration in $\mathrm{LiCl}$ solutions and $\mathrm{NiCl}_{2}$ solutions by NDIS, where results show that the $\mathrm{Cl}^{-}$hydration shell is more strongly affected in the lithium chloride solutions. ${ }^{159}$ 


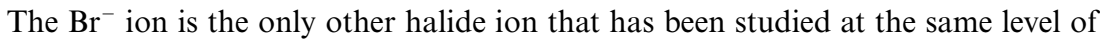
detail as $\mathrm{Cl}^{-}$. The AXD method was used to investigate $\mathrm{Br}^{-}$hydration structure in an aqueous solution of 6 molal rubidium bromide. ${ }^{6}$ The results show a strong near neighbour $\mathrm{Br}^{-} \cdots \mathrm{H}_{2} \mathrm{O}$ correlation centred at $\sim 3.4 \AA$ which can accommodate around 7 water molecules, and are in good agreement with recent $a b$ initio calculations of $\mathrm{Br}^{-}$solvation. ${ }^{160}$ As for the case of $\mathrm{Cl}^{-}$there is no evidence to suggest the existence of a second hydration shell. It is also worth noting that the positions of the ionoxygen correlations approximately scale with ion size. AXD experiments are being planned to investigate $\mathrm{I}^{-}$hydration structure to see whether the trend of increased ion-oxygen distance and slightly larger coordination number continues. The small number of EXAFS studies of $\mathrm{Br}^{-}$hydration generally confirm the information derived from AXD. A range of AXD and EXAFS measurements were made by Wallen et al. ${ }^{161}$ on bromide salt solutions as a function of concentration, pressure and temperature. The results show a pronounced dehydration of the $\mathrm{Br}^{-}$ion as the temperature changes from ambient to $425{ }^{\circ} \mathrm{C}$. Additionally, a slight increase in the coordination distance is seen from 3.35(07) $\AA$ to 3.41(02) $\AA$ near the critical point. This is less pronounced at higher concentrations. These results were recently confirmed by MD simulation analysis on the re-measured 0.2 molar data up to the supercritical point. $^{162}$

Alkaline earth metal cations $\left(\mathrm{Mg}^{2+}, \mathrm{Ca}^{2+}\right.$ and $\left.\mathrm{Sr}^{2+}\right)$. Results for the hydration of $\mathrm{Mg}^{2+}$ and $\mathrm{Ca}^{2+}$ are now well established. The former is similar to $\mathrm{Ni}^{2+}$ and has a sixfold hydration shell with well-defined correlations between the ion and the oxygen and hydrogen atoms of the water molecules. A recent NDIS study of $\mathrm{Ca}^{2+}$ hydration by Badyal and Barnes ${ }^{163}$ confirms the well-defined structure of $\mathrm{Ca}^{2+}$ found earlier by Hewish et al.,${ }^{164}$ and is in good agreement with a recent MD simulation. ${ }^{165}$ An AXD study of a strontium chloride solution shows that the $\mathrm{Sr}^{2+}$ cation also retains a well defined first hydration shell with around 9 water molecules, a result in general agreement with earlier NDIS study of a concentrated strontium perchlorate solution. ${ }^{166}$ The AXD study also showed some evidence of solvent separated $\mathrm{Sr}^{2+}-\mathrm{Cl}^{-}$ pairing. ${ }^{167}$

EXAFS studies of $\mathrm{Sr}^{2+}$ show a decrease in the coordination distance (2.63(3) $\AA$ to 2.59(3) $\AA$ ) and a very large drop in coordination number is observed, (7.7(5) to 3.5(4)) as the system is heated to supercritical temperatures. This observation corresponds to the drop in macroscopic density, and is consistent with a cluster expansion observed in MD calculations. ${ }^{168}$

Other ions (transition metal ions, lanthanides, etc.). Typically transition metal ions such as $\mathrm{Cr}^{3+}, \mathrm{Fe}^{2+}, \mathrm{Fe}^{3+}, \mathrm{Ni}^{2+}$ and $\mathrm{Cu}^{2+}$ all have their own characteristic first hydration shells usually containing 6 water molecules. The most extensive structural work has been carried out on $\mathrm{Ni}^{2+}$, the aqua ion structure of which is accurately determined from NDIS. Because of this, nickel is often used as a reference system to test the accuracy of other methods, and then to use these methods to determine structural properties in ranges of concentration, temperature and pressure which are harder to obtain with NDIS methods. For example, EXAFS measurements on a nickel chloride solution at ambient conditions are shown to confirm the six-fold coordination of $\mathrm{Ni}^{2+}$ with a $\mathrm{Ni}^{2+}$-.- O near-neighbour distance of $2.06 \AA$. More interestingly they also show that the nickel hydration sphere is strongly perturbed by counter ions in supercritical conditions with a reduction in hydration number to 2.3(3), and an extension of 
the $\mathrm{Ni}^{2+}$---O near neighbour distance to 2.086(6) $\AA$. Moreover, the disruption of the hydration sphere correlates with the density, ${ }^{161}$ a result consistent with NDIS studies. ${ }^{158}$

Another transition metal ion, which is favourable to the NDIS method is $\mathrm{Cr}^{3+} \cdot{ }^{169} \mathrm{~A}$ careful EXAFS study has also been carried out on a set of different $\left[\mathrm{CrCl}_{n}\right.$ $\left.\left(\mathrm{H}_{2} \mathrm{O}\right)_{6-n}\right]^{(3-n)+}$ groups in dilute solution. The data show some secondary $\mathrm{Cl}^{-}$coordination at $4.3 \AA{ }^{170}$ To reduce the ambiguity of the fitted data, ab initio quantum chemistry calculations have also been made on $\mathrm{Cr}^{3+}$ solutions to determine the fitting parameter $E_{0}$ and the Debye-Waller terms. Results show that about 1/3 of the second feature in the Fourier transform of the data can be attributed to the second shell. ${ }^{171}$

Because ferrous and ferric ions are present in many chemical and biological processes, it is clearly desirable to have accurate knowledge of their hydration shells. The only NDIS studies to be carried out show they each have a characteristic first shell with 6 water molecules. ${ }^{172,173}$ EXAFS studies have also been used to probe the environment of $\mathrm{Fe}^{3+}$ in a variety of chemical environments and under different physical conditions. Of biochemical interest is the finding that $\mathrm{Fe}^{3+}$ dimerization occurs in iron(III) complexes of sugar type ligands. ${ }^{174}$

$\mathrm{Cu}^{2+}$ solutions show a range of structures due to the Jahn-Teller effect which causes the distortion of any symmetric octahedral arrangement around the $\mathrm{Cu}^{2+}$ ion. A recent NDIS study combined with first principles $\mathrm{MD}$ of $\mathrm{Cu}^{2+}$ hydration in an aqueous solution of 2 molal copper perchlorate gives evidence for a fivefold coordination shell around $\mathrm{Cu}^{2+} \cdot{ }^{175}$ This controversial result challenges earlier studies which show the classical $4+2$ configuration. Work is continuing in this area on other cupric systems with a view to assessing the generality of these findings.

Early XANES work on dilute aqueous solutions of copper bromide suggests that $\mathrm{Cu}^{2+}$ has a 4+2 coordination. Additionally, the work of Ludwig et al. ${ }^{5}$ and Garcia et al., ${ }^{176}$ suggested that in concentrated $\mathrm{CuBr}_{2}$ solution direct $\mathrm{Cu}^{2+}-\mathrm{Br}$ contacts occur. However, the method used to analyse their data is now regarded as simplistic.

A comprehensive EXAFS analysis was carried out on 0.82 molar $\mathrm{CuSO}_{4}$ solution ${ }^{177}$ and showed a clear $4+2$ arrangement of an octahedral hydration shell. Controversy still surrounds the case of $\mathrm{CuCl}_{2}$, where the chloride ion has sufficient strength, to form $\mathrm{Cu}^{2+}-\mathrm{Cl}^{-}$pairs in concentrations above 1 molar. The solution changes colour from blue to green in the range 1 to 4 molar. EXAFS work by D'Angelo et al. ${ }^{178}$ carried out on solutions in the range 0.1 molal to 3.0 molal showed that the axial coordination number of $\mathrm{Cu}^{2+}$ is unchanged at $4.0(1)$ at $1.966(4) \AA$. Small concentrations of $\mathrm{Cu}^{2+}-\mathrm{Cl}^{-}$contacts were observed at 0.1 molal and these increased to 1.0(3) atoms at 3 molal.

In a mixed salt aqueous solution of 5 molal sodium chloride and 0.5 molal cupric chloride system, ${ }^{179}$ a system used to represent the prebiotic environment in which amino acids might dimerise, NDIS results show, perhaps unsurprisingly, $\operatorname{direct} \mathrm{Cu}^{2+}$ $\mathrm{Cl}^{-}$ion contacts giving rise to the species $\left[\mathrm{Cu}\left(\mathrm{H}_{2} \mathrm{O}\right)_{5} \mathrm{Cl}\right]^{+}$. Moreover, as found in other studies of water structure in the presence of large amounts of strongly hydrating ions, the hydrogen bond structure is appreciably different from that in pure water.

The case of strong hydration is well established by XD and NDIS for the lanthanide ions, with well defined first hydration shells of 8 or 9 water molecules. ${ }^{180-182}$ A similar result has recently been firmly established by an AXD study of $\mathrm{Y}^{3+}$ that belongs to the same Group (3) of the Periodic Table as $\mathrm{La}^{3+} \cdot{ }^{183}$ As an example of what AXD can 


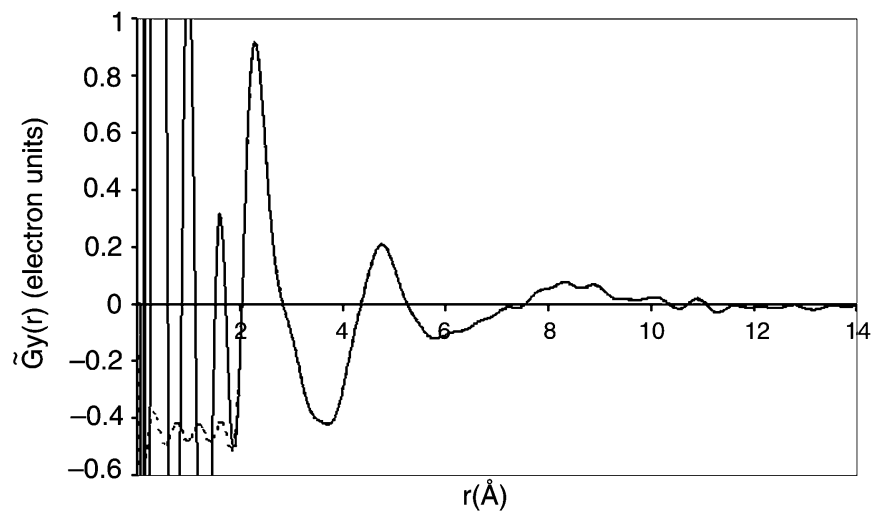

Fig. 4 Total pair distribution function $\tilde{G}_{Y}(r)$ for $\mathrm{Y}^{3+}$ obtained by AXD. The dashed line represents the best fitting function to the experimental data when a cut-off is applied in the region between 0 and $1.96 \AA$ A. Figure adopted from ref. 183 .

achieve, Fig. 4 shows that the $\mathrm{Y}^{3+}$ cation retains at least two strong hydration shells. Moreover, more detailed analysis of the data can be carried out to locate the position of the hydrogen atom of the hydrated water molecules in the first hydration shell.

Interest in the structural properties of rare earths has not been as extensive as for other elements due to technical difficulties or backgrounds and energies involved. A comprehensive study of 3.0 molar $\mathrm{ErBr}_{3}$ solution has been made using both AXD and EXAFS of the $\mathrm{Br}$ and the Er edges which shows that there is no inner shell complexation and that $\mathrm{Er}^{3+}$ has 8 neighbours, and a planar bridging model of the $\mathrm{Br}^{-}$ions is proposed. ${ }^{184}$

The EXAFS and XANES work cited above are merely a few of the many extensive studies carried out on transition metal cations, lanthanide cations and other ions of $Z>28$. The interested reader is referred to journals such as Chem. Geol. which has several papers concerned with the speciation of ions found in the Earth's mantle. ${ }^{185-188}$

Complex anions. Much of the motivation for the study of complex anions derives from their relative effectiveness in denaturation processes of biologically active materials. The various Hofmeister series are used to distinguish between the ability of ions in the salting out or denaturation of protein molecules. ${ }^{189}$ Most prominently, it is the anion series which appears to exert the strongest influence in such processes. In an attempt to quantify the effect of anions on water solvent structure, Leberman and Soper ${ }^{150}$ carried out NDIS experiments on three equimolal solutions of ammonium nitrate, sodium nitrate and sodium chloride in water/heavy water mixtures. Calculations based on changes in the pair distribution function $g_{\mathrm{HH}}(r)$ between pairs of solutions allowed them to establish a correlation between the 'induced pressure of a particular anionic species with its efficacy in precipitating or salting-out protein from solution'.

By investigating the structure around the ions themselves with NDIS methods it is also hoped to see whether one can distinguish the relative effectiveness of particular ions in the series. The effects are likely to be subtle and could be long range in 
character. Thus it might well be that the $q$ space information is likely to be more useful.

The hydration structures of several anions including $\mathrm{NO}_{2}{ }^{-}, \mathrm{NO}_{3}{ }^{-}, \mathrm{SCN}^{-}$have been studied by NDIS methods. ${ }^{1}$ The three phosphate anions $\mathrm{H}_{2} \mathrm{PO}_{4}{ }^{-}, \mathrm{HPO}_{4}{ }^{2-}, \mathrm{PO}_{4}{ }^{3-}$, also play critical roles in many biological processes and phosphate groups are components in the DNA structure itself. ${ }^{190}$ Results from recent NDIS experiments on concentrated solutions of the potassium salts were used to calculate $g_{\mathrm{OH}}(r) .{ }^{191}$ A preliminary analysis of this function shows that the hydration of $\mathrm{H}_{2} \mathrm{PO}_{4}{ }^{-}, \mathrm{HPO}_{4}{ }^{2-}$, $\mathrm{PO}_{4}{ }^{3-}$ becomes progressively more structured.

Solute structure. The determination of solute structure in solution remains the greatest challenge to the experimentalist. In principle, NDIS and AXD, second order difference methods, offer a means to calculate uniquely the three $g_{a \beta}(r)$ s of a salt in water. However, the conditioning of the equations used to carry out the calculation seriously limits the accuracy of the information obtained, and it is for this reason that only a few systems have been studied. As yet the AXD second difference method has not been applied. However, Ramos has carried out preliminary experiments on caesium iodide at 3 energies around both Cs and I edges and it will be interesting to see whether the data will be of sufficient quality to allow the determination of $g_{\text {II }}(r)$ and $g_{\mathrm{CsCs}}(r)$.

Results on solute structure are continuing to become available for a few select systems at relatively high concentrations. Within the past few years second difference experiments have been carried out on heavy water solutions of lithium chloride, ${ }^{192}$ copper chloride, ${ }^{193}$ nickel nitrate and nickel sulfate. ${ }^{194}$ The main focus of the lithium choride study was to monitor changes in $g_{\mathrm{ClCl}}(r)$ with concentration and examine in detail the results of theoretical model calculations which suggest direct $\mathrm{Cl}^{-} \cdot \mathrm{Cl}^{-}$ contacts exist, even at infinite dilution. ${ }^{195}$ The experimental results at 8.6 molal in $\mathrm{LiCl}$ show that although there are still direct contacts between chloride ions, the coordination number is about $30 \%$ of that at 14 molal, and suggests that such contacts will become negligible at concentrations below $\sim 1$ molal. By contrast, in nickel chloride at the same chloride concentration, there is no evidence of direct contacts between chloride ions. ${ }^{196}$

Although there is now a large body of knowledge on the structure of aqueous electrolytes there remains much to be undertaken. In the short term, questions regarding individual hydration functions and the extent of overlap etc. will be addressed. The AXD method is clearly useful for heavy ions $(Z>28)$. Where appropriate AXD and NDIS methods will be needed to help interpret neutron diffraction data obtained for more complex systems such as aqueous electrolyte solutions containing large complex molecules such as polyelectrolytes and biopolymers. Besides the role of the counterions in such solutions, it is also necessary to discover the structural aspects of all parts of the solution. For example, it will be particularly interesting to determine how the conformation of biomolecules such as proteins depends on counterions, especially those anions in the Hofmeister series.

At the level of second differences, a knowledge of ion-ion pair distribution functions will be useful in assessing the validity of primitive model (PM) calculations in ionic solutions. ${ }^{195}$

Finally, if EXAFS is to become as effective as AXD and NDIS it will be necessary to carry out equivalent experiments on the same system with each technique. This 
could be problematical since the multiple scattering from the first hydration sphere and the single scattering from the second coordination shell all arise from the same effective correlation within the Fourier transform of the EXAFS spectra. Moreover, the low $k$ region of the EXAFS spectra rapidly becomes contaminated by the XANES region and by the strongest atomic background features.

\subsubsection{Aqueous solutions of complex and biologically significant molecules. During} the past five years the proceedings of 2 major conferences have appeared in the literature, both concerned with Hydration in Biology. ${ }^{197,198}$ Many of the papers identify several important questions for the diffractionist, such as 'where is the water in crystal hydrates?' 'how much water is bound to a protein?'. Moreover, although not strictly in the realm of structure, one might also ask about the residence time of water around a protein; such information may be inferred from the line shapes and strength of correlations in the RDFs, (see caption to Fig. 1). From the perspective of this review, similar questions can be posed regarding the coordination of water molecules around biologically active material in the liquid or diffuse phase, i.e. the phase in which biological activity is most clearly manifest.

Because most biological material is composed of lighter elements the dominant structural probe continues to be neutron diffraction and NDIS. However, X-ray methods are certainly used effectively in protein crystal structure determination and often raise questions that can subsequently be best answered by NDIS. Even here the complexity of the situation is all too apparent with the number of correlations increasing in proportion to the number of specific atoms present. To accommodate this situation Soper, Finney and co-workers have combined the EPSR method with their NDIS results to extract more detailed information on changes in water structure in aqueous mixtures of biologically important molecules such as urea and the alcohols. ${ }^{199-201}$ By concentrating on the coordination in these systems they have been able to address questions regarding the structure of water in the presence of both hydrophobic and hydrophilic groups. One of their recent studies has been carried out on tert-butanol. By focussing mainly on the exchangeable and non-exchangeable protons in the liquid, they have carried out several detailed studies of representative systems that reflect hydrophobic bonding, Their results on the influence of temperature, show 'a structural perturbation of the water solvent structure which could relate to the entropic driving force of the hydrophobic interaction'.

NDIS studies have also been reported on modifications to the water solvent structure within the hydration shell of a 'hydrophobic amino acid' ${ }^{202}$ The results show evidence for an expansion of the water structure such as occurs when water itself is supercooled. ${ }^{142}$

NDIS methods have also been used to study the role of cations and anions in solution and changes to the water structure in aqueous electrolyte solutions of small sugar molecules, proteins and DNA. Wilson et al. showed that the $\mathrm{Cl}^{-}$hydration is modified by the presence of large molecules such as glycine and poly-glycine and RNA (poly U). ${ }^{156}$ In an attempt to see whether this effect is specific to polyelectrolytes or may be a general signature associated with the denaturation of proteins, NDIS studies were used to study $\mathrm{Cl}^{-}$hydration in an aqueous electrolyte solution containing the protein melittin. This protein is soluble in water and undergoes a cold naturationdenaturation transition at around $18{ }^{\circ} \mathrm{C}$. The $q$ space data for $G_{\mathrm{Cl}}(r)$ suggest a small 
but appreciable change in the $\mathrm{Cl}^{-}$hydration structure. However, of arguably more significance, there appears to be a significant change in the hydrogen bond structure in crossing this transition. ${ }^{203}$

By contrast NDIS studies of water structures in highly concentrated glucose solutions show almost no change in the hydrogen bond structure. ${ }^{204}$ This is a remarkable result, as similar studies on salt solutions show large structural changes in $g_{\mathrm{OH}}(r)$ even at relatively low ionic concentrations. ${ }^{149} \mathrm{It}$ is, however, of more interest in systems such as glucose in water to investigate how the water molecules are coordinated to the various hydroxy groups on the sugar molecule itself. Brady and his co-workers have carried out MD studies on model systems and concluded that there is a high degree of anisotropy associated with the hydration structure of simple sugar molecules. ${ }^{205}$ The NDIS method is the only one available which can test these simulations at the required level of atomic resolution.

All the results on aqueous solutions of biomolecules are usefully compared with those obtained from MD simulation, ${ }^{206}$ and spectroscopy such as NMR and most recently the methods of Fourier transform infrared spectroscopy. ${ }^{207}$ The NMR method has provided most of our understanding to date on the molecular structure and dynamics of the hydrated water molecules in solution and in the crystalline phase.

3.4.3 Apolar molecules in water. The NDIS method has been shown to offer a means to probe the fundamental aspects of the hydrophobicity, the generic term used to describe such contrasting behaviour as the immiscibility of oil and water and the manner in which proteins fold in an aqueous environment. Small apolar species, such as argon, krypton, xenon, methane, etc. are sparingly soluble in water and also exhibit hydrophobicity in the formation of large hydration shells. ${ }^{208}$ They comprise 'ideal systems' for theoretical and experimental studies of hydrophobicity. ${ }^{209,210}$

In our previous review we presented and discussed results of NDIS experiments on aqueous mixtures of apolar molecules such as $\operatorname{argon}\left({ }^{36} \mathrm{Ar} /{ }^{\mathrm{N}} \mathrm{Ar}\right)$ and methane $\left(\mathrm{CH}_{4} /\right.$ $\left.\mathrm{CD}_{4}\right)$ in water under pressure. Results for $G_{\mathrm{A}}(r)^{211}$ confirm the existence of relatively well defined near neighbour hydration shells around the isotopically substituted argon. There are $\sim 16(2)$ water molecules in the range $2.2 \leq r / \AA \leq 4.6$, and for methane there are 19(2) in the range $2.4 \leq r / \AA \leq 5$, with the water molecules orientated tangentially around the $\mathrm{CH}_{4}$ molecule. ${ }^{212}$ Of particular interest is the fact that $\mathrm{Ar}$ is isoelectronic with both $\mathrm{Cl}^{-}$and $\mathrm{K}^{+}$. Inspection of the $G_{\mathrm{A}}(r)$ s for these 3 species shows that the structure around argon is more pronounced than that of $\mathrm{K}^{+}$but less than that for $\mathrm{Cl}^{-}$. Although the coordination numbers are widely different between $\mathrm{K}^{+}$and $\mathrm{Cl}^{-}$ on the one hand and $\mathrm{Ar}$ on the other, the results show that the water molecules themselves play the more active role when apolar species are present. Additionally, it is found that both the argon atom and methane molecules show no appreciable structure beyond their first hydration shells. This observation conflicts with results from computer simulations that generally show the existence of a well-defined second hydration shell. ${ }^{213}$

During the past five years two significant studies have been undertaken in this area. The first concerns an investigation of the temperature dependence of $G_{\mathrm{Ar}}(r)$ in an argon/water mixture at $318^{\circ} \mathrm{C}$. ${ }^{214} \mathrm{It}$ is found (Fig. 5), that the hydration shell of argon is appreciably changed with the number of water molecules falling to around 9(1), in 


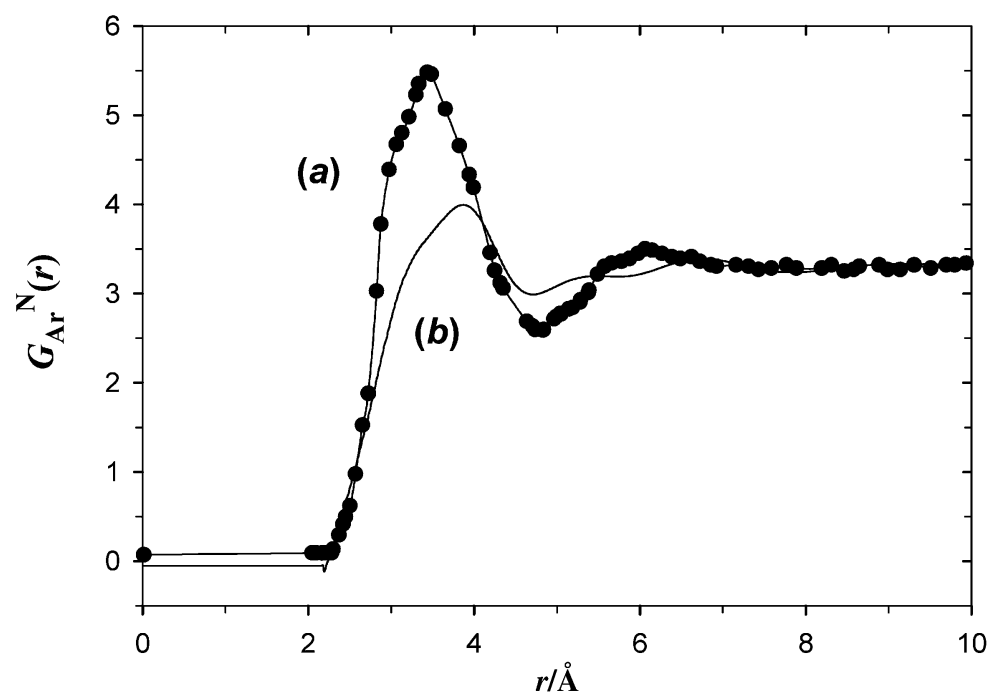

Fig. 5 Comparison between normalised $\tilde{G}_{\mathrm{Ar}}{ }^{\mathrm{N}}(r)$, (a) at $25^{\circ} \mathrm{C}$ and 240 bar and (b) at $318^{\circ} \mathrm{C}$ and 300 bar. Normalisation was carried out by dividing the $G_{\operatorname{Ar}}(r)$ s by the coefficient of $g_{\text {Aro }}(r)$ in eqn. (4), and adding on the zero limit constant. i.e. $G^{\mathrm{N}}(r)=g_{\mathrm{ArO}}(r)+2.28 g_{\mathrm{ArD}}(r)+0.10 g_{\mathrm{ArAr}}(r)$. Figure adopted from ref. 214.

excellent agreement with the predictions of a computer simulation study by Guillot and Guisani. ${ }^{215}$

The second study involved the use of EXAFS to investigate the nearest neighbour correlations of heavy noble gas atoms such as krypton and xenon as a function of temperature and pressure. ${ }^{216,217}$ The results provide evidence for a systematic thermal perturbation of each atoms' hydration shell over the range $300 \mathrm{~K}$ to $373 \mathrm{~K}$ and are again consistent with the computer simulation results of Guillot and Guisani. However, at a given temperature the structure remains unchanged with increasing pressure.

At temperatures close to the freezing point of water, NDIS studies are reported on changes to water structure on clathrate formation in methane/water mixtures. ${ }^{218}$ Results were obtained in the temperature range $4<T /{ }^{\circ} \mathrm{C}<18$ and at two pressures and, inter alia, show that 'the hydration sphere around methane in the liquid changes dramatically only once the hydrate has been formed'. Moreover once the hydrate has been formed the hydration shell of the methane becomes less well ordered. Such wellcharacterised behaviour presents a reference for computer simulation to describe the origins of clathrate formation in low temperature apolar liquids.

\subsection{Non-aqueous electrolyte solutions}

Non-aqueous electrolyte solutions (NAES) are a special class of condensed and disordered ion-molecular systems with a well-pronounced short-range order. In comparison with aqueous electrolyte solutions, they exhibit larger liquid ranges, higher stability for both electrolytes and non-electrolytes, better compatibility with the 
electrode material, enhanced stability of the solutions, and relatively high electrochemical stability, i.e., increased resistance to reduction or oxidation. These properties render them particularly important media for a variety of electrochemical devices and processes, such as high-energy density commercial batteries, electro-synthesis of polymer and semi-conducting materials, and cation inhibitors of iron corrosion.

In our previous review ${ }^{1}$ we described results on NAES derived from NDIS. We now report data from more recent NDIS studies together with other X-ray diffraction and EXAFS measurements.

Within the past few years, Kalugin and Adya ${ }^{219}$ have carried out a detailed NDIS study of a concentrated $\mathrm{NiCl}_{2}-$ methanol $(\mathrm{MeOH})$ solution, which included an investigation of the $\mathrm{Ni}^{2+}$ and $\mathrm{Cl}^{-}$co-ordination shells. The first-, second- and higherorder difference methods of NDIS on nickel, chlorine, and hydroxy hydrogen (Ho) were used in conjunction with ab initio calculations of the $\mathrm{Ni}^{2}$-methanol complex to determine the $g_{\mathrm{NiO}}(r), g_{\mathrm{NiHo}}(r), g_{\mathrm{NiCl}}(r), g_{\mathrm{NiC}}(r)$, and $g_{\mathrm{NiH}(\text { methyl) }}(r)$ PDFs of the $\mathrm{Ni}^{2+}$ (Fig. 6). The results show that the chloride ion penetrates the nickel (II) solvation shell, forming a contact ion pair (CIP), the $\mathrm{Ni}-\mathrm{Cl}$ complex, with a mean separation of $2.348(2) \AA$ and a coordination number $(\mathrm{CN})$ of $0.72(5)$. It was also demonstrated that because of this inner-sphere complexation, it is not possible to derive exact values of the mean Ni-O distance and the $\bar{n}_{\mathrm{Ni}}^{\mathrm{O}}$ co-ordination number purely from the first-order difference functions reported previously. ${ }^{220}$ These results were inconsistent with a wellestablished 6-coordinated octahedral structure of the 3d-transition metal ions in aqueous solutions, ${ }^{221}$ and with the results of the $\mathrm{Ni}(\mathrm{II})$ coordination in non-aqueous oxygen-donating solvents. ${ }^{222,223}$

The second- and high-order difference methods of NDIS, were used to yield a mean $\mathrm{Ni}-\mathrm{O}$ distance of 2.057(1) $\AA$ and $\bar{n}_{\mathrm{Ni}}^{\mathrm{O}}$ value of 5.0(3). This distance is in excellent agreement with the mean $\mathrm{Ni}-\mathrm{O}$ distance of $2.05 \AA$ in $\mathrm{Ni}\left(\mathrm{CF}_{3} \mathrm{SO}_{3}\right)_{2}$-methanol solution obtained from recent EXAFS experiments. ${ }^{223}$ Integration of $g_{\mathrm{NiHo}}(r)$ over a peak whose maximum is at 2.619(6) $\AA$ gives a coordination number of 5.4(5) for the $\bar{n} \mathrm{Ni}$. This mean Ni-Ho distance of $2.619 \AA$ in 1.4 molal solution of $\mathrm{NiCl}_{2}$ in methanol is comparable to that in aqueous ${ }^{224}(2.67-2.80(2) \AA)$, and in ethylene glycol ${ }^{222}(2.82$ $2.86(2) \AA)$ solutions with the same concentration of $\mathrm{Ni}^{2+}$. The $\mathrm{Ni}-\mathrm{Cl}$ nearestneighbour distance of $2.348 \AA$ is very close to the sum of the Pauling ionic radii ${ }^{225}(0.6$ $+1.81)=2.41 \AA$, which gives clear evidence of direct cation-anion complexation of the type $\left[\mathrm{NiCl}(\mathrm{MeOH})_{5}\right]^{+}$, forming a CIP in $\mathrm{NiCl}_{2}-$ methanol solutions. This is in contrast to the results on aqueous solutions of $\mathrm{NiCl}_{2}{ }^{226}$

The mean coordination numbers, $\bar{n}_{\mathrm{Ni}}^{\mathrm{Cl}}=0.72$ and $\bar{n}_{\mathrm{Ni}}^{\mathrm{Ho}}=5.4$ in $\mathrm{NiCl}_{2}-\mathrm{MeOH}$ solution, are consistent with the 6-site octahedral coordination of $\mathrm{Ni}^{2+}$ that corresponds to the $\mathrm{sp}^{3} \mathrm{~d}^{2}$ hybridisation of its atomic orbitals. This type of coordination is typical of $\mathrm{Ni}^{2+}$ cation in its aqueous ${ }^{221}$ and non-aqueous ${ }^{222,223}$ solutions. Salmon and coworkers ${ }^{222,227}$ from their NDIS studies of the coordination environment of $\mathrm{Ni}^{2+}$ in nominally 1 molal solutions of nickel triflate $\left(\mathrm{Ni}\left(\mathrm{CF}_{3} \mathrm{SO}_{3}\right)_{2}\right)$ in fully deuterated ethylene glycol $\left(\mathrm{EG}=\mathrm{DOCD}_{2} \cdot \mathrm{CD}_{2} \mathrm{OD}\right)$ and glycerol $\left(\mathrm{DOCD} \mathrm{D}_{2} \cdot \mathrm{CD}(\mathrm{OD}) \cdot \mathrm{CD}_{2} \mathrm{OD}\right)$ found the existence of highly stable chelate complexes of the type $\left[\mathrm{Ni}(\mathrm{EG})_{3}\right]^{2+}$ and $[\mathrm{Ni}(\mathrm{gly}-$ cerol $\left.)_{2}\right]^{2+}$. Similar studies of the coordination environment of $\mathrm{Cu}^{2+}$ in a 2.18 molal solution of copper triflate $\left(\mathrm{Cu}\left(\mathrm{CF}_{3} \mathrm{SO}_{3}\right)_{2}\right)$ in fully deuterated EG revealed ${ }^{228}$ the existence of a tris-chelate complex, $\left[\mathrm{Cu}(\mathrm{EG})_{3}\right]^{2+}$, in which $\mathrm{EG}$ acts as a bidentate ligand, thus giving an octahedral coordination around $\mathrm{Cu}^{2+}$. However, the complex, 

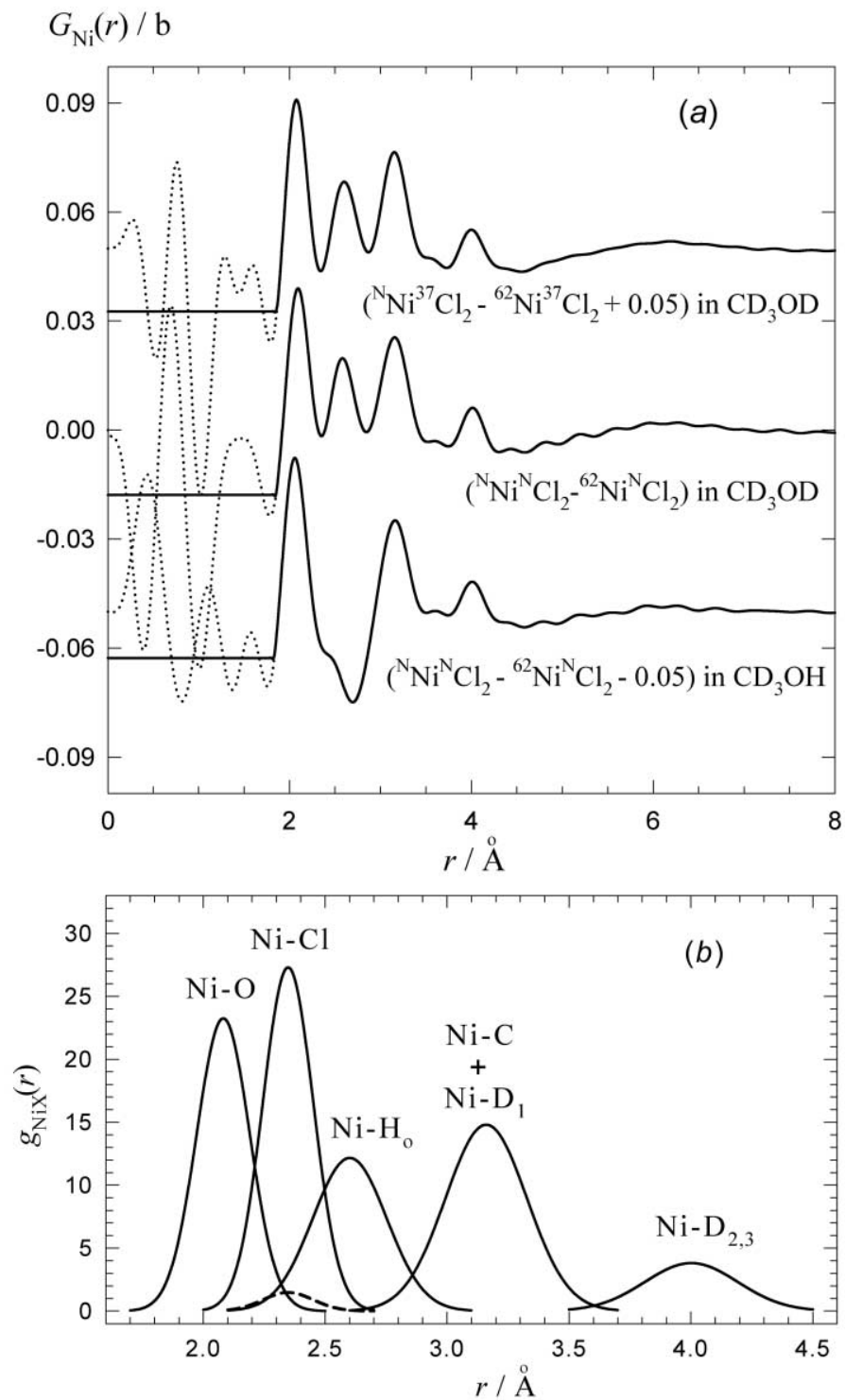

Fig. 6 (a) First order difference functions, $G_{\mathrm{Ni}}(r)$ versus $r$. Dotted curves are the Fourier transforms of the measured $Q$-space data and full curves after setting the unphysical oscillations at $r \leq 1.85 \AA$ to their low- $r$ value limits. Note that the second peak is negative for $\mathrm{NiCl}_{2}$ solutions in $\mathrm{CD}_{3} \mathrm{OH}$ and positive for those in $\mathrm{CD}_{3} \mathrm{OD}$. (b) The pair RDFs, $g_{\mathrm{Nix}}(r)$, in $\mathrm{NiCl}_{2}$-methanol solutions obtained by the second- and high-order difference NDIS techniques. Ho = hydroxy hydrogen, $\mathrm{D}_{2,3}=$ two methyl hydrogens close to the Ho and lying out of the symmetry plane of the methanol molecule, $\mathrm{D}_{1}=$ the third methyl hydrogen, which together with $\mathrm{C}, \mathrm{O}$ and Ho define the symmetry plane. It can be seen clearly that chloride ion penetrates the $\mathrm{Ni}$ (II) solvation shell forming contact ion pair (CIP) at 2.348(2) Å. Figure adopted from ref. 219. 
$\left[\mathrm{Cu}(\mathrm{EG})_{3}\right]^{2+}$ was found to be Jahn-Teller distorted with a tetragonal elongation with a $4+2$ configuration containing 4 oxygen atoms at $1.98 \AA$ and 2 oxygen atoms at $2.26 \AA$.

The above results show that a reduction of the cation solvation number from 6 to 5 occurs on changing the solvent from water ${ }^{1}$ to methanol ${ }^{219}$ owing to strong ioncounter-ion association in $\mathrm{NiCl}_{2}-\mathrm{MeOH}$ solutions. Kameda et al. ${ }^{229}$ also showed from the ND studies of $\mathrm{Li}^{+}$coordination in highly concentrated solutions of lithium bromide ( 16.7 molal) and lithium iodide ( 22 molal) in methanol that the $\mathrm{Li}^{+}$coordination is similarly altered from that in aqueous solution. Although, the distance between $\mathrm{Li}^{+}$and the oxygen of the nearest-neighbour methanol molecule (1.97(5) $\AA$ in $\mathrm{LiBr}-\mathrm{MeOH}$ and $1.93(5) \AA$ in $\mathrm{LiI}-\mathrm{MeOH}$ solutions) is similar to that in aqueous solutions (1.95(2) $\AA$ in 3.6 molal and 1.96(2) $\AA$ in 1 molal) of $\mathrm{LiCl}^{230}$ the coordination numbers are appreciably lower (3.0(5) in $\mathrm{LiBr}-\mathrm{MeOH}$ and $1.8(5)$ in $\mathrm{LiI}-\mathrm{MeOH})$ as compared to those (6.0(5) and 6.5(10), respectively in 3.6 molal and 1 molal) in aqueous solutions of $\mathrm{LiCl}$. This again suggests a substantial amount of cation-anion contact in highly concentrated methanolic solutions of $\mathrm{LiBr}$ and LiI.

Cartailler et al. ${ }^{231}$ employed the neutron first-order difference technique to make a comparative study of the nearest-neighbour structure around $\mathrm{Li}^{+}$in solutions of $\mathrm{LiBr}$ in acetonitrile $(0.58 \mathrm{M})$ vis a vis that in water $(1.88 \mathrm{M})$, and found that while the bromide ion entered into the first solvation shell around the cation in its non-aqueous solution, the first hydration shell was not disturbed by the anion. While the first solvation sphere around $\mathrm{Li}^{+}$consists of 4.5(5) water molecules with the nearestneighbour $\mathrm{Li}-\mathrm{O}$ distance $=1.94 \AA$ in the aqueous solution, the nearest neighbours in the non-aqueous solution are $\sim$ three (2.9(3)) acetonitrile molecules at the $\mathrm{Li}-\mathrm{N}$ distance of $2.05 \AA$, and one bromide ion at $2.46 \AA$.

The question that naturally arises is whether such a strong ion-counter-ion association in $\mathrm{NiCl}_{2}-\mathrm{MeOH}$ solutions would also cause a reduction of the anion $\left(\mathrm{Cl}^{-}\right)$ solvation number within its nearest-neighbour environment, "the solvation shell". Yamagami et al. ${ }^{232}$ reported from their NDIS studies of $5.8 \mathrm{M} \mathrm{LiCl-methanol} \mathrm{solu-}$ tion, the mean $\mathrm{Cl}-\mathrm{Ho}$ distance, $r_{\mathrm{Cl}-\mathrm{Ho}}=2.21(3) \AA$ and coordination number, $\bar{n}_{\mathrm{Cl}}^{\mathrm{Ho}}=$ 3.6(5). Other studies ${ }^{233-239}$ report these values to be $r_{\mathrm{Cl}-\mathrm{X}}=2.4 \AA_{,}{ }^{236} 2.35 \AA^{233,237}$ (for $\mathrm{X}=\mathrm{Ho}$ ), $3.3 \AA \AA^{236} 3.28 \AA^{233,237}$ (for $\mathrm{X}=\mathrm{O}$ ), and $\bar{n}_{\mathrm{Cl}}^{\mathrm{X}}\left(\right.$ for $\mathrm{X}=\mathrm{O}$ or $\mathrm{Ho}$ ) $=1.6,{ }^{235}$ $4,{ }^{234} 4-5,{ }^{239} 5,{ }^{236} 6.3,{ }^{238} 6.4,{ }^{233} 6.6,{ }^{233} 7.0,{ }^{237} 7.2 .^{237}$

Adya and Kalugin ${ }^{240}$ recently carried out a further study of $\mathrm{Cl}^{-}$-coordination shell in 1.4 molal $\mathrm{NiCl}_{2}-\mathrm{MeOH}$ solution by the NDIS technique. ND measurements were made on seven different isotopically enriched samples and the results conclusively showed that nickel-chlorine correlation contributes significantly to the first peak corresponding to the nearest-neighbour $\mathrm{Cl}-\mathrm{Ho}$ correlations occurring at 2.11-2.16 $\AA$ in the real-space first-order difference functions. From these results a mean $\mathrm{Cl}-\mathrm{Ho}$ distance, $r_{\mathrm{Cl}-\mathrm{Ho}}$ of 2.17(2) $\AA$ and coordination number, $\bar{n}_{\mathrm{Cl}}^{\mathrm{Ho}}$ of 2.2(4) were calculated. Due to a high degree of overlap between $g_{\mathrm{CIO}}(r), g_{\mathrm{CIC}}(r)$ and $g_{\mathrm{ClH}(\text { methyl) }}(r)$ with the other peaks in the first-order difference functions, exact assignment of these peaks to individual correlations was arbitrary. However, by working at the neutron second-order difference level it was possible to determine, $g_{\mathrm{ClHo}}(r)$ and $g_{\mathrm{ClCl}}(r)$. The results showed that the methanol molecules bind to the $\mathrm{Cl}^{-}$via hydrogen atoms of the hydroxy groups with a mean $\mathrm{Cl}-\mathrm{Ho}$ separation distance, $r_{\mathrm{Cl}-\mathrm{Ho}}=2.179(2) \AA$ and coordination number of $\cong 2$. This distance is comparable to that in 2.0 molal aqueous solutions of 
$\mathrm{NiCl}_{2}(2.28(3) \AA),{ }^{241} 5.8 \mathrm{M}$ solutions of $\mathrm{LiCl}$ in methanol (2.21(3) $\left.\AA\right),{ }^{232}$ and 1.0 molal solutions of $\mathrm{NaCl}$ in ethylene glycol $(2.14(3) \AA)^{242}$ and glycerol $(2.17-2.20(3) \AA)^{243}$ With a change of cation from $\mathrm{Li}^{+}$to $\mathrm{Ni}^{2+}$, a marked reduction in the solvation number of chloride, $\bar{n}_{\mathrm{Cl}}^{\mathrm{Ho}}$, from approximately $4^{232}$ to $2^{240}$ occurs in methanolic solutions. This reduction in the solvation number is undoubtedly caused by strong inner-sphere complexing of the chloride ion by nickel (II) in $\mathrm{NiCl}_{2}-\mathrm{MeOH}$ solutions. Moreover, the solvation numbers of chloride ion in non-aqueous media are found, in general and as expected, to be relatively low as compared to those in its aqueous solutions. For instance, the solvation numbers of $\mathrm{Cl}^{-}$are found to be $3.6(5)$ in a $5.8 \mathrm{M}$ solution of $\mathrm{LiCl}$ in methanol, ${ }^{232} 4.1(2)$ in a 1.0 molal solution of $\mathrm{NaCl}$ in ethylene glycol, ${ }^{242}$ and $3.0(2)$ in a 1.0 molal solution of $\mathrm{NaCl}$ in glycerol. ${ }^{243}$ In comparison, the values for the solvation numbers $\left(6.4(3)\right.$ in a 2 molal solution of $\mathrm{NiCl}_{2},{ }^{241}$ and $5.8(5)$ in $8.6 \mathrm{M}$ solution of $\mathrm{LiCl}^{232}$ ) in aqueous solutions of chloride are found to be larger. In contrast to the above findings, the larger value (6.8(5)) for the coordination number of $\mathrm{Cl}^{-}$ in a $1.7 \mathrm{M}$ solution of $\mathrm{LiCl}$ in $N, N$-dimethylformamide (DMF) by Yamagami et al. ${ }^{232}$ is assumed to be due mainly to ion-dipole interactions. Additionally, the results obtained for concentrated aqueous solutions of chlorides of divalent cations show that whenever direct cation-anion complexation occurs, it is accompanied by a decrease ${ }^{226}$ in the solvation numbers of both the cations and the anions. For example, the hydration number of chloride ion was found to be 3.4(2) in a 4.9 molal solution of $\mathrm{ZnCl}_{2}$ as compared to 5.7-5.8(2) for $\mathrm{NiCl}_{2}$ and $\mathrm{CaCl}_{2}$ solutions of the same concentration. Similarly, the hydration number of $\mathrm{Cu}^{2+}$ was found to be 2.3(3) in a 4.32 molal solution of $\mathrm{CuCl}_{2}$ as compared to 5.3(5) and $\sim 6$, respectively, for 2 molal $\mathrm{Cu}\left(\mathrm{ClO}_{4}\right)_{2}$ and $1-4$ molal $\mathrm{NiCl}_{2}$ solutions. It is undoubtedly the case from the foregoing discussion that the formation of inner-sphere complexation or direct cation-anion "contact ion pair' (CIP) also reduces the solvation numbers of both the cations and anions in non-aqueous media.

Another example of the association (complex formation) reactions between the solute components being much more favoured in the NAES than in aqueous solutions is provided by the formation of a series of four mononuclear complexes of the type, $\mathrm{HgX}_{j}^{2-j}, j=1$ to $4(\mathrm{X}=\mathrm{Cl}, \mathrm{Br}$ and $\mathrm{I})$ in dimethyl sulfoxide (DMSO: $\left.\left(\mathrm{CH}_{3}\right)_{2} \mathrm{SO}\right)$ solutions at different concentrations. Ahrland et al. ${ }^{244}$ used X-ray diffraction and Raman measurements to elucidate the structures of these complexes in DMSO solutions. While the complexes, $\mathrm{HgX}^{+}$are very stable in dilute solutions, tetrahedral complexes of the type, $\mathrm{HgX}_{4}{ }^{2-}$ form as the halide concentration is increased. $\mathrm{The} \mathrm{Hg}-\mathrm{X}$ bond distance (in $\AA$ ) is found to increase in the order $\mathrm{HgX}_{2}<\mathrm{HgX}_{3}^{-}<\mathrm{HgX}_{4}{ }^{2-}$ $(2.350(3)<2.434(3)<2.532(2)$ for $\mathrm{X}=\mathrm{Cl}, 2.455(2)<2.547(3)<2.628(2)$ for $\mathrm{X}=\mathrm{Br}$, $2.624(8)<2.733(3)<2.796(3)$ for $\mathrm{X}=\mathrm{I}$ ) indicating that the strength of the bond decreases as more ligands are coordinated to the central ion. In all the $\mathrm{HgX}_{4}{ }^{2-} \mathrm{com}$ plexes, the $\mathrm{Hg}-\mathrm{X}$ bonds are found to be longer in DMSO than in water; this implies that the complexes are more strongly solvated by DMSO than by water. In the pure solvates, $\mathrm{Hg}\left(\mathrm{H}_{2} \mathrm{O}\right)_{6}{ }^{2+}$ and $\mathrm{Hg}(\mathrm{DMSO})_{6}{ }^{2+}$, the $\mathrm{Hg}-\mathrm{O}$ bonds are however, found ${ }^{244}$ to be of much the same length (2.39 and $2.40 \AA$ ) and strength.

Sandström and coworkers ${ }^{245}$ recently investigated the structure of solvated lantha-

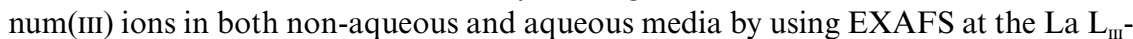
edge, and wide-angle X-ray scattering (WAXS) techniques. They performed measurements on solutions of lanthanum(III) trifluoromethanesulfonate $\left[\mathrm{La}\left(\mathrm{CF}_{3} \mathrm{SO}_{3}\right)_{3}\right]$ in 
DMSO, $\left[\mathrm{La}\left(\mathrm{CF}_{3} \mathrm{SO}_{3}\right)_{3}\right]$ in $N, N^{\prime}$-dimethylpropyleneurea (DMPU), and $\mathrm{La}\left(\mathrm{ClO}_{4}\right)_{3}$ in water at $\mathrm{La}^{3+}$ concentrations of $0.75 \mathrm{M}, 0.08 \mathrm{M}$ and $0.662 \mathrm{M}$, respectively, in the three solvents. The solvated $\mathrm{La}$ (III) ion is found to exhibit different coordination/solvation numbers and configurations in the three oxygen donor solvents. In aqueous solution $\mathrm{La}^{3+}$ is found to be nine-coordinated to the solvent molecules in a tricapped trigonal prism configuration with $\mathrm{Li}-\mathrm{O}$ bond distances of 2.52(2) $\AA$ to the 6 oxygen atoms in the prism and 2.65(3) $\AA$ to the 3 capping oxygens. By contrast, the solvated La(III) ion shows eight-fold coordination in a square antiprism or tricapped trigonal prism (no significant preference found between the two models used) arrangement in DMSO, and a seven-coordinated solvate (with no configuration established) in DMPU. Ishiguro et al..$^{246-248}$ also proposed from their X-ray measurements that the solvation number of $\mathrm{La}(\mathrm{III})$ in two other oxygen donor solvents, $N, N$-dimethylformamide (DMF) and $N, N$-dimethylacetamide (DMA), is eight. The observed La-O distances in the five solvents [2.52(2), 2.65(3) $\AA$, aqueous; 2.504(3) $\AA$, DMSO; 2.4855(7) $\AA$, DMF; 2.4745(8) $\AA$, DMA; 2.438(4) $\AA$, DMPU] reflect a strong correlation between the observed distances and the coordination numbers (CNs: 9, 8, 8, 8, 7, respectively), since the ionic radii of the metal ions, in general, increase significantly with increasing $\mathrm{CN}$ (see Shannon ${ }^{249}$ ). The decrease in the $\mathrm{CN}$ of $\mathrm{La}^{3+}$ in DMPU as compared to the other solvents is almost certainly due to the bulkiness of the solvent molecules, which results in a strong steric ligand-ligand repulsion.

The structures of the solvated scandium $\left(\mathrm{Sc}^{3+}\right)$ and yttrium $\left(\mathrm{Y}^{3+}\right)$ ions in these nonaqueous and aqueous oxygen donor solvents have been investigated in solution by the EXAFS and WAXS methods. The observed metal-O bond distances and proposed solvation numbers $\left(n_{\text {solv. }}\right)$ of the metal ions in different solvents have been reported for $\mathrm{Sc}-\mathrm{O}:{ }^{245,250}\left[2.19\right.$ (1) $\AA, n_{\text {solv. }}=\sim 8$ in aqueous; $2.085(4) \AA, n_{\text {solv. }}=6$ in DMSO; $2.084(4)$ $\AA, n_{\text {solv. }}=6$ in DMPU], and for Y-O: ${ }^{245,251,252}$ [2.366(5) $\AA, n_{\text {solv. }}=8$ in aqueous; $2.360(3)$ $\AA, n_{\text {solv. }}=8$ in DMSO; $2.347(3) \AA, n_{\text {solv. }}=8$ in DMF; $2.242(3) \AA, n_{\text {solv. }}=6$ in DMPU].

The structures of the solvated bismuth(III) ion in oxygen donor aqueous and non-aqueous (DMSO, DMPU), and sulfur donor non-aqueous ( $N, N$-dimethylthioformamide: DMTF) solvents have also been studied ${ }^{253}$ in solutions of bismuth(III) trifluoromethanesulfonate $\left[\mathrm{Bi}\left(\mathrm{CF}_{3} \mathrm{SO}_{3}\right)_{3}\right]$ and bismuth(III) perchlorate $\left[\mathrm{Bi}\left(\mathrm{ClO}_{4}\right)_{3}\right]$ by means of EXAFS (at the $\mathrm{Bi}_{\mathrm{III}}{ }^{-}$edge) and WAXS techniques. The results reveal that the hydrated $\mathrm{Bi}^{3+}$ ion is eight-fold coordinated in acidic aqueous solution, with a mean

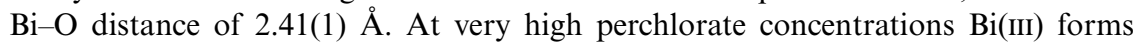
weak ion-pair complexes with perchlorate ions, which enter the inner coordination sphere, showing that $\mathrm{Bi}(\mathrm{III})$ has a slightly higher affinity for perchlorate ions than water molecules at very high ionic strengths. The hydrated $\mathrm{Bi}(\mathrm{III})$ ion hydrolyses easily to hexameric $\mathrm{Bi}_{6} \mathrm{O}_{4}(\mathrm{OH})_{4}{ }^{6+}$ complexes if the excess of strong acid is lower than $1 \mathrm{~mol}$ $\mathrm{dm}^{-3}$. The Bi(III) ion coordinates to eight DMSO molecules via the oxygen atoms in the NAES in a square antiprismatic configuration with mean $\mathrm{Bi}-\mathrm{O}$ and $\mathrm{Bi}--\mathrm{S}$ distances of 2.411(6) and 3.535(12) A, respectively. With DMPU, the $\mathrm{Bi}^{3+}$ coordinates through six oxygen atoms octahedrally with $\mathrm{Bi}-\mathrm{O}$ distance of $2.322(3) \AA$. The lower $\mathrm{CN}$ in DMPU than in DMSO and water are due to the steric effects of the more space-requiring DMPU ligands. In the sulfur donor solvent DMTF, the $\mathrm{Bi}^{3+}$ coordinates six solvent molecules with a mean Bi-S bond distance of 2.794(8) $\AA$.

D'Angelo et al. ${ }^{254}$ performed EXAFS studies on a $0.15 \mathrm{M}$ methanolic solution of tetramethylammonium bromide above the bromine K-edge to investigate the 
coordination of $\mathrm{Br}^{-}$in methanol $(\mathrm{MeOH})$. They used the pair distribution functions (PDFs), $g_{\mathrm{BrH}}(r), g_{\mathrm{Bro}}(r)$ and $g_{\mathrm{BrMe}}(r)$ obtained from MD simulations (of $1 \mathrm{Br}^{-}+124$ $\mathrm{MeOH}$ molecules) as relevant models in the calculation of the EXAFS signal, which was found to be comprised of all the three pair contributions. By comparing the results obtained from the Gaussian and asymmetric peak analysis, the authors showed that the accuracy of the EXAFS analysis is improved by using asymmetric shells. This procedure gives values for the average $\mathrm{Br}-\mathrm{H}, \mathrm{Br}-\mathrm{O}, \mathrm{Br}-\mathrm{Me}$ distances as 2.46(3), 3.40(1), 4.23(3) Å, respectively, and corresponding coordination numbers as 6.8(9), 6.1(2), 7.0(7). In comparison, an earlier EXAFS study by Tanida et al..$^{255}$ in which a single Gaussian shell $(\mathrm{Br}-\mathrm{O})$ analysis was used gave a relatively low value of 3.7 for the $\mathrm{Br}-\mathrm{O}$ coordination number in methanol. The MD simulation ${ }^{254}$ showed that most of the methanol molecules lie in a linear configuration of the form $\mathrm{O}-\mathrm{H}-\mathrm{Br}^{-}$. MD simulations of $\mathrm{MgCl}_{2}$ and $\mathrm{NaCl}$ in methanol are consistent with this result. ${ }^{237}$

Roccatano et al. ${ }^{256}$ combined MD simulations with EXAFS experimental results for a detailed investigation of $\mathrm{Sr}^{2+}$ in $\mathrm{MeOH}$. They assessed the reliability of $\mathrm{Sr}^{2+}-\mathrm{MeOH}$ potential models in order to predict inter alia structural and dynamic properties. The asymmetric peak analysis of the EXAFS data comprising $\mathrm{Sr}-\mathrm{O}, \mathrm{Sr}-\mathrm{H}$ and $\mathrm{Sr}-\mathrm{C}$ pair contributions yielded the values for the average distances as 2.611(3), 3.16(3), 3.65(3) $\AA$, and the corresponding coordination numbers as 7.2(3), 8(1), 7.4(8), respectively for the three pairs. These studies revealed the formation of a very stable ion-solvent complex, and a high degree of order within $\sim 5 \AA$ beyond which the preferential orientation of the solvent molecules slowly decreases. Thus, the methanol molecules of the first solvation shell strongly solvate the $\mathrm{Sr}^{2+}$ ion, and the resulting complexes migrate together.

Adya, Kalugin, and coworkers, ${ }^{257,258}$ having obtained reasonable agreement between the ND and MD results on the pure non-aqueous solvent DMSO, used MD simulations to contrast the microscopic structures of NAES composed of single ions, $\mathrm{Na}^{+}, \mathrm{Ca}^{2+}, \mathrm{Cl}^{-}$, and 1:1 (NaCl) and 2:1 $\left(\mathrm{CaCl}_{2}\right)$ electrolytes in DMSO. They found that the influence of the doubly charged $\mathrm{Ca}^{2+}$ in orienting the polar $\mathrm{S}=\mathrm{O}$ bonds in DMSO towards the cation in the first- and second- solvation shells is much stronger than that of the singly charged $\mathrm{Na}^{+}$having almost the same radius $(0.98 \AA)$ as $\mathrm{Ca}^{2+}$ $(1.06 \AA)$. The influence of the ions on the stability of their solvation shells varies in the order $\mathrm{Ca}^{2+}>\mathrm{Na}^{+}>\mathrm{Cl}^{-}$. The well-defined first solvation shells of $\mathrm{Na}^{+}$and $\mathrm{Ca}^{2+}$ are composed of 6 and 8 DMSO molecules, respectively. For $\mathrm{Cl}^{-}$, however, a wide distribution (4-11) of co-ordination numbers with a mean value of $\sim 8$ is found. The DMSO molecules in the first solvation shell of $\mathrm{Na}^{+}$are arranged octahedrally, with four oxygen atoms arranged in a plane within a circle of radius $2.4 \AA$ and the other two lying on a line perpendicular to this plane. The nearest-neighbour oxygen atoms from the eight DMSO molecules arranged around $\mathrm{Ca}^{2+}$ form a distorted square antiprism. By contrast, the first solvation shell of $\mathrm{Cl}^{-}$was found to have no regular polygonal structure. The results revealed that while the cations together with their first solvation shells may be considered as steady solvato-complexes with a fixed number of ligands, the first solvation shell of $\mathrm{Cl}^{-}$represents a rather loose and weak associate with a variable amount of poorly oriented solvent (DMSO) molecules.

For electrolytes in DMSO, it is found ${ }^{257}$ that solvent separated ion-pairs (SSIPs) exist with one or two DMSO molecules between the ions at $8 \AA$ and $12 \AA$, respectively, at a lower concentration, $0.066 \mathrm{M}$, of $\mathrm{CaCl}_{2}$. At the same concentration of $\mathrm{NaCl}$ in 
DMSO, however, no SSIPs are found to exist. At electrolyte concentrations greater than $\sim 0.27 \mathrm{M}$, mutual penetration of the ions' first solvation shells lead to the formation of stable contact ion pairs (CIPs), $[\mathrm{NaCl}]^{0}$ and $[\mathrm{CaCl}]^{+}$, at an inter-ion separation distance of $\sim 3 \AA$. The boundary between the first- and second-solvation shells of $\mathrm{Ca}^{2+}$ disappears due to increased interactions between the counterions at the higher concentrations. No similar effect of concentration change on the solvation shells of $\mathrm{Na}^{+}$ could be seen, and the chloride ions in $\mathrm{NaCl}-\mathrm{DMSO}$ solutions retained the geometry of their molecular environment to a greater degree than in $\mathrm{CaCl}_{2}-\mathrm{DMSO}$. At lower electrolyte concentrations, the $\mathrm{Na}^{+}$and $\mathrm{Ca}^{2+}$ show unimodal distributions with coordination numbers (CNs) of 6 and 8, respectively, and these results are similar to those in infinitely dilute solutions of single ions in DMSO. However, when the concentration increases to a level where the CIPs are formed, the cations reveal additional CNs of lower probability than the main ones. The eight-fold coordination of $\mathrm{Cl}^{-}$in $\mathrm{NaCl}-\mathrm{DMSO}$ does not change with increasing electrolyte concentration due to the weaker orienting influence of $\mathrm{Na}^{+}$on the DMSO molecules. By contrast, in $\mathrm{CaCl}_{2}-$ DMSO solutions, the presence of the doubly charged cation shifts the $\mathrm{CN}$ of $\mathrm{Cl}^{-}$from 8 to lower values $(\sim 6-6.2)$ at all the concentrations. With the formation of CIPs at higher concentrations, the influence of an ion on its counterion increases, thereby, leading to a reduction in the $\mathrm{CN}$ of $\mathrm{Cl}^{-}$. Based on the above structural results the authors ${ }^{257}$ proposed the most probable orientation of the DMSO molecules in the first solvation shells of the investigated ions in their infinitely dilute solutions, and in the solvation shells of the CIPs in the electrolyte solutions of $\mathrm{NaCl}$ and $\mathrm{CaCl}_{2}$ in DMSO.

As illustrated by some of the examples given above, one has to resort to different forms of modelling such as ab initio calculations, or MD simulations. MD simulations of the NAES, in addition, permit us to calculate separately the properties of the local subsystems, viz., the first- and second-solvation shells, and the bulk solvent.

There remain several questions to be answered by diffraction methods. For example, it is useful to know the nature of the ion-aggregates (ion-pairs, ion-triples or more complex form) that may be identified in solutions of varying salt concentrations (from dilute up to saturated). Such information is crucial to the development of theoretical models that are suitable for more realistic calculations of NAES.

\subsection{Glasses and amorphous materials}

Within the past five years, there has been a shift away from purely structural studies of glasses towards the study of their dynamical properties. This is in part driven by theoretical developments particularly in mode coupling theory. ${ }^{259}$ Consequently, we only report on a few studies based on diffraction methods.

In glass studies the challenge is to obtain both local order and a detailed understanding of the medium or intermediate range order, which includes, angular bonding distributions and connectivity. Many molten salts and aqueous systems are fragile glass formers, and in recent years various studies have shown that the better glass formers have significant intermediate range connectivity. In the case of molten salts, a comparative study of $\mathrm{ZnCl}_{2}$ and $\mathrm{MgCl}_{2}$ which combined neutron and $\mathrm{X}$-ray data showed that $\mathrm{ZnCl}_{2}$ is the better glass former (and less fragile) due to its higher

Annu. Rep. Prog. Chem., Sect. C, 2002, 98, 273-322 
tendency to form network structures. ${ }^{260}$ Recent work on the classic fragile system of $\mathrm{Ca}_{0.4} \mathrm{~K}_{0.6}\left(\mathrm{NO}_{3}\right)_{1.2}$ shows that the nitrate ion facilitates intermediate range order and demonstrated that the orientational bonding of the $\mathrm{NO}_{3}$ was lost between the glass and the liquid. ${ }^{261} \mathrm{~A}$ similar increased orientation was seen in the aqueous nitrate system $\mathrm{NH}_{4} \mathrm{Ca}\left(\mathrm{NO}_{3}\right)_{3} \cdot 4 \mathrm{H}_{2} \mathrm{O} .^{262}$

In the interpretation of total diffraction data, emphasis is often placed on the analysis of a first sharp diffraction peak (FSDP) that occurs in many glasses. This is clearly seen in molecular systems and certain ionic systems (e.g. $\mathrm{ZnCl}_{2}$ solution). Various studies on hydrogen bonded systems have indicated that this may come about due to the frustration of the local hydrogen bond clusters to extend through the system, which gives rise to a discrete maximum size, ${ }^{263,264}$ however, this is not universal to all hydrogen bonded systems. ${ }^{265}$

For the determination of structure in amorphous systems, the methods of NDIS and AXD are particularly useful. The work of Skipper and co-workers has been of particular interest since it combines NDIS measurements, with computer simulation, and theoretical work on very complex liquids systems. ${ }^{266-269}$ By using highly orientated clay systems, they were able to study a system of clay-solution-clay layers and determine atomic density profiles through this sandwich layer. The clay boundaries were varied by changing the water content of the clay. Initial measurements on $\mathrm{Ni}^{2+}$ ion showed that although the ion did not change its normal coordination number from 6 , the associated water was strongly hydrogen bonded to the clay layers. Subsequent work showed that there are two layers, associated with the clay, the first, the so-called Stern layer, contains the highest counter-ion density and has strong hydrogen bonds to the surface and the water density is higher than in the bulk. The second layer, has an increased oxygen-oxygen distance in the water and a much lower ion concentration. Throughout these studies, the cation remains mostly fully coordinated. ${ }^{267,268}$ Recent work, at high pressure and temperature has shown that these findings hold up to the critical point when the water loses its hydrogen bonds to the clay surface. ${ }^{269}$

There clearly remains much diffraction work to be carried out in this area with its richness of structures and environments.

\section{Summary and future work}

The above examples illustrate the extent to which present day neutron and X-ray diffraction methods are being used to determine interatomic structure in a wide range of liquid and amorphous systems. The determination of pair radial distribution functions not only offers a means to characterise different structures in liquids, but also provides theorists with information to construct realistic model potentials that can be used to calculate macroscopic behaviour and structural properties in regimes not currently accessible to experiment.

The well-established NDIS difference methods remain superior to all other methods for the determination of interatomic pairwise structure. The relatively new AXD (or DAS) difference methods have the potential to answer long-standing questions about the structure around species with mass number greater than about 30 . However, the relatively low X-ray scattering power from light elements such as hydrogen, carbon, nitrogen etc. means that it will never be possible to resolve completely 
structures of biologically important liquids by X-ray methods alone. EXAFS spectroscopy has the distinct advantage over both diffraction techniques as it can be used to study local structure around particular species at high dilution. Therefore studies which combine reference data from AXD or NDIS, with extensive EXAFS data, are likely to be useful in studies of structure in regimes which prove difficult for AXD and NDIS.

It is clear that no one method will be sufficient to resolve structure at the required level of detail around all species in a complex liquid. Instead one must rely on a full complement of diffraction and other techniques including computer simulation to determine the complete atomic structure of a complex liquid or amorphous system.

On the technical front, the construction and commissioning of new neutron diffractometers with higher count rates, such as D20 and D4C at ILL, and GEM at ISIS with an optimised sample environment for work at non-ambient conditions, will enable new and more extensive research to be undertaken. Additionally, the new custom built X-ray diffractometer for liquids proposed for the DIAMOND synchrotron being established at RAL, will provide a much needed boost for wide ranging AXD and EXAFS investigations of complex liquids.

Besides the many studies of immediate interest suggested at the end of some sections, there are several investigations that will become feasible in the longer term as the technology develops. These include (1) the use of isotopes such as ${ }^{12} \mathrm{C}$ and ${ }^{13} \mathrm{C}$ and ${ }^{33} \mathrm{~S}$ and ${ }^{32} \mathrm{~S}$ which will enable detailed and extensive structural studies to be carried out on a wide range of biologically significant materials, and (2) the exploitation of higher neutron and $\mathrm{X}$-ray count rates to facilitate real time experiments to investigate changes of structure as a chemical or biochemical reaction occurs.

The one strong theme which emerges from all the work described in this paper is that diffraction, especially that based on difference techniques, remains the best means to determine structure at atomic resolution in complex liquids.

\section{Acknowledgements}

We wish to thank our many colleagues whose work we have referred to in the preceding pages. We are particularly grateful to our colleagues Drs Adrian Barnes, Alan Soper and Chris Wormald for their advice on many occasions when we discuss the results of NDIS and AXD investigations. We also thank Professor John Enderby for his enthusiastic support and insightful comments on many of the neutron results. We acknowledge our co workers, Drs Phil Mason, Silvia Ramos, Oleg N. Kalugin, Toshio Yamaguchi, Haruaki Matsuura, Laurent Bianchi, Marcelle Gaune-Escard, and Paul Madden, and thank them for access to unpublished and about-to-be published results. We also thank our colleagues at ILL, ESRF, ISIS and LLB, where many of the experiments were carried out. In particular, the services of Drs Henry Fischer and Gabriel Cuello of the ILL, Marie Claire Bellissent Funel (LLB, Saclay), and Spencer Howells (ISIS) and A.Mazuelas, M. Borowski (ESRF) have been crucial to the success of most of the experiments described above. Finally we wish to thank EPSRC for their support for the many neutron and X-ray programmes with which we have been associated. 


\section{References}

1 G. W. Neilson and A. K. Adya, Annu. Rep. Prog. Chem. Sect. C: Phys. Chem., 1997, 93, 101.

2 G. W. Neilson and J. E. Enderby, J. Phys. Chem., 1996, 100, 1317.

3 W. Bol, G. J. A. Gerrits and C. L. v. P. Eck, J. Appl. Crystallogr., 1970, 3, 486.

4 N. T. Skipper, G. W. Neilson and S. Cummings, J. Phys.: Condens. Matter, 1989, 1, 3489.

5 K. F. Ludwig, Jr., W. K. Warburton, L. Wilson and A. I. Bienenstock, J. Chem. Phys., 1987, 87, 104.

6 S. Ramos, A. C. Barnes, G. W. Neilson and M. Capitan, Chem. Phys., 2000, 258, 171.

7 J. E. Enderby and G. W. Neilson, in Water, A Comprehensive Treatise, ed. F. Franks, Plenum Press, New York, 1979, vol. 6, ch. 1.

8 P. A. Egelstaff, An Introduction to the Liquid State, Oxford University Press, Oxford, 1992.

9 J. D. Bernal and R. H. Fowler, J. Chem. Phys., 1933, 1, 515.

10 N. T. Skipper and G. W. Neilson, J. Phys.: Condens. Matter, 1989, 1, 4141.

11 P. Dreider, P. Rabe, W. Malzfeldt and W. Niemann, J. Phys. C: Solid State Phys., 1984, 17, 3123.

12 S. Ramos, A. C. Barnes, G. W. Neilson, S. Lequien and D. Thiaudiere, J. Phys.: Condens. Matter, 2000, 12(8A), 203

13 S. Jayanetti, R. A. Mayanovic, A. J. Anderson, W. A. Bassett and I.-M. Chou, J. Chem. Phys., 2001, 115, 954.

14 A. Filipponi, J. Phys: Condens. Matter, 2001, 13, R23.

15 M. Benfatto, C. R. Natoli, A. Bianconi, J. Garcia, A. Marcelli and M. Fanfoni, Phys. Rev B, 1986, $34,5774$.

16 J. Kodre, I. Arcon and R. Frahm, J. Phys. IV, 1997, 7, 197.

17 D. E. Sayers, E. A. Stern and F. W. Lytle, Phys. Rev. Lett., 1971, 27, 1204.

18 G. Bunker, Nucl. Instrum. Methods, 1983, 207, 437.

19 P. A. Lee, P. H. Citrin, P. Eisenberg and B. M. Kincaid, Rev. Mod. Phys., 1981, 53, 769.

20 A. Filipponi and A. Di Cicco, Phys. Rev. B, 1995, 51, 12322.

21 J. Baro, A. M. Roteta, J. M. Fernadezvasea and F. Salvat, Radiat. Phys. Chem., 1994, 44, 531.

22 P. D'Angelo and N. V. Pavel, J. Synchrotron Rad., 1999, 6, 281.

23 P. J. Merkling, A. Munoz-Paez, R. R. Pappalardo and E. S. Marcos, Phys. Rev. B, 2001, 64, 12201.

24 A. Di Cicco, A. Filipponi, J. P. Itie and A. Polian, Phys. Rev. B, 1996, 54, 9086.

25 A. Filipponi, J. Phys.: Condens. Matter, 1994, 6, 8415.

26 J. E. Enderby and A. C. Barnes, Rep. Prog. Phys., 1990, 53, 85.

27 T. Pfleiderer, I. Waldner, H. Bertagnolli, K. Todheide and H. E. Fischer, J. Chem. Phys., 2000, 113, 3690.

28 C. Andreani, M. A. Ricci, M. Nardone, F. P. Ricci and A. K. Soper, J. Chem. Phys, 1997, 107, 214.

29 C. Andreani, J. Mol. Liq., 1998, 78, 217.

30 H. Bertagnolli and K. Todheide, J. Phys.: Condens. Matter, 1996, 8, 9293.

31 P. Cipriani, M. Nardone and F. P. Ricci, Nuovo Cim. Soc. Ital. Fis. D, 1998, 20, 1147.

32 P. Cipriani, M. Nardone and F. P. Ricci, Physica B, 1997, 241, 940.

33 R. Ishii, S. Okazaki, I. Okada, M. Furusaka, N. Watanabe, M. Misawa and T. Fukunaga, Mol. Phys., 1998, 95, 43.

34 T. Morita, K. Nishikawa, M. Takematsu, H. Iida and S. Furutaka, J. Phys. Chem. B, 1997, 101, 7158.

35 H. Ebata, J. Tokuda, K. Maruyama and M. Misawa, J. Phys. Soc. Jpn., 1998, 67, 2747.

36 P. Jovari, Mol. Phys., 1999, 97, 1149.

37 P. Jovari, European Powder Diffraction Pts 1 and 2, 2000, 321-3, 492.

38 G. Santoli, F. Bruni, F. P. Ricci, M. A. Ricci and A. K. Soper, Mol. Phys., 1999, 97, 777.

39 G. Strauss, A. Bassen, H. Zweier, H. Bertagnolli, K. Todheide, A. K. Soper and J. Turner, Phys. Rev. E, 1996, 53, 3505.

40 A. Bassen, I. Waldner and H. Bertagnolli, Phys. Chem. Chem. Phys., 1999, 1, 737.

41 H. Bertagnolli, I. Waldner, K. Todheide and H. Fischer, Mol. Phys., 1998, 94, 325.

42 M. I. Cabaco, Y. Danten, M. Besnard, Y. Guissani and B. Guillot, Mol. Phys., 1997, 90, 829.

43 M. I. Cabaco, Y. Danten, M. Besnard, M. C. Bellissent-Funel, Y. Guissani and B. Guillot, Mol. Phys., 1997, 90, 817 .

44 J. D. Londono, B. K. Annis, A. Habenschuss, G. D. Smith, O. Borodin, C. Tso, E. T. Hsieh and A. K. Soper, J. Chem. Phys., 1999, 110, 8786.

45 T. Tassaing, M. I. Cabaco, Y. Danten and M. Besnard, J. Chem. Phys., 2000, 113, 3757.

46 M. I. Cabaco, Y. Danten, M. Besnard, Y. Guissani and B. Guillot, J. Phys. Chem. B, 1997, 101, 6977.

47 A. K. Adya, L. Bianchi, A. K. Soper and C. J. Wormald, to be published.

48 L. Bianchi, PhD Thesis, University of Abertay-Dundee, 2000.

49 D. Morineau and C. Alba-Simionesco, J. Chem. Phys., 1998, 109, 8494.

50 I. Waldner, A. Bassen, H. Bertagnolli, K. Todheide, G. Strauss and A. K. Soper, J. Chem. Phys., 1997, 107, 10667.

51 K. A. Mort, K. A. Johnson and A. N. Burgess, Mol. Phys., 2000, 98, 999.

52 M. I. Cabaco, T. Tassaing, Y. Danten and M. Besnard, Chem. Phys. Lett., 2000, 325, 163.

53 J. Neuefeind, H. E. Fischer and W. Schroer, J. Phys.: Condens. Matter, 2000, 12, 8765.

54 J. Neuefeind, H. E. Fischer and W. Schroer, Physica B, 2000, 276, 481. 
55 K. A. Johnson and W. S. Howells, J. Phys.: Condens. Matter, 1999, 11, 9239.

56 I. Bako, J. C. Dore and D. W. Huxley, Chem. Phys., 1997, 216, 119.

57 H. Drozdowski, J. Mol. Struct., 2000, 526, 391.

58 R. Rey, L. C. Pardo, E. Llanta, K. Ando, D. O. Lopez, J. L. Tamarit and M. Barrio, J. Chem. Phys., 2000, $112,7505$.

59 P. Bhattarai, M. D. Zeidler and P. Chieux, J. Mol. Liq., 1998, 76, 127.

60 T. Weitkamp, J. Neuefeind, H. E. Fischer and M. D. Zeidler, Mol. Phys., 2000, 98, 125.

61 T. Yamaguchi, K. Hidaka and A. K. Soper, Mol. Phys., 1999, 97, 603.

62 T. Yamaguchi, K. Hidaka and A. K. Soper, Mol. Phys., 1999, 96, 1159.

63 T. Yamaguchi, C. J. Benmore and A. K. Soper, J. Chem. Phys., 2000, 112, 8976.

64 A. K. Adya, L. Bianchi and C. J. Wormald, J. Chem. Phys., 2000, 112, 4231.

65 L. Bianchi, A. K. Adya, O. N. Kalugin and C. J. Wormald, J. Phys.: Condens. Matter, 1999, $11,9151$.

66 L. Bianchi, O. N. Kalugin, A. K. Adya and C. J. Wormald, Mol. Simul., 2000, 25, 321.

67 C. J. Benmore and Y. L. Loh, J. Chem. Phys., 2000, 112, 5877.

68 D. T. Bowron, J. L. Finney and A. K. Soper, Mol. Phys., 1998, 93, 531.

69 S. Nasr, M. C. Bellissent-Funel and R. Cortes, J. Chem. Phys., 1999, 110, 10945.

70 R. H. Tromp, S. H. Spieser and G. W. Neilson, J. Chem. Phys., 1999, 110, 2145.

71 H. Bertagnolli, I. Waldner, K. Todheide and A. K. Soper, Mol. Phys., 1999, 96, 1075.

72 M. I. Cabaco, Y. Danten, M. Besnard, Y. Guissani and B. Guillot, J. Phys. Chem. B, 1998, 102, 10712.

73 A. K. Soper, J. Mol. Liq., 1998, 78, 179.

74 M. Saito, C. Park, K. Omote, K. Sugiyama and Y. Waseda, J. Phys. Soc. Jpn., 1997, 66, 633.

75 A. Di Cicco, M. J. Rosolen, R. Marassi, R. Tossici, A. Filipponi and J. Rybicki, J. Phys. : Condens. Matter, 1996, 8, 10779.

76 A. Di Cicco, M. Minicucci and A. Filipponi, Phys. Rev. Lett., 1997, 78, 460.

77 A. Di Cicco, J. Phys.: Condens. Matter, 1996, 8, 9341.

78 A. Di Cicco and M. Minicucci, Phys. Rev. B, 1997, 56, 11456.

79 K. Lu, H. Li, Z. Wu, J. Dong and Z. Cheng, Physica B, 1995, 208-209, 339.

80 H. Li, K. Lu, Z. Wu and J. Dong, J. Phys.: Condens. Matter, 1994, 6, 3629.

81 A. Di Cicco, M. Taglienti, M. Minicucci and A. Filipponi, Phys. Rev. B, 2000, 62, 12001.

82 H. Ohno, K. Igarashi, N. Umesaki and K. Furukawa, Molten Salt Forum, 1994, 3, 1-230.

83 M. Wilson and P. A. Madden, J. Phys.: Condens. Matter, 1993, 5, 6833; M. Wilson and P. A. Madden, J. Phys.: Condens. Matter, 1994, 6, 159.

84 F. Hutchinson, A. J. Rowley, M. K. Walters, M. Wilson, P. A. Madden, J. C. Wasse and P. S. Salmon, J. Chem. Phys., 1999, 111, 2028.

85 F. Hutchinson, M. K. Walters, A. J. Rowley and P. A. Madden, J. Chem. Phys., 1999, 110, 5821.

86 M. Wilson and P. A. Madden, J. Phys.: Condens. Matter, 1993, 5, 6833.

87 M. Wilson, P. A. Madden and B. J. Costa-Cabral, J. Phys. Chem., 1996, 100, 1227.

88 A. K. Adya, R. Takagi, Y. Sato, M. Gaune-Escard, A. C. Barnes and H. E. Fischer, to be submitted.

89 A. K. Adya, R. Takagi, M. Sakurai and M. Gaune-Escard, Proc. 11th Int. Symp. Molten Salts, ed. P.C. Trulove, H. De Long and S. Deki, Electrochemistry Society, Pennington, NJ, 1998, 98-11, 499-512.

90 R. Takagi, F. Hutchinson, P. A. Madden, A. K. Adya and M. Gaune-Escard, J. Phys.: Condens. Matter, $1999,11,645$.

91 A. K. Adya, H. Matsuura, F. Hutchinson, M. Gaune-Escard, P. A. Madden, A. C. Barnes and H. E. Fischer, Progress in Molten Salt Chemistry 1, ed. R. W. Berg and H. A. Hjuler, Elsevier, Amsterdam, 2000, p. 37-44.

92 J. C. Wasse and P. S. Salmon, J. Phys.: Condens. Matter, 1999, 11, 1381.

93 J. C. Wasse and P. S. Salmon, Physica B, 1998, 241-243, 967.

94 J. C. Wasse and P. S. Salmon, J. Phys.: Condens. Matter, 1999, 11, 9293.

95 M. P. Tosi, G. Pastore, M.-L. Saboungi and D. L. Price, Phys. Scr., 1991, T39, 367.

96 M.-L. Saboungi, D. L. Price, C. Scamehorn and M. P. Tosi, Europhys. Lett., 1991, 15, 283.

97 J. C. Wasse and P. S. Salmon, J. Phys.: Condens. Matter, 1999, 11, 2171.

98 J. C. Wasse, P. S. Salmon and R. G. Delaplane, Physica B, 2000, 276-278, 433

99 Y. S. Badyal, D. A. Allen and R. A. Howe, J. Phys.: Condens. Matter, 1994, 6, 10193.

100 R. Triolo and A. H. Narten, J. Chem. Phys., 1978, 69, 3159.

101 E. Johnson, A. H. Narten, W. E. Thiessen and R. Triolo, Faraday Discuss. Chem. Soc., 1978, 66, 287.

102 D. L. Price, M.-L. Saboungi, S. Hashimoto and S. C. Moss, Proc. 8th Int. Symp. Molten Salts, ed. R. J. Gale, G. Blomgren and H. Kojima, Electrochemistry Society, Pennington, NJ, 1992, 92-16, 14.

103 D. L. Price, M.-L. Saboungi, Y. S. Badyal, J. Wang, S. C. Moss and R. L. Leheny, Phys. Rev. B, 1998, 57, 10496.

104 Y. Fukushima, M. Misawa and K. Suzuki, Res. Rep. Lab. Nucl. Sci. (Tohoku University), 1975, 8, 113.

105 D. L. Price, M.-L. Saboungi, W. S. Howells and M. P. Tosi, Proc. Int. Symp. Molten Salts, ed. M.-L. Saboungi and H. Kojima, Electrochemistry Society, Pennington, NJ, 1993, 93-9, 1.

106 M.-L. Saboungi, M. A. Howe and D. L. Price, Proc. 7th Int. Symp. Molten Salts, ed. C. L. Hussey, S. N. Flengas, J. S. Wilkes and Y. Ito, Electrochemistry Society, Pennington, NJ, 1990, 90-17, 8. 
107 A. K. Adya, H. Matsuura, F. Hutchinson, P. A. Madden and M. Gaune-Escard, to be submitted.

108 A. K. Adya, H. Matsuura, R. Takagi, L. Rycerz and M. Gaune-Escard, Proc. XII Int. Symp. Molten Salts, Electrochemistry Society, Pennington, NJ, 2000, 99-41, 341.

109 M.-L. Saboungi, M. A. Howe and D. L. Price, Mol. Phys., 1993, 79, 847.

110 J. C. Wasse, P. S. Salmon and R. G. Delaplane, J. Phys.: Condens. Matter, 2000, 12, 9539.

111 R. L. Harris, R. E. Wood and H. L. Ritter, J. Am. Chem. Soc., 1951, 73, 3151.

112 J. Mochinaga, Y. Iwadate and K. Fukushima, Mater. Sci. Forum, 1991, 73-75, 147.

113 J. Mochinaga, Y. Iwadate and K. Fukushima, Mater. Sci. Forum, 1991, 73-75, 147.

114 K. Igarashi, M. Kosaka, M. Ikeda and J. Mochinaga, Z. Naturforsch. A, 1989, 45, 623.

115 J. Mochinaga, M. Ikeda, K. Igarashi, K. Fukushima and Y. Iwadate, J. Alloys Compds., 1993, 193, 36

116 Y. Okamoto, F. Kobayashi and T. Ogawa, J. Alloys Compds., 1998, 271-273, 355.

117 Y. Okamoto and T. Ogawa, Z. Naturforsch. A, 1999, 54, 91.

118 Y. Iwadate, T. Iida, K. Fukushima, J. Mochinaga and M. Gaune-Escard, Z. Naturforsch. A, 1994, 49, 811.

119 A. K. Adya, R. Takagi and M. Gaune-Escard, Z. Naturforsch. A, 1998, 53, 1037.

120 A. K. Adya, in Molten Salts from Fundamentals to Applications, ed. M. Gaune-Escard, Kluwer, Dordrecht, 2002, p. 107-148.

121 F. Hutchinson, M. Wilson and P. A. Madden, J. Phys.: Condens. Matter, 2000, 12, 10389.

122 H. Matsuura, A. K. Adya and D. T. Bowron, J. Synchrotron Radiat., 2001, 8, 779.

123 H. Matsuura, A. K. Adya and D. T. Bowron, in Progress in Molten Salt Chemistry 1, ed. R. W. Berg and H. A. Hjuler, Elsevier, Amsterdam, 2000, p. 335.

124 G. Pastore, Z. Akdeniz and M. P. Tosi, J. Phys.: Condens. Matter, 1991, 3, 8297.

125 Y. Iwadate, K. Fukushima, R. Takagi and M. Gaune-Escard, Electrochemistry, 1999, 67, 553.

126 A. K. Adya, R. Takagi, K. Kawamura and M. Mikami, Mol. Phys., 1987, 62, 227.

127 B. Holmberg and G. Johansson, Acta Chem. Scand. A, 1983, 37, 367.

128 S. Ansell, S. Krishnan, J. K. R. Weber, J. J. Felten, P. C. Nordine, M. A. Beno, D. L. Price and M.-L. Saboungi, Phys. Rev. Lett., 1997, 78, 464.

129 S. Krishnan, S. Ansell and D. L. Price, J. Am. Ceram. Soc., 1998, 81, 1967.

130 C. Landron, L. Hennet, T. E. Jenkins, G. N. Greaves, G. Derbyshire, J. P. Coutures and A. K. Soper, ISIS 2000, Scientific Highlights, 2000, p. 40.

131 S. Takahashi, K. Suzuya, S. Kohara, N. Koura, L. A. Curtiss and M.-L. Saboungi, Z. Phys. Chem., 1999, 209, 209.

132 C. Hardacre, K. Seddon and J. McGrath, ISIS 2001, Scientific Highlights, 2001, p. 30.

133 T. Steiner, Acta Crystallogr., Sect. B, 1998, 54, 464.

134 A. K. Soper, Chem. Phys., 2000, 258, 121.

135 A. K. Soper, Mol. Phys., 2001, 99, 1503.

136 F. H. Stillinger and A. Rahman, J. Chem. Phys., 1974, 60, 1545.

137 A. G. Kalinichev and J. D. Bass, J. Phys. Chem. A, 1997, 101, 9720.

138 P. Jedlovszky, J. P. Brodholt, F. Bruni, M. A. Ricci, A. K. Soper and R. Vallauri, J. Chem. Phys., 1998, 108, 8528.

139 A. Botti, F. Bruni, M. A. Ricci, A. K. Soper and R. Vallauri, J. Chem. Phys., 1998, 109, 3180.

140 G. Hura, J. M. Sorenson, R. M. Glaeser and T. Head-Gordon, J. Chem. Phys., 2000, 113, 9140.

141 A. H. Narten, M. D. Danford and H. A. Levy, Discuss. Faraday Soc., 1967, 43, 97.

142 J. Teixeira and A. Luzar, in Hydration Processes in Biology, ed. M.-C. Bellissent-Funel, IOS Press, Amsterdam, 1999, p. 35.

143 H. E. Stanley, in Hydration Processes in Biology, ed. M.-C. Bellissent-Funel, IOS Press, Amsterdam, 1999, p. 3.

144 A. K. Soper and M. A. Ricci, Phys. Rev. Lett., 2000, 84, 2881.

145 J. Dore, Chem. Phys., 2000, 258, 327.

146 D. M. Sullivan, G. W. Neilson, H. Fischer and A. R. Rennie, J. Phys.: Condens. Matter, 2000, $12,3531$.

147 M. Bonneti, G. Romet-Lemonne, P. Calmettes and M.-C. Bellissent-Funel, J. Chem. Phys., 2000, $112,268$.

148 G. W. Neilson, P. E. Mason, S. Ramos and D. Sullivan, Philos. Trans. R. Soc. London, Ser. A, 2001, 359, 1575.

149 R. H. Tromp, G. W. Neilson and A. K. Soper, J. Chem. Phys., 1992, 96, 8460.

150 R. Leberman and A. K. Soper, Nature, (London), 1995, 378, 364.

151 F. Bruni, M. A. Ricci and A. K. Soper, J. Chem. Phys., 2001, 114, 8056.

152 H. Ohtaki and T. Radnai, Chem. Rev., 1993, 93, 1157.

153 D. H. Powell, G. W. Neilson and J. E. Enderby, J. Phys.: Condens. Matter, 1993, 5, 5723.

154 I. Howell and G. W. Neilson, J. Phys.: Condens. Matter, 1996, 8, 4455.

155 J. L. Fulton, M. Pfund, S. L. Wallen, M. Newville, E. A. Stern and Y. Ma, J. Phys. IV, 1997, 7, 1007.

156 J. E. Wilson, S. Ansell, J. E. Enderby and G. W. Neilson, Chem. Phys. Lett., 1997, $278,21$.

157 R. H. Tromp and G. W. Neilson, J. Phys. Chem., 1996, 100, 6483.

158 P. H. K. de Jong, G. W. Neilson and M.-C. Bellissent-Funel, J. Chem. Phys., 1996, 105, 5155.

159 D. H. Powell and G. W. Neilson, J. Phys.: Condens. Matter, 1990, 2, 3871.

160 S. Raugei and M. L. Klein, J. Chem. Phys., 2002, 116, 196.

161 S. L. Wallen, B. J. Palmer and J. L. Fulton, J. Chem. Phys., 1998, 108, 4039. 
162 G. Ferlat, A. San-Miguel, J. F. Jal, J. C. Soetens, P. A. Bopp, I. Daniel, S. Guillot, J. L. Hazemann and R. Argoud, Phys. Rev. B., 2001, 63, 134202.

163 A. C. Barnes, personal communication.

164 N. A. Hewish, G. W. Neilson and J. E. Enderby, Nature, 1982, 138, 297.

165 C. F. Schwenk, H. H. Loeffler and B. M. Rode, J. Chem. Phys., 2001, 115, 10808.

166 G. W. Neilson and R. D. Broadbent, Chem. Phys. Lett., 1990, 167, 429.

167 S. Ramos, G. W. Neilson, A. C. Barnes and A. Mazuelas, to be submitted.

168 D. M. Pfund, J. G. Darab, J. L. Fulton and Y. Ma, J. Phys. Chem., 1994, 98, 13102.

169 R. D. Broadbent, G. W. Neilson and M. Sandstrom, J. Phys.: Condens. Matter, 1992, 4, 639.

170 S. Diaz-Moreno, A. Munoz-Paez, J. M. Martenez, R. R. Pappalardo and E. S. Marcos, J. Am. Chem. Soc., 1996, 118, 12654.

171 L. Campbell, J. J. Rehr, G. K. Schenter, M. I. McCarthy and D. Dixon, J. Synchrotron Radiat., 1999, 6, 310.

172 J. Herdman and G. W. Neilson, J. Phys.: Condens. Matter, 1992, 4, 627.

173 J. Herdman and G. W. Neilson, J. Phys.: Condens. Matter, 1992, 4, 649.

174 L. Nagy, H. Ohtaki, T. Yamaguchi and M. Nomura, Inorg. Chim. Acta, 1989, 159, 201.

175 A. Pasquallero, I. Petri, P. S. Salmon, O. Parisel, R. Car, E. Toth, D. H. Powell, H. E. Fischer, L. Helm and A. E. Merbach, Science, 2001, 291, 856.

176 J. Garcia, M. Benfatto, C. R. Natoli, A. Banconi, A. Fontaine and H. Tolentino, Chem. Phys., 1989, 132, 295.

177 P. D’Angelo, E. Bottari, M. R. Festa, H.-F. Nolting and N. V. Pavel, J. Chem. Phys, 1997, 107, 2807.

178 A. Filipponi, P. D’Angelo, N. V. Pavel and A. Di Cicco, Chem. Phys. Lett., 1994, 225, 150.

179 N. R. Texler, S. Holdway, G. W. Neilson and B. M. Rode, J. Chem. Soc., Faraday Trans., 1998, 94, 59.

180 M. A. Marques, M. I. Cabaco, M. I.de B. Marques, A. M. Gasper and C. M. de Morais, J. Phys.: Condens. Matter, 2001, 13, 4367.

181 B. K. Annis, R. L. Hahn and A. H. Narten, J. Chem. Phys., 1985, 82, 2086.

182 C. Cossy, A. C. Barnes, J. E. Enderby and A. Merbach, J. Chem. Phys., 1989, 90, 3254.

183 S. Ramos, G. W. Neilson, A. C. Barnes and A. Mazuelas, J. Phys. Chem. B, 2001, 105, 2694.

184 R. Beudert, H. Bertagnolli and M. Zeller, J. Chem. Phys., 1997, 106, 8841.

185 J. L. Fulton, M. M. Hoffmann and J. G. Darab, Chem. Phys. Lett., 2000, 330, 300.

186 M. D. Collings, D. M. Sherman and K. V. Ragnarsdottir, Chem. Geol., 2000, 167, 65.

187 T. M. Seward, C. M. B. Henderson and J. M. Chaenock, Chem. Geol., 2000, 167, 117.

188 D. M. Sherman, K. V. Ragnarsdottir, E. H. Oelkers and C. R. Collins, Chem. Geol., 2000, 167, 169.

189 M. Ries-Kautt and A. Ducruix, Methods Enzymol., 1997, 276, 23.

190 B. Schneider, K. Patel and H. M. Berman, Biophys. J., 1998, 75, 2422.

191 P. E. Mason, personal communication, manuscript in preparation.

192 S. Ansell and G. W. Neilson, J. Chem. Phys., 2000, 112, 3942.

193 S. Ansell, R. H. Tromp and G. W. Neilson, J. Phys.: Condens. Matter, 1995, 7, 1513.

194 I. Howell and G. W. Neilson, J. Mol. Liq., 1997, 73,74, 337.

195 H. L. Friedman, Faraday Discuss. Chem. Soc., 1988, 85, 1.

196 G. W. Neilson and J. E. Enderby, Proc. R. Soc. London, Ser. A, 1983, 390, 353.

197 Hydration Processes in Biology, ed. M.-C. Bellissent-Funel, IOS Press, Amsterdam, 1999.

198 Faraday Discuss., 1996, 103.

199 J. L. Finney, in Hydration Processes in Biology, ed. M.-C. Bellissent-Funel, IOS Press, Amsterdam, 1999 , p. 115.

200 D. T. Bowron, J. L. Finney and A. K. Soper, J. Phys. Chem. B, 1998, 102, 3551.

201 D. T. Bowron, A. K. Soper and J. L. Finney, J. Chem. Phys., 2001, 114, 6203.

202 A. Pertsemlidis, A. M. Saxena, A. K. Soper, T. Head-Gordon and R. M. Glaeser, Proc. Natl. Acad. Sci. USA, 1996, 93, 10760.

203 P. E. Mason, G. W. Neilson, A. C. Barnes, P. Buchanan, C. Dempsey and M. Murray, in preparation.

204 P. E. Mason, G. W. Neilson, A. C. Barnes and M.-L. Saboungi, in preparation.

205 Q. Liu and J. W. Brady, J. Am. Chem. Soc., 1996, 118, 12276.

206 B. Jayaram and D. L. Beveridge, Annu. Rev. Biomol. Struct., 1996, 25, 367.

207 W. B. Fischer, A. Fedorowicz and A. Koll, Phys. Chem. Chem. Phys., 2001, 3, 4228.

208 O. R. Croveto, R. Fernandez-Prini and M. L. Japas, J. Chem. Phys, 1982, 76, 1077.

209 W. Blokjil and J. B. F. N. Engberts, Angew. Chem. Int. Ed. Engl., 1993, 32, 1545.

210 G. Hummer, S. Garde, A. E. Garcia, M. E. Paulaitis and L. R. Pratt, J. Phys. Chem. B, 1998, $102,10469$.

211 R. D. Broadbent and G. W. Neilson, J. Chem. Phys, 1994, 100, 7543.

212 P. H. K. de Jong, G. W. Neilson and A. D. Buckingham, Mol. Phys., 1997, 91, 99.

213 C. Pangali, M. Rao and B. J. Berne, J. Chem. Phys., 1979, 71, 2975.

214 D. M. Sullivan, G. W. Neilson and H. E. Fischer, J. Chem. Phys., 2001, 115, 339.

215 B. Guillot and Y. Guisani, J. Chem. Phys., 1993, 99, 8075.

216 D. T. Bowron, A. Filipponi, C. Lobban and J. L. Finney, Chem. Phys. Lett., 1998, $293,33$.

217 A. Filipponi, D. T. Bowron, C. Lobban and J. L. Finney, Phys. Rev. Lett., 1997, 79, 1293.

218 C. A. Koh, R. P. Wisbey, X. Wu, R. E. Westacott and A. K. Soper, J. Chem. Phys., 2000, 113, 6390 
219 O. N. Kalugin and A. K. Adya, Phys. Chem. Chem. Phys., 2000, $2,11$.

220 D. H. Powell and G. W. Neilson, J. Phys.: Condens. Matter, 1990, 2, 5867.

221 R. Ripan and I. Ceteanu, Chimia Metalelor, Editura Didactica Si Pedagogica, Bucharest, Romania, 1969, vol. II.

222 P. B. Lond, P. S. Salmon and D. C. Champeney, J. Am. Chem. Soc., 1991, 113, 6420.

223 Y. Inada, H. Hayashi, K. Sugimoto and S. Funahashi, J. Phys. Chem. A, 1999, 103, 1401.

224 D. H. Powell and G. W. Neilson, J. Phys.: Condens. Matt., 1990, 2, 3871.

225 R. A. Robinson and R. H. Stokes, Electrolyte Solutions, Butterworths, London, 1959.

226 G. W. Neilson, in Water, Aqueous Solutions, ed. G. W. Neilson and J. E. Enderby, Adam Hilger, Bristol, 1986, p. 169.

227 S. E. Okan, P. S. Salmon, D. C. Champaney and I. Petri, Mol. Phys, , 1995, 84, 325.

228 S. E. Okan and P. S. Salmon, Mol. Phys., 1995, 85, 981.

229 Y. Kameda, H. Ebata, T. Usuki and O. Uemura, Physica B, 1995, 213 \& 214, 477.

230 I. Howell and G. W. Neilson, J. Phys.: Condens. Matter, 1996, 8, 4455.

231 T. Cartailler, W. Kunz, P. Turq and M.-C. Bellisent-Funel, J. Phys.: Condens. Matter, 1991, 3, 9511.

232 M. Yamagami, H. Wakita and T. Yamaguchi, J. Chem. Phys., 1995, 103, 8174.

233 Y. Tamura, E. Spohr, K. Heinzinger, G. Pálinkás and I. Báko, Ber. Bunsen-Ges. Phys. Chem., 1992, 96, 147.

234 (a) H. L. Robinson and M. C. R. Symons, J. Chem. Soc., Faraday Trans. 1, 1985, 81, 2131; (b) M. C. R. Symons, J. Chem. Soc., Faraday Trans. 1, 1983, 79, 1273.

235 G. A. Krestov, N. P. Novoselov, I. S. Pereligin, et al., Ionic Solvation, Nauka Press, Moscow, 1987.

236 R.W. Impey, M. Sprik and M. L. Klein, J. Am. Chem. Soc., 1987, 109, 5900.

237 D. Marx, K. Heinzinger, G. Pálinkás and I. Bakó, Z. Naturforsch. A, 1991, 46, 887.

238 G. Sese, E. Guàrdia and J. A. Padró, J. Chem. Phys., 1996, 105, 8826.

239 H. Torii, J. Phys. Chem. A, 1999, 103, 2843.

240 A. K. Adya and O. N. Kalugin, J. Chem. Phys., 2000, 113, 4740.

241 D. H. Powell, G. W. Neilson and J. E. Enderby, J. Phys.: Condens. Matter, 1993, 5, 5723.

242 P. S. Salmon and P. B. Lond, J. Phys.: Condens. Matter, 1992, 4, 5249.

243 S. E. Okan and P. S. Salmon, J. Phys.: Condens. Matter, 1994, 6, 3839.

244 S. Ahrland, E. Hansson, A. Iverfeldt and I. Persson, Acta Chem. Scand. A, 1981, 35, 275.

245 J. Näslund, P. Lindqvist, I. Persson and M. Sandström, Inorg. Chem., 2000, 39, 4006.

246 S.-i. Ishiguro, Y. Umebayashi, K. Kato, R. Takahashi and K. Ozutsumi, J. Chem. Soc., Faraday Trans., 1998, 94, 3607.

247 S.-i. Ishiguro, K. Kato, R. Takahashi and S. Nakasone, Rare Earths, 1995, 11, 61.

248 S.-i. Ishiguro, Bull. Chem. Soc. Jpn., 1997, 70, 1465.

249 R. D. Shannon, Acta Crystallogr., Sect. A, 1976, 32, 751.

250 T. Yamaguchi, M. Niihara, T. Takamuku, H. Wakita and H. Kanno, Chem. Phys. Lett., 1997, $274,485$.

251 P. Lindqvist-Reis, K. Lamble, S. Pattanaik, I. Persson and M. Sandström, J. Phys. Chem. B, 2000, 104, 402 .

252 S. Díaz-Moreno, A. Muños-Páez and J. Chaboy, J. Phys. Chem., 2000, 104, 1278.

253 J. Näslund, I. Persson and M. Sandström, Inorg. Chem., 2000, 39, 4012.

254 P. D’Angelo, A. Di Nola, M. Mangoni and N. V. Pavel, J. Chem. Phys., 1996, 104, 1779.

255 H. Tanida, H. Sakane and I. Watanabe, J. Chem. Soc., Dalton Trans., 1994, 2321.

256 D. Roccatano, H. J. C. Berendsen and P. D'Angelo, J. Chem. Phys., 1998, 108, 9487.

257 A. K. Adya, O. N. Kalugin, M. N. Volobuev and Y. V. Kolesnik, Mol. Phys., 2001, 99, 835.

258 O. N. Kalugin, M. N. Volobuev, A. V. Ishchenko and A. K. Adya, J. Mol. Liq., 2001, 91, 312.

259 W. Götze, J. Phys.: Condens. Matter, 1999, 11, A1.

260 L. Pusztai and R. L. McGreevy, J. Phys.: Condens. Matter, 2001, 13, 7213.

261 C. Tengroth, J. Swenson, A. Isopo and L. Borjesson, Phys. Rev. B, 2001, 64, 224207.

262 S. Ansell and G. W. Neilson, J. Phys.: Condens. Matter, 2000, 11, 9071.

263 D. Morineau, C. Albra-Siminoesco, M. C. Bellissent-Funel and M. F. Lauthie, Euro. Phys. Lett, 1998, 43, 195.

264 D. Morineau and C. Albra-Siminoesco, J. Chem. Phys., 1998, 109, 8494.

265 R. L. Leheny, N. Menon and S. R. Nagel, J. Chem. Phys., 1996, 105, 7783.

266 N. T. Skipper, A. K. Soper and J. D. C. McConnell, J. Chem. Phys, 1991, 94, 5751.

267 R. J. F. Leote de Carvalho and N. T. Skipper, J. Chem. Phys., 2001, 114, 3727.

268 C. H. Bridgeman and N. T. Skipper, J. Phys.: Condens. Matter, 1997, 9, 4081.

269 A. V. deSiqueira, C. Lobban, N. T. Skipper, G. D. Williams, A. K. Soper, R. Done, J. W. Dryer, R. J. Humphreys and J. A. R. Bones, J. Phys.: Condens. Matter, 1999, 11, 9179. 